Florida International University FIU Digital Commons

$3-21-2013$

\title{
An Analysis of the Factors that Influence Regional Economic Development Cooperation
}

Terence G. Murphy

Florida International University, terrymurphy06@gmail.com

DOI: $10.25148 /$ etd.FI13042312

Follow this and additional works at: https://digitalcommons.fiu.edu/etd

Part of the Public Affairs, Public Policy and Public Administration Commons

\section{Recommended Citation}

Murphy, Terence G., "An Analysis of the Factors that Influence Regional Economic Development Cooperation" (2013). FIU Electronic Theses and Dissertations. 852.

https://digitalcommons.fiu.edu/etd/852

This work is brought to you for free and open access by the University Graduate School at FIU Digital Commons. It has been accepted for inclusion in FIU Electronic Theses and Dissertations by an authorized administrator of FIU Digital Commons. For more information, please contact dcc@fiu.edu. 


\section{FLORIDA INTERNATIONAL UNIVERSITY}

Miami, Florida

\section{AN ANALYSIS OF THE FACTORS THAT INFLUENCE \\ REGIONAL ECONOMIC DEVELOPMENT COOPERATION}

A dissertation submitted in partial fulfillment of

the requirements for the degree of

DOCTOR OF PHILOSOPHY

in

PUBLIC AFFAIRS

by

Terence Murphy

2013 
To: Dean Kenneth G. Furton

College of Arts and Sciences

This dissertation, written by Terence Murphy, and entitled An Analysis of the Factors that Influence Regional Economic Development Cooperation, having been approved in respect to style and intellectual content, is referred to you for judgment.

We have read this dissertation and recommend that it be approved.

$\begin{array}{r}\hline \text { Sukumar Ganapati } \\ \hline \text { Shaoming Cheng } \\ \hline \text { John F. Stack } \\ \hline \text { Allan Rosenbaum, Major Professor }\end{array}$

Date of Defense: March 21, 2013

The dissertation of Terence Murphy is approved.

$\begin{array}{r}\hline \begin{array}{r}\text { Dean Kenneth G. Furton } \\ \text { College of Arts and Sciences }\end{array} \\ \hline \begin{array}{r}\text { Dean Lakshmi N. Reddi } \\ \text { University Graduate School }\end{array}\end{array}$

Florida International University, 2013 


\section{DEDICATION}

As I conclude this lengthy, grueling and enlightening feat, I recall my mother's words.

She once noted, as I finished a long overdue project, that perseverance was an admirable character trait. Her Irish compliment kept me going. I dedicate this dissertation in memory of Norine Murphy (1919-2011). 


\section{ACKNOWLEDGMENTS}

I wish to thank my committee chairman, Dr. Allan Rosenbaum, for his patience in guiding me through this dissertation process, and for his friendship over the many years of my graduate work at Florida International University. I am grateful to all of my committee members for being so generous with their time and intellect, and am especially appreciative of the guidance provided by Dr. Sukumar Ganapati.

I also want to acknowledge the inspirational instruction from Dr. Ned Murray, who is responsible for piquing my curiosity about the economic development policy arena. And finally, I must express my heartfelt appreciation to Liga Replogle, the graduate student services coordinator in the Department of Public Administration, for always being there to assist me at the critical moments. 


\begin{abstract}
OF THE DISSERTATION
AN ANALYSIS OF THE FACTORS THAT INFLUENCE REGIONAL ECONOMIC DEVELOPMENT COOPERATION
\end{abstract}

by

Terence Murphy

Florida International University, 2013

Miami, Florida

Professor Allan Rosenbaum, Major Professor

This dissertation is a comparative case study of regional cooperation in the field of economic development. As citizens have developed a greater appreciation for the fastpaced dynamics of the global economy, proponents of regionalism have put forth fresh arguments to improve the competitive advantages of a region through collective action. There is a growing regional movement in the economic development arena. A regional approach to economic development activity, however, presents a classic social dilemma: How is it possible to commit resources to improve the economic prospects of a region, and remain autonomous to act in the best interest of the local community? My research examines the role of social capital in overcoming this social dilemma.

Three Metropolitan Statistical Areas (MSAs) with different degrees of regional cooperation form the empirical basis of this research. The Houston MSA has institutionalized regional cooperation very well, the Atlanta MSA is at the intermediate stage with capacity to function regionally for economic development purposes, and the Miami MSA has very little regional economic development cooperation. The dissertation seeks to explain why this is so, in order to obtain insights into the process by which 
regional economic cooperation evolves. The hypothesis is that accrued social capital is crucial to obtaining economic development cooperative agreements.

In his explanation of regional cooperation, Richard Feiock argues for the importance of observable community characteristics such as charter provisions for electing officials, heterogeneity in the structure of local governments; socio-economic characteristics, and information asymmetry across jurisdictions. Elinor Ostrom has suggested that experiences of reciprocity, reputation, and the level of trust among the stakeholders positively influence the outcome of negotiations.

My dissertation extends the literature by focusing on the quality of the relations among the stakeholders. Social capital assessments gathered through surveys and interviews of civic leaders, public officials, and business executives of each region provided the basis for comparison. The study concludes that the significant factors associated with successful regional economic development cooperation are the actions of state executives and the policies adopted by state legislatures to incentivize regional cooperation. 
TABLE OF CONTENTS

CHAPTER

PAGE

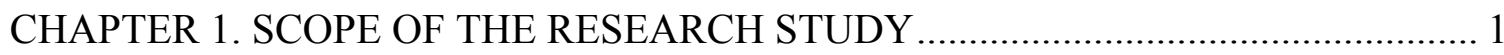

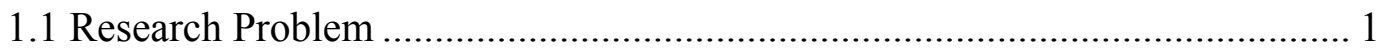

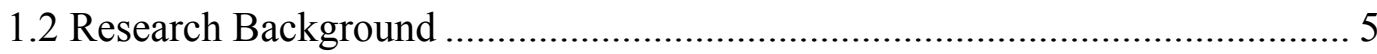

1.3 Research Purpose and Significance ........................................................... 8

1.4 Social Capital in Regional Economic Development........................................ 9

1.5 Research Questions, Hypothesis and Design.................................................. 11

1.6 Justification of the Selected Regions of Empirical Study............................. 13

1.7 The Stakeholders of Regional Economic Development Cooperation ............. 15

1.8 Organization of the Dissertation .................................................................. 17

CHAPTER 2. THEORETICAL FRAMEWORK AND LITERATURE REVIEW ......... 18

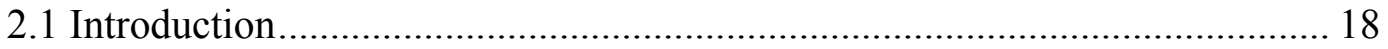

2.2 Beyond Smokestack Chasing........................................................................ 19

2.3 Economic Growth and Innovation ................................................................. 21

2.4 Entrepreneurial Support and Economic Development ……………………..... 22

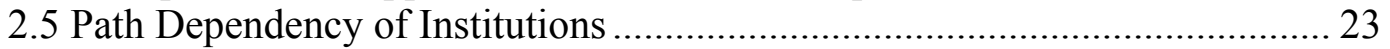

2.6 Transaction Costs for Regional Cooperation................................................ 26

2.7 Factors that Influence Cooperative Economic Development Transactions.... 28

2.8 The Stakeholders of Regional Economic Development Cooperation ............. 30

2.9 Social Capital and the Transaction Costs Approach........................................ 32

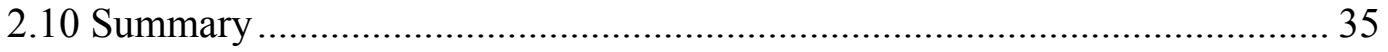

CHAPTER 3. RESEARCH METHODS AND PROCEDURES ……………………..... 38

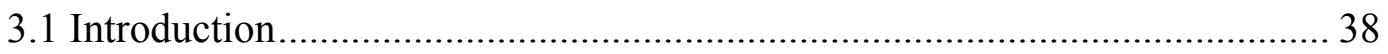

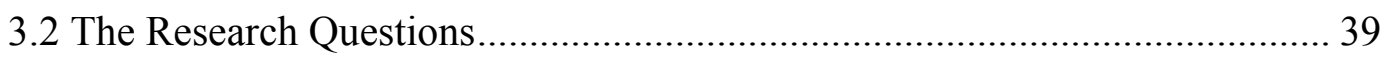

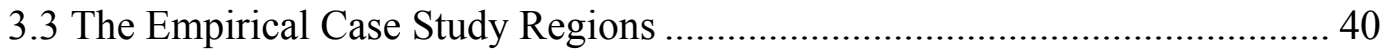

3.4 The Dependent Variable .......................................................................... 42

3.5 Demographic Context .............................................................................. 43

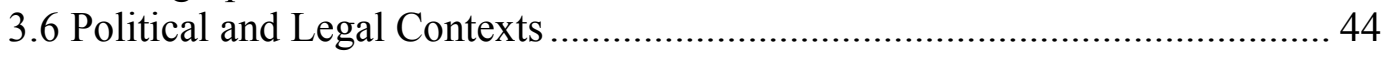

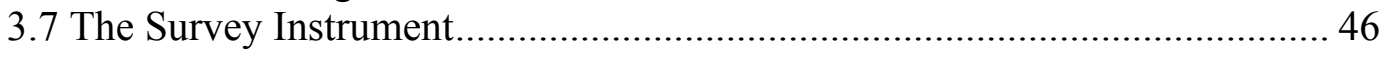

3.8 Site Visits, Interviews and Personal Conversations.......................................... 49

\section{CHAPTER 4. ECONOMIC DEVELOPMENT COOPERATION IN THE ATLANTA}

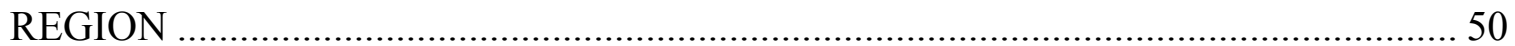

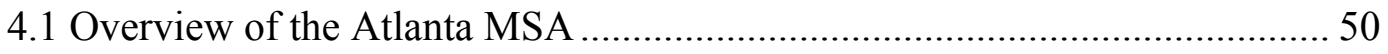

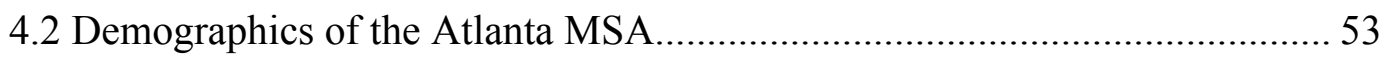

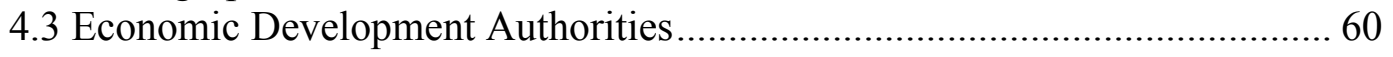

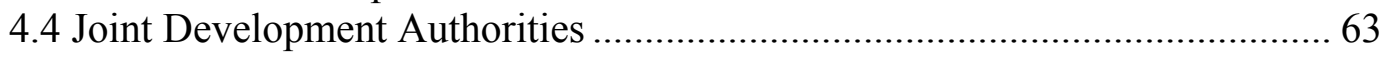




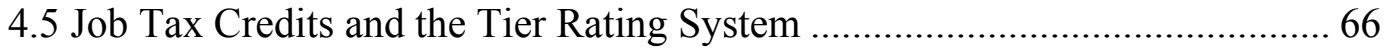

4.6 Comprehensive Economic Development Strategies (CEDS) ........................6 68

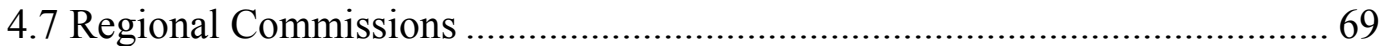

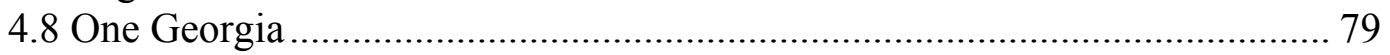

4.9 Cooperative Organizations of the Atlanta MSA ….................................... 82

4.10 Social Capital Survey............................................................................. 86

4.11 The Dependent Variable: Regional Economic Development Cooperation .. 92

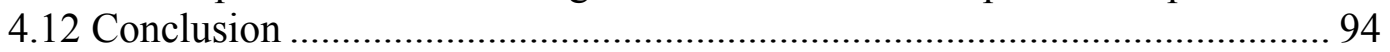

\section{CHAPTER 5. ECONOMIC DEVELOPMENT COOPERATION IN THE HOUSTON}

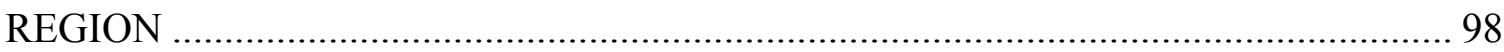

5.1 An Overview of the Houston MSA ............................................................ 98

5.2 Demographics and Characteristics of the Houston MSA ............................ 103

5.3 The Constitutional and Statutory History ................................................. 107

5.4 Greater Houston Partnership ...................................................................... 113

5.5 Sub-regional Economic Development Organizations............................... 117

5.6 Houston-Galveston Area Council ........................................................ 120

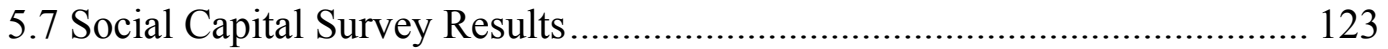

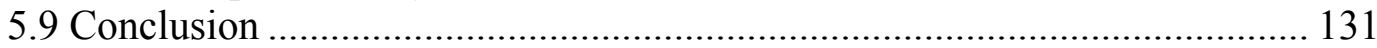

\section{CHAPTER 6. ECONOMIC DEVELOPMENT COOPERATION IN THE MIAMI}

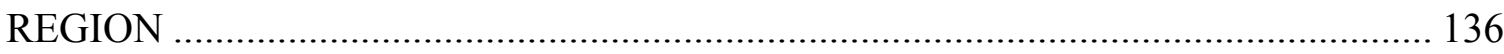

6.1 An Overview of the Miami MSA ............................................................ 136

6.2 Demographics and Characteristics of the Miami MSA .............................. 140

6.3 Statutes, Regulations and Politics ........................................................... 144

6.4 Regional Public Organizations ................................................................ 153

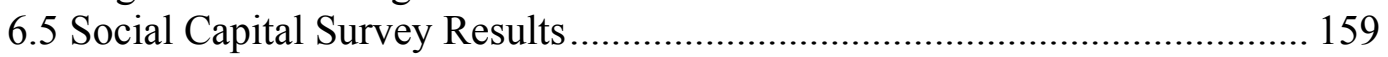

6.6 The Dependent Variable: Regional Economic Development Cooperation .. 166

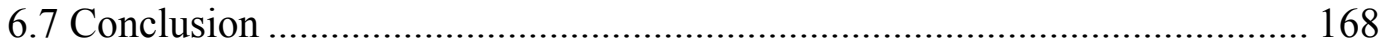

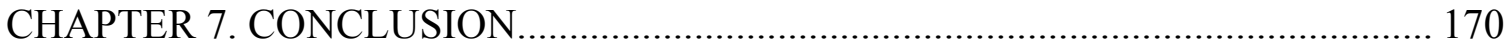

7.1 Rejecting the Primary Hypothesis .......................................................... 170

7.2 The Survey Results and Community Profile Attributes ............................. 173

7.3 The Impact of the State on Regional Cooperation..................................... 179

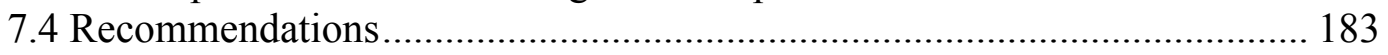

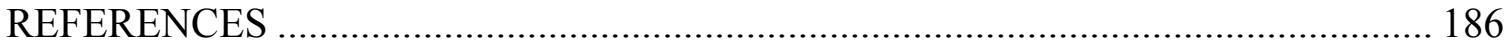

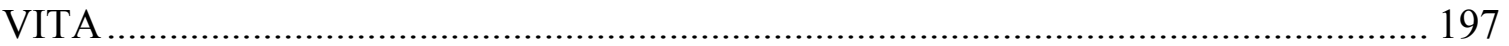




\section{LIST OF TABLES}

TABLE

PAGE

Table 1. Population size of the 16 largest metropolitan areas in the United States .......... 13

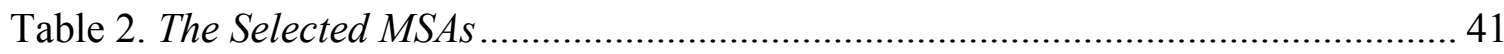

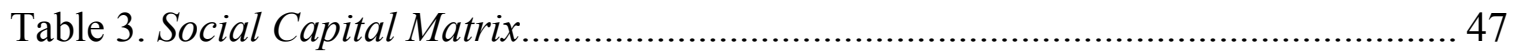

Table 4. The Industry Clusters of the Atlanta MSA Source: StatsAmerica, 2012.......... 51

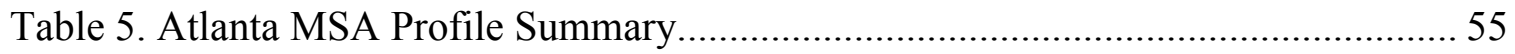

Table 6. Atlanta MSA Diverse Communities .............................................................. 58

Table 7. Atlanta MSA Somewhat Diverse Counties ................................................. 59

Table 8. Atlanta MSA Somewhat Homogenous Counties............................................. 59

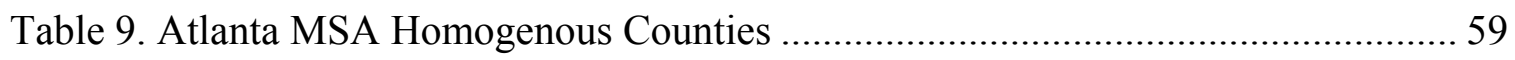

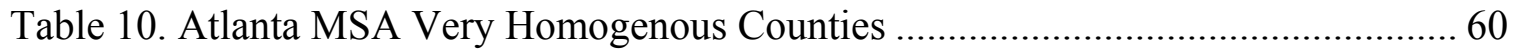

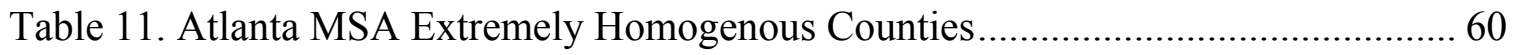

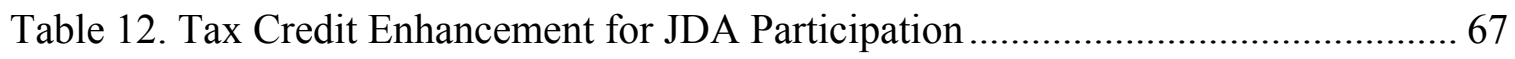

Table 13. County Profiles in the Atlanta Regional Commission.................................. 72

Table 14. County Profiles of the Three Rivers Regional Commission........................... 74

Table 15. County Profiles of the Northwest Georgia Regional Commission .................. 76

Table 16. County Profiles of the Georgia Mountains Regional Commission ................. 77

Table 17. County Profiles of the Northeast Georgia Regional Commission ................... 78

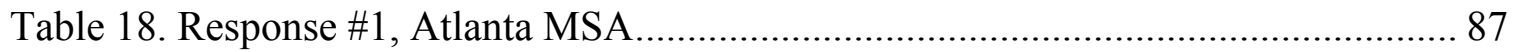

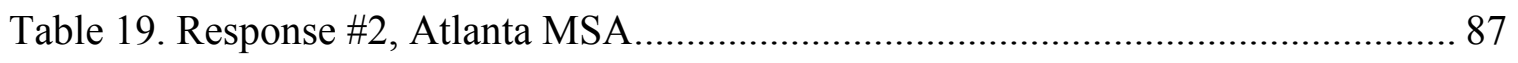

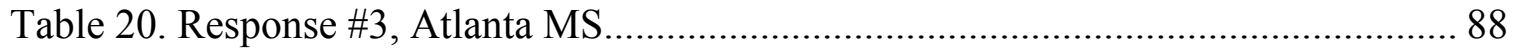




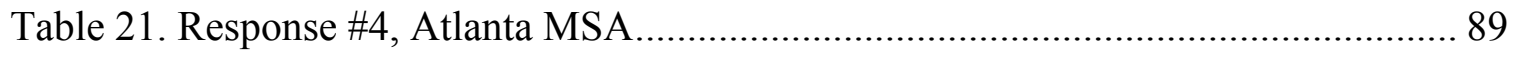

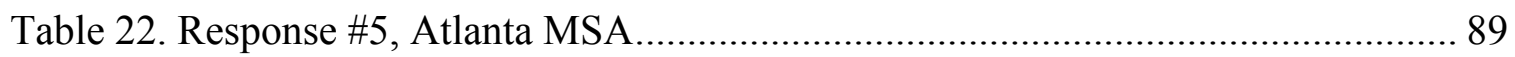

Table 23. Response \#6, Atlanta MSA.................................................................... 90

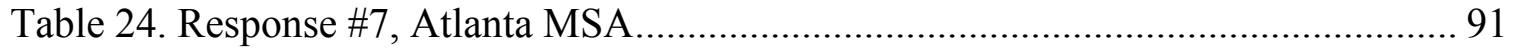

Table 25. Response \#8, Atlanta MSA.................................................................... 91

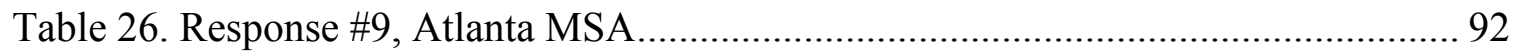

Table 27. Industry Clusters of the Houston MSA...................................................... 99

Table 28. Unemployment History for all three (3) MSAs .......................................... 100

Table 29. County Profile Summary in the Houston MSA ........................................... 104

Table 30. Municipal Incentive Programs in the Houston MSA................................... 109

Table 31. County Tax Reinvestment Zones in the Houston MSA ............................... 111

Table 32. Private Sector Contributors to GHP......................................................... 115

Table 33. Allies of the Greater Houston Partnership ............................................... 120

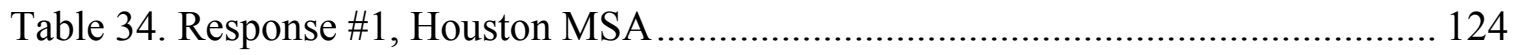

Table 35. Response \#2, Houston MSA .................................................................. 125

Table 36. Response \#3, Houston MSA .............................................................. 125

Table 37. Response \#4, Houston MSA .................................................................. 126

Table 38. Response \#5, Houston MSA …........................................................... 127

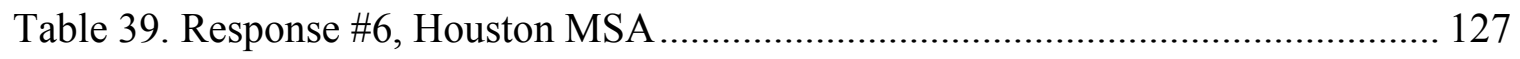

Table 40. Response \#7, Houston MSA ................................................................. 128

Table 41. Response \#8, Houston MSA ............................................................... 129

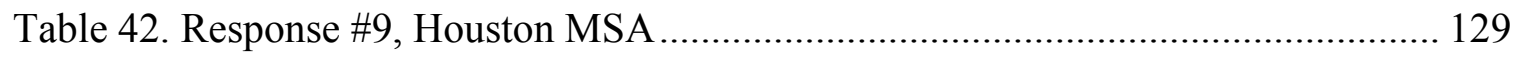

Table 43. Industry Clusters of the Miami MSA …................................................. 139 
Table 44. County Summary Profiles of the Miami MSA .......................................... 141

Table 45. Cluster Industries of the Treasure Coast Region ....................................... 156

Table 46. Cluster Industries of the South Florida Region ....................................... 156

Table 47. Response \#1, Miami MSA .................................................................... 161

Table 48. Response \#2, Miami MSA ..................................................................... 161

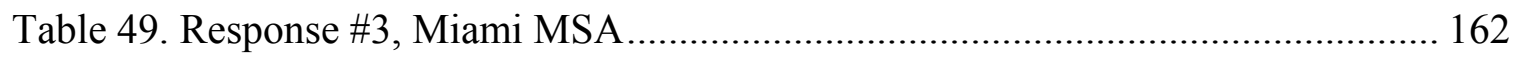

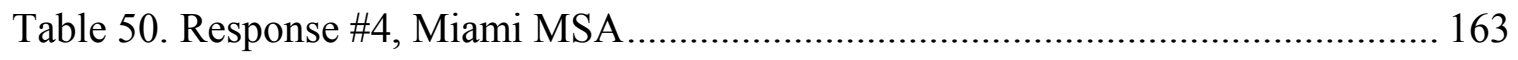

Table 51. Response \#5, Miami MSA ................................................................... 163

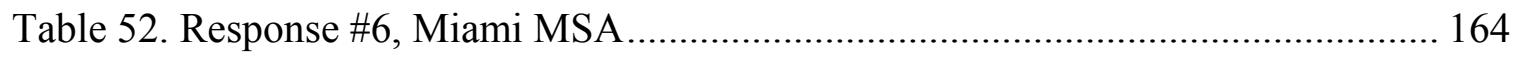

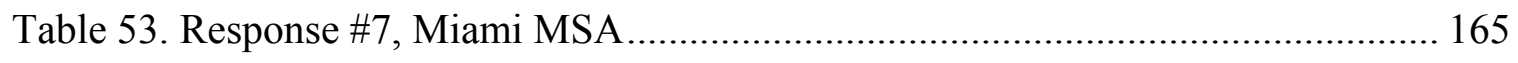

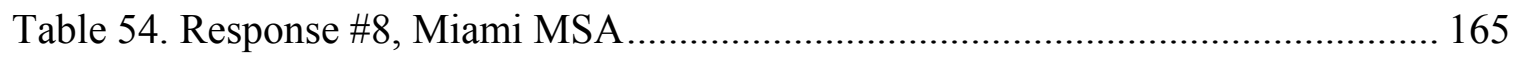

Table 55. Response \#9, Miami MSA .................................................................... 166

Table 56. Aggregated Positive Survey Responses................................................. 174

Table 57. Aggregated Positive Responses Graph ................................................. 175

Table 58. Comparative Economic Heterogeneity of the MSAs ................................. 176

Table 59. Lower value indicates greater fragmentation......................................... 177

Table 60. Herfindahl Index, Diversity Results for MSAs ...................................... 178 


\section{CHAPTER 1. \\ SCOPE OF THE RESEARCH STUDY}

\subsection{Research Problem}

Regionalism has once again emerged as a solution to the limited ability of local jurisdictions to effectively address a particular problem. In light of the challenges of a global economy, local officials are being encouraged to engage in collective action to improve the competitive posture of the nation's regions. My dissertation is a comparative study of efforts to regionalize economic development activity in metropolitan areas of the United States.

The present study maps regional economic development cooperation in three (3) Metropolitan Statistical Areas (MSAs) to discern the factors that most influence the cooperative process. Extant literature shows that the likelihood of achieving regional collective action, an agreement to address regional concerns, is linked to community profile characteristics (Feiock, Steinacker, \& Park, 2009) and reserves of social capital among the participating parties (Ostrom, 1998) (Olberding, 2002b).

The research concentrates on social capital among the key stakeholders engaged in economic development activity, and maps other contributing factors that have shaped economic development cooperation, as it exists in the three subject regions of my study. If a regional approach to economic development policies is indeed warranted, as the advocates of regionalism suggest (Fehr, 2010; Peirce, Johnson, \& and Hall, 1993; Porter, 2001), greater knowledge of the factors that influence regional economic development cooperation is needed. 
The move to regionalize economic development activity is being pushed by federal authorities as a strategic response to the challenges of global economic competition. President Obama recently declared, "Strong cities are the building blocks of strong regions and strong regions are essential for a strong America" (Fehr, 2010). Regional economic development cooperation is not simply an altruistic idea being promoted to encourage prosperous communities to assist the less fortunate neighboring jurisdictions. The federal government is encouraging regional cooperation as a strategic domestic policy to improve the overall global competitiveness of the national economy. Some economic development experts argue that that there is a correlation between vibrant regional economies and macro-economic growth (Porter, 2001; Drabenstott, 2006). The importance of improving the performance of the regional economies is underscored by the fact that 90 percent of the U.S. Gross Domestic Product is produced within the metropolitan areas (Panek, Baumgardner, \& McCormick, 2007).

To what extent must local jurisdictions within a region cooperate to improve economic prosperity? Is it necessary to centralize the economic development functions for the region in one agency? Should all prospective employers interested in locations within the region be facilitated by a single economic development organization? Should one agency allocate incentive packages throughout a region? The complete consolidation of economic development powers in one regional agency is highly unlikely.

The push for this type of regional consolidation of government services by metropolitan reformers dissipated before it was able to become a movement (Norris, 2001). There are remnants of the metropolitan reform movement throughout the United States. Region-wide structural reform was embraced in Portland and Minneapolis. There 
are unified county-municipal governments of Indianapolis, Indiana and Jacksonville, Florida. Miami-Dade County, a local jurisdiction included in this study, is often cited as an example of a two-tiered regional government.

The arguments advanced by the metropolitan reformers were focused on the concepts of efficiency and the cost-saving benefits of providing aggregated services associated with economies of scale. Over the last 50 years, these rational arguments have been effectively subverted under by the characteristically American preference for local control and autonomy (Norris, 2001). The new regionalist proponents have shifted the argument away from efficiency and equity and have couched the discussion of regionalism in terms of global competitiveness (Peirce et al., 1993).

From the new regionalist perspective, regional economic development cooperation involves a strategic alignment of the key agencies and entities capable of improving the economic functionality of a region. A coordinating agency overseeing the full range of economic development activities in a region might be considered ideal. The definition of regional cooperation in my research is not framed in legal, structural and organizational terms, but rests solely upon evidence of cooperation: Regional economic development cooperation is manifested when there is utilization of region-wide economic data in support of a unified cross-jurisdictional marketing strategy. As defined, regional economic development cooperation may be a fleeting thing, or it could be embedded in an institutional framework. The main focus of my dissertation is not dissecting the governance form that 'regional cooperation' takes; my research concentrates on the factors that influence whether or not 'regional cooperation' occurs at all. 
From the federal perspective, a regional approach is an efficiency measure to improve the performance of the national economy. From the local perspective, a regional approach to economic development activity is a classic social dilemma. For local jurisdictions to collectively embrace a regional approach to economic development activity, each jurisdiction must be prepared to occasionally relegate its own interests to a subordinate position.

Traditionally, local economic development activity has entailed competition among neighboring jurisdictions. Adopting a regional approach to economic development is a sea change for many local economic development practitioners. To fully regionalize economic development activity, local competitors would have to become regional confederates in a common endeavor to increase prosperity for the greater good. Such a scenario presents a real social dilemma.

The social dilemma inherent in any collaborative economic development program is not usually of compelling public urgency to ordinary citizens. Engaging in a regional economic development social dilemma is largely a matter of choice, dependent upon the good will and vision of public officials, civic leaders and the business community. For local public officials, the political benefits of acting regionally lie somewhere between marginally better than zero to negative. Local officials are more likely to engage regionally if there are incentives embedded in state and federal policies (Gordon, 2007). By and large, though, regional cooperation for economic development purposes is a uniquely voluntary act.

Clearly, cooperation for regional economic development is a difficult task. There are political risks associated with cooperation. Public officials who enter into such 
agreements may have to endure criticism from local constituents. Despite the uncertainties and risks inherent in this voluntary process, more than 100 economic regions across the nation have addressed this social dilemma and creatively structured organizations to conduct regional economic development activities (Olberding, 2002a). The structures of the organizations include varying degrees of public-private partnerships (Olberding, 2002).

\subsection{Research Background}

While federal officials may encourage regional cooperation to advance national prosperity, and economic studies may provide evidence of regional prosperity linked to cooperation, a collective decision to cooperate is a complicated transaction for economic development stakeholders in metropolitan regions. Cooperation is conceptually at odds with the historic competitiveness among the political jurisdictions and economic development organizations of a region.

Smokestack chasing, a phrase coined to describe the competitive practices honed by officials during the last century in the American South to lure northern manufacturers, is an enduring practice today (Fredriksson, List, \& Millimet, 2004; Boothroyd \& Davis, 1993). Extreme examples include the incentive package worth over $\$ 300$ million that Alabama used to lure a Mercedes sports utility vehicle plant; Tennessee offered similar conspicuous packages to attract Nissan and Saturn plants (Fredriksson et al., 2004).

An inducement-based economic development strategy relies on a sound, rational economic proposition: employers will choose a location in a jurisdiction that offers the most attractive incentive package. Site selection consultants representing prospective 
employers routinely search for and negotiate the most lucrative combination of tax breaks, economic incentives, subsidized labor, free land, and donated infrastructure that a local jurisdiction can afford. In more colorful language, site selection consultants and their footloose clients have been described as an "international jet set of con artists, charlatans, and plain crooks who demand grants, incentives, and tax advantages to set up plants that employ workers at low wages. They move in, skim off the cream, then move on to another 'disadvantaged' area" (Lotz, 1977).

Whether or not a jurisdiction can truly afford to offer such incentives, and whether the return on investment warrants such public largesse, are issues open for debate. There is even continuing debate about the best approach to calculate the costbenefit analyses for smokestack chasing policies. There is no consensus in the literature regarding the best methodology for calculating the costs and benefits associated with tax incentive policy (Buss, 2001). Geographically focused tax incentive studies invariably yield conflicting results. As benefits and costs vary with each project, and there is no agreed upon method for calculating the benefits and costs, broad generalizations about the efficacy of the policies are simply not defensible (Bartik, 1994).

However, there is consensus among economic development professionals that incentive packages will remain a fundamental component of state and local programs (Morfessis, 2011). There is one compelling argument for continuing this dubious practice that has been labeled 'corporate welfare' by critics: no state or local jurisdiction can afford to unilaterally discontinue offering incentives. Unless the courts or federal legislation ban smokestack chasing and declare such tax incentive policies illegal, 
incentive package competition will continue among the states and local jurisdictions all across the nation.

For the proponents of regional economic development cooperation, finding common ground for cooperation among competing jurisdictions presents an obvious challenge. If there is a history of intense economic development competition between the local jurisdictions of a region, the capacity to cooperate may be quite limited. The problems inherent in any effort to institutionalize regional economic development cooperation are myriad. Stakeholders do not necessarily share a common understanding of the competitive dynamics of a global economy, nor are they uniformly infused with an urgency to improve a region's competitive posture.

Stakeholders must be convinced of the benefits of aligning programs regionally, and be assured of the equity of those benefits. And, in light of the persistence of 'smokestack chasing' practices, mutual commitments for cooperation must be designed to preserve the ability of regional partners to occasionally compete with each other for prospective employers. My study concentrates on the factors that influence the ability of stakeholders to overcome jurisdictional constraints and engage in some form of intraregional cooperation for economic prosperity. The dissertation begins by recognizing the difficulties of crafting meaningful regional economic development cooperation agreements across local jurisdictions, and seeks to determine if accumulated social capital among the stakeholders of a region is a critical and catalytic ingredient in the formulation of such cooperative agreements. (Feiock, Steinacker, \& Park, 2009)(Olberding, 2002a) Ostrom, 1998). 


\subsection{Research Purpose and Significance}

The purpose of this study is to determine if social capital influences the capacity of stakeholders to cooperate in establishing protocols for regional economic development cooperation. Social capital factors are examined in concert with the community profile factors such as demographics and political fragmentation, which have been highlighted in extant studies to influence the likelihood of achieving cooperation (Feiock, Steinacker, \& Park, 2009). Methodologically, the dissertation uses a comparative case study approach, mapping the factors that have influenced the current state of regional economic development cooperation within each subject region.

The research addresses a deficiency in the literature pertaining to social capital among the stakeholders of regional economic development cooperation. The extant research indicates social capital variables are contributing factors that merit greater consideration, but there has not been a systematic effort to directly measure the influence of social capital variables among the essential network of individuals involved in regionalizing economic development activity. Olberding's (2002, p. 486) large-scale analysis of regional economic development cooperation finds "some support of the hypothesis that cooperative norms are positively related to the formation of regional partnerships for economic development." By narrowing the research focus to the essential network of individuals, this study is designed to directly test the influence of social capital among the stakeholders of regional economic development.

My research also extends the work of Feiock (2009), who has argued that there is a correlation between community profile variables and the likelihood of intergovernmental cooperation. Feiock notes the explanatory power of the community profile 
variables is limited to scoring the likelihood of cooperation, and concludes that the community profile variables do not adequately explain the inclination or aptitude for regional cooperation. Feiock does suggest the prospects for cooperation are enhanced through informal policy networks, which are the communication channels for building social capital among participants (Feiock, Steinacker, \& Park, 2009).

From a practitioner's perspective, this research provides insights into the process of regionalizing economic development activities. The analysis of the state of cooperation in three metropolitan regions and the factors underlying their existing state of cooperation may suggest a path for others to follow. For those who accept that regional economic development cooperation is vital to the prosperity of the nation, knowing the factors that most influence the cooperative process is important. At the outset, it is my contention that a deeper appreciation of the role of social capital is essential.

\subsection{Social Capital in Regional Economic Development}

Social capital is not a fixed asset to be examined; it is an intangible form of capital that is not easily defined. The concept has evolved and shifted within different contexts over time. Portes (1998) distinguishes social capital from other forms in this way: "Whereas economic capital is in people's bank accounts and human capital is inside their heads, social capital inheres in the structure of their relationships." Relationships exist between individuals, networks, communities and the citizens of a state. Social capital, defined as a measure of trust, has been identified as a cultural commodity at the level of nations (Fukuyama, 1995). Methodologies for determining the value of accrued social capital range from the level of the individual to a community, or to a nation 
(Woolcock, 2004). In this study, social capital is measured collectively among the economic development stakeholders of a region.

Social capital has become commonly associated with measures of community civic engagement following Robert Putnam's seminal book, Bowling Alone (Putnam, 1995). My research uses Putnam's concept centrally to explain regional cooperation. For the purposes of this research, social capital refers to "the norms and relationships that enhance people's ability to collaborate on common endeavors" (Putnam, 2005). The norms and relationships among the stakeholders of regional cooperation are defined in terms of trust, reciprocity and reputation (Ostrom, 1998).

According to Ostrom (1998), the elements of trust, reciprocity and reputation are the social capital variables that enable participants to resolve social dilemmas in ways that often exceed rational expectations. She asserts that the rational choice models when applied to social dilemmas routinely underestimate the willingness of parties to cooperate. Given the potential inequities and uncertainties inherent in a social dilemma, rational decision-making expectedly diminishes the likelihood of a resolution among the parties. In many instances, however, the relationships among the respective agents, and the clarity of the rules surrounding the particular problem, combine to produce better cooperative results in social dilemmas than the rational choice models suggest.

In theory, trust, reciprocity and reputation influence the collaboration process by enabling the capacity to cooperate to override legitimate concerns that arise during a collective action transaction. Presence of associations that provide formal and informal social interaction among stakeholders increases the likelihood of regional cooperation for economic development (Feiock, Steinacker, \& Park, 2009). Statistical analyses of 
regional economic development cooperative agreements have been conducted to broadly test the influence of social capital. Olberding (2002) found that cooperative norms in government, the private sector and among citizens positively influence the process of establishing regional economic development organizations. Olberding measured social capital as follows: the inverse ratio of political fragmentation among governments, the number of business associations per capita, and the total number of membership organizations per capita (Olberding, 2002b). Feiock (2009) and Olberding (2002) generally confirm the theory advanced by Ostrom (1998) that social dilemmas are often resolved with "better than rational results" due to the influence of social capital.

\subsection{Research Questions, Hypothesis and Design}

Drawing from the literature review, there are two main research questions and related hypotheses in this study. These questions have not yet been dealt with in the existing literature. They are as follows:

Question \#1: Is accumulated social capital essential for regional economic development cooperation to occur?

Hypothesis \#1: For regional economic development cooperation to occur, a reserve of social capital among the stakeholders is essential.

Question \#2: Is regional economic development cooperation an endeavor that requires the consent and approval of local public officials and civic leaders?

Hypothesis \#2: Regional economic development programming is only possible if the local public officials and civic leaders reach an agreement to cooperate. 
There are two categories of independent variables operationalized for this research project: social capital variables and community profile variables. The social capital variables are measured through a survey of the stakeholders and interviews. The community profile variables are derived from the descriptive data and public records of the counties that comprise each MSA. The dependent variable is the state of regional economic development cooperation.

The following three (3) MSAs were selected to conduct this study: HoustonSugar Land-Baytown, Texas; Atlanta-Sandy Springs-Marietta, Georgia; and Miami-Fort Lauderdale-Pompano Beach, Florida (American community survey 2009). For brevity, in the remainder of this dissertation, the selected MSAs are referred to by their principal cities, Houston, Atlanta and Miami, respectively. These MSAs are the focus of this study primarily because of their similarity in population size. These metropolitan areas also do not cross state boundaries, and are located in different states.

For each of the three metropolitan regions, existing databases were reviewed to compile community profile data. This information afforded an opportunity to utilize various data sets to gauge the similarities and differences that exist within and among the counties of each region. Included in the community profile variables are demographics, government structures, political fragmentation, industry cluster composition, as well as the state constitutional provisions and statutory regulations that govern regional economic development pursuits.

The social capital variables of trust, reciprocity and reputation were assessed through the lens of a transaction cost model. The transaction cost model outlines the three stages of a cooperative agreement: discovery, negotiation and conclusion (Coase, 1988). I 
measured the social capital variables at each stage of these cooperative transactions. In this, I conducted a survey of stakeholders to determine the elements of trust, reciprocity and reputation at each stage of the transaction. Examining the social capital variables through the lens of the transaction cost model provides a good basis for comparison across the three MSAs.

\subsection{Justification of the Selected Regions of Empirical Study}

Since federal policies encourage regional economic development cooperation, the most populated regions across the country were examined to select the case studies. The three comparable regions needed to meet the following criteria: 1) the MSAs had to be entirely within the boundaries of a single state (to avoid conflicting state economic development policies); and 2) the regions would be selected from three different states. The MSAs of Houston, Atlanta, and Miami satisfied the study requirements.

\begin{tabular}{|l|r|}
\hline \multicolumn{1}{|c|}{ MSA } & Population \\
\hline New York-Northern New Jersey-Long Island, NY- & $19,069,796$ \\
\hline Los Angeles-Long Beach- Santa Ana, CA & $12,874,797$ \\
\hline Chicago-Naperville-Joliet, IL-IN-WI & $9,580,567$ \\
\hline Dallas-Fort Worth-Arlington, TX & $6,447,615$ \\
\hline Philadelphia-Camden-Wilmington, PA-NJ-DE-MD & $5,968,252$ \\
\hline Houston-Sugarland-Baytown, TX & $5,867,489$ \\
\hline Miami-Fort Lauderdale-Pompano Beach, FL & $5,547,051$ \\
\hline Washington-Arlington-Alexandria, DC-VA-MD- & $5,476,241$ \\
\hline Atlanta-Sandy Springs-Marietta, GA & $5,475,213$ \\
\hline Boston-Cambridge-Quincy, MA-NH & $4,588,680$ \\
\hline Detroit-Warren-Livonia, MI & $4,403,437$ \\
\hline Phoenix-Mesa-Scottsdale, AZ & $4,363,094$ \\
\hline San Francisco-Oakland-Fremont, CA & $4,317,853$ \\
\hline Riverside-San Bernardino-Ontario, CA & $4,143,113$ \\
\hline Seattle-Tacoma-Bellevue, WA & $3,407,848$ \\
\hline Minneapolis-St. Paul-Bloomington, MN-WI & $3,269,814$ \\
\hline
\end{tabular}

Table 1. Population size of the 16 largest metropolitan areas in the United States 
In arriving at these three MSAs, I first identified the sixteen largest MSAs using 2009 census estimates (American community survey, 2009) [listed in Table 1]. Six of these MSAs were not considered since they spanned multiple state boundaries. Regional economic development cooperation in such areas is challenging because of the different state economic development policies and regulations that the metropolitan areas would have to undertake. Also, from a social capital perspective, the stakeholders in multiplestate regions are likely have fewer opportunities for social interaction as civic organizations and professional associations are generally chartered to address the issues of one particular state. To limit the complexities of multi-state regional collaboration, the six MSAs were redacted from further consideration. The redacted MSAs include: New York-Northern New Jersey-Long Island; Chicago-Naperville-Joliet; PhiladelphiaCamden-Wilmington; Washington-Arlington-Alexandria; Boston-Cambridge-Quincy; Minneapolis-St. Paul-Bloomington.

Of the remaining ten regions, the Los-Angeles-Long Beach-Santa Ana, CA region is quite distinctive in terms of its size, with over 12 million people. Hence it was not selected. The next largest region is the Dallas-Fort Worth-Arlington, TX (Dallas) MSA, but is significantly larger (standard deviation=456,479) than the next three MSAs of Houston, Atlanta, and Miami. Another reason not to choose both Dallas and Houston is that they are in the same state; Houston was chosen since it is closer to Atlanta and Miami in population size. The standard deviation of the population among these three MSAs is much lower $(208,855)$.

The screening criteria that guided the selection yielded a group of MSAs with a number of similar attributes. All three regions are served by major international airports 
and are globally recognized as commercial gateways to the U.S. domestic market. Each region is well positioned to facilitate trade and commerce with Central and South America and the entire western hemisphere. In many ways, history and geography have combined to provide each of these regions competitive advantages in the global economy. The three MSAs have diverse urban populations, fairly similar climates, similar international cache, and prominence as key economic regions in the American South. These common attributes serve to make these regions good candidates for comparison in this study.

\subsection{Identifying the Stakeholders of Regional Economic Development Cooperation}

County governments are the first-tier political subdivisions of the state and constitute the primary local jurisdictions that define MSA regions. MSAs are identified by principal cities within the counties of the region, but the regional boundaries are fixed along county lines. Just as MSAs are a composite assembly of county jurisdictions, regional economic development cooperation requires the coming together of county stakeholders. For the purposes of this research, the stakeholders of regional cooperation for economic development in MSAs are considered as individuals who belong to either of the following groups: 1) the elected and appointed county public officials, and 2) the civic and business leaders on the boards of county economic development organizations.

The research's focus at the county level does not preclude the participation of municipal officials. Those city officials who are active on the boards of economic development organizations (EDOs) are also considered stakeholders. All civic and business leaders who are members of county EDOs, including individuals representing 
chambers of commerce, are considered vital stakeholders of any regional initiative for economic prosperity.

There is not much distinction between civic and business leaders involved with EDOs and chambers of commerce. The distinction, if at all, is a matter of function and outlook. The civic and business leaders active with EDOs are focused on external affairs that impact the economic vitality of a community. These EDO members engage themselves in recruitment and retention efforts, and work to expand the capacity of the local economy. Members of county EDOs are essential stakeholders in any process to regionalize economic development activity.

Individuals from chambers of commerce mostly provide services to members and advocate on local matters that directly impact the interests of its membership (Hanson, 2009). For this reason, membership alone in a chamber of commerce is considered an insufficient qualifier for designation as a stakeholder for this study. But, as stated earlier, chamber of commerce leaders who are also active on the boards of EDOs are included.

The civic and business leaders often play an important role in any effort to regionalize economic development programming. If a downtown business community sees advantages in regionalizing the economic development programming of a metropolitan area, they are uniquely capable of activating a network of actors to accomplish such a goal (Gainsborough, 2003). In this research, the downtown business community is defined as those individuals active on the board of the local EDO.

I conducted a survey to measure social capital among the above stakeholders in each region. A pool of stakeholders in each region was identified using the definitions given above, and they were asked questions related to the social capital variables. The 
survey questions were specifically designed to gauge the availability of social capital at the different stages of transactions (i.e. discovery, negotiation and conclusion). The survey questions were the same across the regional economic development stakeholders of the three MSAs, so that the social capital variables measured are the same in each region.

\subsection{Organization of the Dissertation}

The scope of this research endeavor is covered in this present Chapter 1. This research is a qualitative, comparative case study examining the contributing factors and the state of economic development cooperation in three regional MSAs of the United States. In Chapter 2, the theoretical framework and literature review relevant to this research will be presented. Chapter 3 details the research design and methodologies utilized in this dissertation. In the subsequent chapters, the findings of the study for each of the MSAs are presented. Chapter 4 covers the Atlanta MSA. Chapter 5 is dedicated to the Houston MSA. Chapter 6 coves the Miami MSA. Finally, Chapter 7 concludes with a discussion regarding the comparative findings of the study, the validity of the research hypothesis, and recommendations for the proponents of regional economic development programs. 


\section{CHAPTER 2.}

\section{THEORETICAL FRAMEWORK AND LITERATURE REVIEW}

\subsection{Introduction}

Coordinated regional initiatives for economic development purposes are relatively new phenomena. Collaborative economic development initiatives across jurisdictional boundaries involving private and public leadership have only recently become commonplace. There is a substantial body of public policy literature examining the topics of governance and regionalism. And, the broader topic of social capital and its influence on various aspects of civic life has generated substantial interest and a wide range of literature.

There is growing evidence that social capital plays an important role in the collective process of regionalizing economic development activity. Research focused on economic development collective action has certainly carved out a space for conjecture about the role of social capital in this process (Feiock, Steinacker, \& Park, 2009). Recent contributions of targeted research have concluded that community attributes of social capital do positively influence the cooperative efforts to regionalize economic development activity (Olberding, 2002a). The comparative case study will contribute to the research on this specific topic by specifically examining the influence of social capital on the network of essential stakeholders involved in regional economic development transactions.

In this study, the social capital variables among the network stakeholders of a regional cooperative transaction are operationalized at each stage of a collective action transaction. The three stages of the transaction are discovery phase, negotiation phase and 
conclusion phase (Fox, 2007). By doing so, the goal of the present study is to provide critical knowledge to the economic development practitioners interested in improving the prospects of regional cooperation.

Since this dissertation is focused on the influence of social capital on the cooperative process of regionalizing economic development activity, I reviewed the current status of domestic economic development policy. Regional cooperation for economic development purposes requires local stakeholders to adopt new perspectives, new policies and new programs. It is not sufficient to simply elevate the time-tested local economic development programs of the past to the regional level. Toward this end, I synthesize the evolving theoretical framework for regional economic development policy. The discussion includes the theories that illuminate the dynamics of the transition to regional cooperation.

\subsection{Beyond Smokestack Chasing}

Smokestack chasing, the practice of luring prospective employers with lucrative incentive packages, has been an enduring public policy endeavor. Incentive-based competition has been the core economic development strategy among state and local officials in the United States for generations (Blakely, 2002) . Every instance of competitive smokestack chasing between jurisdictions in a region could negatively affect social capital among the regional stakeholders. Rather than collectively addressing the challenges of global competitors, neighboring jurisdictions are then pitted as contestants in the quest for increasing employment opportunities for their own residents. 
Critics of the practice of smokestack chasing mounted a legal challenge that went all the way to the United States Supreme Court in 2006, but did not prevail. According to Peter Enrich, the Northeastern University law professor who argued the case against smokestack chasing, "the states are caught in an expensive and ineffectual competition from which none can risk unilaterally withdrawing. Only enforcement of the Constitution's constraints by the courts can end this race to the bottom" (Vock, 2006). The assessment by Enrich — that no jurisdiction can risk unilaterally suspending the practice of offering tax incentives_-is a view shared by many economic development professionals (Morfessis, Motoyama, \& Malachuk, 2011).

The problem confronting local economic development organizations today is that smokestack chasing is now a global phenomenon. Over the past two decades, geopolitical changes and the advent of the World Wide Web have dramatically expanded the competitive playing field by lowering barriers to trade and commerce around the globe. In the 'flattened' global market, production from early design to final assembly and packaging may occur sequentially in multiple locations, domestically and internationally, efficiently orchestrated using high-speed telecommunications. Companies can easily assign research, low-end manufacturing, and high-end manufacturing to multiple locations across the world (Friedman, 2005).

Manufacturing firms now have the ability to explore markets around the globe to find locations that offer the lowest possible cost on all factors of production. As a consequence of the worldwide geopolitical changes since the 1989 collapse of the Soviet empire, the number of low-cost locations around the globe far exceeds the capacity of locations in the United States to counter such offers (Friedman, 2005). According to 
Blakely (2002), it is now very unlikely that any local economic development organization in the United States will significantly increase employment opportunities by attracting new manufacturing industries.

As the economic development literature suggests, smokestack chasing is no longer the most effective method of attracting and retaining major employers. As location competition has expanded to global destinations, it is increasingly difficult for states and local jurisdictions to assemble packages of incentives that are both competitive and justified. Studies of 'successful' attraction and retention efforts suggest that there is little evidence of positive or negative growth impacts once the tax breaks, financial incentives and other inducements are taken into account (Fox \& Murray, 2004; Hansen \& Kalambokidis, 2010; Weinstein, 1994) . In this context, new economic development models for securing the growth and prosperity of states and local jurisdictions have emerged.

\subsection{Economic Growth and Innovation}

The Council on Competitiveness, a non-governmental organization of corporate executives, university presidents and labor leaders, published a report by Michael Porter, a well-respected economist, to offer insights for economic development professionals into the new competitive paradigm in the globalized context. The report, Clusters of Innovation: Regional Foundations of U.S. Competitiveness, defined the relationship between innovation and regional economic performance (Porter, 2001). To spur economic growth and prosperity, the report encouraged economic development professionals to identify, support, assist, and nurture the innovation clusters of a region. 
As the Porter study suggests, wealth creation will not be achieved by concentrating solely on attracting manufacturing jobs; it is more likely going to be a result of local entrepreneurs creating the next new thing — whether it is a product, process or procedure. Erecting the socio-economic scaffolding to support greater interaction among entrepreneurial innovators is essential to increase the competitive edge of the regional cluster industries. According to Porter (2001, p.xvi), “successful regional economies benefit from the contributions of a wide array of organizations. Organizing for action entails arriving at consensus and creating the capacity for regions to implement development strategies.”

\subsection{Entrepreneurial Support and Economic Development}

Judd and McNeil (2008) argue that entrepreneurs are the "critical drivers" of the global economy. To advance this concept, they call for the adoption of a $21^{\text {st }}$ Century Economic Development model that has three pillars: 1) develop and support entrepreneurs and small businesses; 2) expand and improve the local infrastructure; and 3) develop or recruit a skilled and educated workforce. Notably, they do not incorporate retention and recruitment economic incentives in their model.

Dabson (2005) advanced a pyramid-shaped policy model, where the broad base represents strategic programs to support innovation and entrepreneurship. Working up the pyramid, the next tier of resources is dedicated toward support for and retention of existing businesses. The top tier, representing the smallest allocation of resources, is reserved for recruitment and attraction initiatives. The Dabson (2005) policy model emphasizes a shift in priorities toward strategies that focus on innovation and 
entrepreneurship. Moving beyond simple smokestack chasing expenditures, the retention and attraction of firms increasingly relies upon funding initiatives that improve commercial networks, support entrepreneurship, and increase collaboration with educational institutions. By creating an environment for innovation, the location decision matrix is effectively modified (Dabson, 2005).

To the extent that resources are expended on economic incentives to attract firms, Dabson (2005) stresses firm selections that complement the region's overall competitive strategy. The notion within this model is that vestiges of the long-standing economic development policies of the last century will continue is both a plausible and acceptable position. The model proposed by Dabson acknowledges that organizations, like individuals, do not readily adapt to change.

\subsection{Path Dependency of Institutions}

Resistance to change within organizations and institutions is explained by the theory of path dependency. The theory of path dependency postulates that contingent events set into motion institutional patterns that are reinforced by the economic principle of increasing returns (Mahoney, 2000). In other words, in response to an unexpected and random occurrence, an organization will formulate a program to address the unexpected situation. As long as the program produces the desired result, as long as there are increasing returns, the organization will not alter its programmatic course. Viewing economic development organizations (EDOs) through this theoretical lens provides useful insight. 
The theory advanced by Mahoney (2000) is applicable not only to the programming decisions of an EDO, but also applies to the circumstances surrounding the formation of an EDO. According to this theory, an institution is formed at a critical juncture in time when a contingent, random event impacts a jurisdiction. A contingent event that results in the formation of an EDO might be a dramatic jump in unemployment due to the departure of a major employer, a base closure, civil disturbances, or some other local economic or political upheaval. Regardless of the exact nature of the contingent event, the theory of path dependency subscribes that unique, random and unexpected circumstances provide the context for the establishment of a new institution, such as an economic development organization.

The theory of path dependency suggests an institution that is established as a result of a random, contingent event is formed with a defined purpose, a strategic course of action, and specific implementing steps. If the strategy works, if there are increasing returns to the organization, the steps will be repeated and become a sustained institution. As long as the patterned response continues to yield positive outcomes, the organization will continue to travel down a defined path.

Dabson (2005) tacitly acknowledged the power of path dependency theory in the construct of the pyramid economic development model. For those EDOs established as an institutional response to an economic crisis, as long as successful projects are reported, smokestack-chasing tactics will continue to be used to attract and retain firms. The pyramid model advanced by Dabson (2005) accepts the continuance of smokestackchasing tactics and does not envision an abandonment of the practices. 
The theory of path dependency not only aptly explains the continuing adherence to programs of dubious value, but also provides insights into the challenges associated with the establishment of new institutions to address regional economic development concerns. Broadly speaking, the global economy has not arrived in the doorsteps of most American communities as an unexpected, contingent event. The realization of the need to address the impact of global economic competition has been a gradual process.

The literature does not identify a precise calendar event when the phenomena of global competition became a critical threat to the economic stability of local communities in the United States. The theory of path dependency provides that absent a contingent event that qualifies as a critical juncture where decisions must be made, change is unlikely.

Though regional cooperation for economic development purposes is couched within the literature as a direct response to the challenges of global economic competition, it appears unlikely that global competition qualifies as a critical juncture to spur such a substantial change in local economic development policy. Other unexpected, random events that equate to a 'critical juncture' are more likely to serve as the impetus for embracing a cooperative regional economic development strategy. A localized economic downturn, the arrival of a bold civic leader with a grand vision for economic prosperity, political upheaval arising from a deteriorating local economy, or the unexpected attention of foreign investors might be events that spark the transformation to regional cooperation. 


\subsection{Transaction Costs for Regional Cooperation}

When circumstances present an opportunity to pursue regional cooperation for economic prosperity, when a region finds itself at a critical juncture, it is important to appreciate the challenges of producing a cooperative agreement. Coase's (1988) economic theory provides an excellent framework for understanding the obstacles and impediments that hinder the establishment of regional economic development cooperative agreements.

Coase (1998) explains that firms expand to reduce the transaction cost involved in procuring the means of production in a free market. In effect, a firm will purchase a supply company and make it a subsidiary in order to reduce the transaction costs involved in acquiring essential supplies. Consistent with this theory, public entities will 'expand' by entering into cooperative agreements if the transaction costs for doing so are low and the expected benefits from collective action are high.

The transaction costs originally identified by Coase in his 1937 essay include: 1) the cost of discovery, 2) the cost of negotiation, and 3) the cost of concluding the agreement (Fox, 2007). In the present research, for each stage of the transaction cost model, topics and issues relevant to economic development cooperation are identified.

The cost of discovery in the context of a regional economic development agreement relates to the gathering and compiling of social and economic data, and defining any potential legal constraints. The parties need to provide data about the demographics, infrastructure, land-use patterns, educational assets, political structure, existing business inventory, regulatory environment, industry clusters and other factors necessary to determine the relative competitive advantages of each participating 
community. The compilation and presentation of this information to the satisfaction of the parties is a transaction cost in both resources and time.

The cost of negotiation of a regional economic development agreement relates to the capacity of the designated representatives to speak on behalf of the respective stakeholders, constituents and voters. To the extent that the representatives are authorized to make obligations, to offer concessions, to accept revisions, and to advance an agreement expeditiously, the transaction costs of negotiations are minimalized. If the representatives require approval from superiors for each step of the negotiations the cost of negotiations escalate. The parties at the table responsible for crafting an agreement must be capable of assessing that the stated goals and objectives of the regional agreement comport with the long-term interests of the entities they represent, and be prepared to make compelling arguments to win approval.

The cost of concluding a regional economic development agreement relates to the transaction costs associated with winning the approval of the various governing boards of the entities involved. There may be adjustments necessary to the proposed division of resources and benefits, internal political concessions, additional cooperative provisions, modifications to the term of the agreement, and other externalities that have to be addressed. Creating an environment for a cooperative decision to occur may involve ancillary public relations costs to secure approval.

Institutions that voluntarily forge collective actions agreements do so in order to improve the conditions for all parties. The voluntary nature of the negotiations underscores the need to discover a Pareto-optimal conclusion. The inherent challenges of 
attaining such a conclusion are starkly revealed with viewed through the lens of the Coasian model of transactions costs.

In the intergovernmental arena, the determination of transaction costs often includes estimated costs associated with the monitoring and enforcement of an agreement. Fox (2007) makes a cogent argument that these factors do not arise during the negotiations of the transaction and should not be considered transaction costs. Monitoring and enforcement are administrative issues relating to implementation. This research study conforms to this view, and does not anticipate the incidental costs of maintenance and compliance associated with the implementation of a successful agreement.

\subsection{Factors that Influence Cooperative Economic Development Transactions}

Feiock, Steinacker and Park (2009) note that even though the potential benefits for all parties can be substantial, institutional collective action agreements are particularly difficult in the field of economic development because the transaction costs tend to be high. The historic competitive posture of the parties, information asymmetry across localities, the challenge of ensuring a fair commitment of resources and reasonable distribution of the gains, a lack of economic homogeneity within and among the respective jurisdictions, and variations in the structures of government all present serious challenges to achieving a collective economic development agreement.

Feiock, Steinacker and Park (2009) utilized data from a national mail-in survey to the lead development officials in 522 cities with populations over 50,000 as per 1990 census. The researchers applied a transaction cost framework for intergovernmental relations to evaluate the results of the survey. According to them, "By focusing attention 
on the transaction costs of inter-local cooperation, institutional collective action provides a coherent explanatory model for cooperative behavior and identifies policy variables that may increase the prospects for cooperation, specifically the development of informal policy networks" (Feiock, Steinacker, \& Park, 2009).

According to the study, the likelihood of successfully concluding a cooperative economic development agreement is positively related to: the council-manager form of government; the tenure in office of elected and appointed officials; initiatives that bridge weak-tie network relations among local governments; tightly clustered strong-tie network relations among local governments; and the history of reciprocal relations across time and policy arenas.

The above study also noted that the likelihood of success is negatively related to: demographic heterogeneity among the component jurisdictions; demographic heterogeneity within the component jurisdictions; geographic distance between the component jurisdictions; the restrictiveness of state laws authorizing inter-local cooperation; district-based representative systems; and institutional heterogeneity in the political structure of local governments.

The study concludes that the primary policy variables that increase the prospects for cooperation are: 1) homogeneous economic demographics; 2) a council-manager structure; 3) geographic proximity; and 4) social links, both formally structured (strongtie) interactions and informal (weak-tie) associations. Notably, the study suggests that racial diversity and ethnic population variance among the jurisdictions do not appear to be influential factors (Feiock, Steinacker, \& Park, 2009). 
While these policy variables serve as general guideposts for estimating the likelihood of institutional collective action, there are unanswered questions relating to increasing regional endeavors. As Feiock (2009) notes:

These factors suggest where cooperative endeavors are most likely to spring up, but they provide few levers to increase the likelihood of those activities. Network activity may offer the greatest opportunities for change. Both strong-tie networks with frequent interaction among cities and weak-tie associational networks that involve only minimal participation are associated with greater use of inter-local partnerships. One way that higher-level governments can encourage collaboration is to structure incentives for local governments and other organization officials to interact in ways that can help build the networks and related social capital that lead to cooperative solutions to metropolitan problems. (Feiock, Steinacker, \& Park, 2009, p. 267).

\subsection{The Stakeholders of Regional Economic Development Cooperation}

In the present research, the 'other organization officials' involved in the collaborative process with local government officials are defined as the board members and executives of local economic development organizations. The literature provides the 
rationale for selecting EDO officials rather than chamber of commerce leaders as regional economic development stakeholders.

The board members and executives of EDOs are philosophically better suited than their counterparts in chambers of commerce for the task of advancing regional economic development initiatives (Hanson, 2009). In the United States, the chambers of commerce are voluntary membership organizations formed to provide services to the members and advance the general interests of businesses within a local jurisdiction. Chamber board members and executives serve as advocates for their business membership and engage in public policy matters on a more limited basis than EDOs. Chamber of commerce engagement in public policy is generally reserved for issues and topics that impact the general welfare of the membership.

Economic development organizations are formed to address broader civic issues and are generally comprised of executives representing major employers, directors of utilities, and leaders from the public sector, schools and universities. An EDO often serves as an extension of local government, entrusted with the responsibility of qualifying firms for the award of tax breaks, incentives and rebates. These organizations and their leadership are oriented toward external developments on the economic horizon that present opportunities to increase the prosperity of the community.

Hanson (2009) suggested that the leadership of EDOs have "different skills and expertise, experience, mind-set and outlook" than their chamber of commerce counterparts. The board members and executives of EDOs seemingly provide a natural pool of leadership talent to further the concept of regional cooperation. My research will 
adhere to this perspective and categorizes the EDO leaders as primary stakeholders in the process of regional cooperation for economic development.

\subsection{Social Capital and the Transaction Costs Approach}

The transaction costs approach provides a coherent explanatory construct for cooperative behavior within the framework of a rational choice paradigm. During negotiations for collective action, each party effectively maintains a ledger of costs and benefits in order to make a rational decision about whether or not to enter into such an agreement. The social dilemma arises when the local costs of participation are measured against collective benefits, and the benefits do not directly accrue to the particular locality.

Feiock, Steinacker, \& Park (2009) utilize the transaction costs model to frame a rational decision-making process regarding economic development. They identified a series of community profile variables that increase the likelihood of cooperation. Many of these variables arguably reduce the tension among the parties (e.g., factors such as having a common demographic or economic community profile). Yet, the final impetus to achieve regional cooperation requires the parties to draw upon the less tangible aspects of social capital.

Social capital has become a familiar concept in the public policy arena in the wake of the two popular publications, Trust: social virtues and the creation of prosperity by Francis Fukuyama (1995) and Bowling Alone, The Collapse and Revival of American Community by Robert Putnam (2001). Fukuyama argued that trust has socioeconomic benefits. Trust is the essential ingredient that reduces friction and eases tension, allowing 
public affairs and commercial transactions to conclude efficiently. Fukuyama found that as a cultural trait, trust varies from nation to nation. In his book, Putnam traced the decline of American civic involvement and a correlating loss of social capital by examining a range of activities like playing cards and going to church. Putnam calls for the social milieu of past generations where informal interactions engendered social capital and warns of the dire consequences if the erosion of social capital is not reversed.

Although the above authors need credit for their endeavor to bring social capital into the political discourse in recent times, the concept of social capital is not entirely new. Hanifan (1916) defined social capital as "the tangible substances that count for most in the daily lives of people: namely good will, fellowship, sympathy, and social intercourse among the individuals and families who make up a social unit" (quoted in Putnam, 2000, p.19). Woolcock (2004) also recognized the contributions of Janae Jacobs and Glen Loury to the concept of social capital. While the former highlighted the value of informal interactions for urban vitality, the later argued for the uses of social capital in overcoming blacks' marginalization. However, it is only recently that the notion of social capital has emerged as a possible mechanism to resolve regional economic development cooperation.

Public officials and civic leaders involved in developing regional economic development agreements must overcome significant hurdles to achieve success. Many times the costs of cooperation can be precisely calculated, but the benefits are less tangible. From a strictly rational economic perspective, it is a notable challenge to justify regional cooperation. Yet, the number of regional organizations responsible for managing 
economic development programs across local and state boundaries has grown (Olberding, 2002a).

Regional partnerships increased five-fold (from three to 16) in the span of just one decade during the 1990s (specifically, from 1987 to 1997). Since then, 191 regional partnerships for economic development have been identified in 147 metropolitan areas across the U.S. (Olberding, 2002b). The Olberding study examined whether or not cooperative norms influence the formation of regional economic development organizations. As per Olberding (2002, p. 487), seven of the eight variables measuring cooperative norms support the hypothesis that "cooperative norms in government, in the private sector, and in the citizenry are positively related to the formation of regional partnerships for economic development."

My dissertation is designed to further probe the influence of cooperative norms by measuring the social capital among the stakeholders in three MSAs. Putnam (2005, p. 288) asserts that "social capital allows citizens to resolve collective problems more easily" and that "social capital greases the wheels that allow communities to advance." My dissertation assesses the amount of social capital available to stakeholders to advance regional economic development cooperation.

Ostrom (1998) suggested that "better than rational" results are possible when reciprocity, trust and reputation allow participants to extend themselves beyond short-run self-interest. According to her, the rational choice models routinely underestimate the willingness of parties to cooperate in order to address social dilemmas. By introducing the value of social capital in the rational choice equation, she encouraged the development of second-generation theories of rational choice that account for these 
observed behavioral traits (Ostrom, 1998). She showed how the capacity of participants to trust and rely on reputation for reciprocity could otherwise alter the expected results of stalemate in cooperation. To measure social capital in my study, I use the three dimensions of social capital identified by Ostrom: reciprocity, trust and reputation.

\subsection{Summary}

The extant literature reveals that there is a positive correlation between regional cooperation and the cooperative norms that exist in government, the private sector, and the citizenry (Olberding, 2002a). This positive correlation of cooperative norms could be used as the leverage to propel negotiations for regional cooperation forward (Feiock, 2009). To determine the specific influence of cooperative norms on regional cooperation, it is necessary to focus on the social capital among the stakeholders involved in a cooperative transaction. Typically, the stakeholders involved in regional cooperation are public officials and the civic leaders prominent within EDOs (Hanson, 2009).

Empirical research reveals that regional cooperation for economic prosperity is an attainable aspiration. Federal officials may have reason for optimism that the message of job creation through innovation and cooperation is producing results (Porter, 2001). While inter-local competition grounded in historic smokestack chasing tactics persists, the increase in the number of regional organizations dedicated to economic development is notable (Olberding, 2002b). In light of this recorded surge in cooperative activity, it is important to understand how regions have overcome the power of path dependency in smokestack chasing (Mahoney, 2000). 
The large-scale quantitative research by Feiock, Steinacker, and Park (2009) identified a range of measurable community profile characteristics that are known to influence the probability of success once the pursuit of a regional cooperative effort is initiated. The research challenge is to recognize and account for the influence of these known variables (which are factors such as homogeneity of economic demographics, government structure, and geographic proximity), while testing for the influence of social capital among the stakeholders.

The literature provides support for the application of a transaction cost model to evaluate regional cooperative initiatives. The transaction cost model consists of three components, or phases: discovery, negotiation and conclusion (Coase, 1988). The transaction cost model is grounded in the theory of rational economic choices.

The results of negotiations often exceed the expectations of rational decisionmaking, in part, due to the influence of social capital. According to Ostrom (1998), the elements of social capital that provide for such better than rational results are: trust, reciprocity and reputation. The present comparative case study tests the influence of trust, reciprocity and reputation on the decision to cooperate for regional prosperity within the transaction model framework. The mechanics of the research design to test the influence of social capital among the stakeholders of regional cooperation are described in the following chapter.

My research effort sought to advance an understanding of the critical importance of social capital in the formation of cooperative regional economic development initiatives. While the findings of this particular research effort are unable to affirm the critical role of social capital as an essential factor for cooperation, the research suggests 
greater attention be focused on the impact of policies adopted by the superior state governments relative to regional economic development pursuits. State policies play a prominent role in the regional economic development arena, at times enhancing the prospects for cooperation, and at other times dimming the likelihood of cooperation. 


\section{CHAPTER 3. RESEARCH METHODS AND PROCEDURES}

\subsection{Introduction}

The aim of this dissertation is to illuminate the factors that influence cooperative regional economic development. Towards this end, I examine the social capital factors that are of great importance to regional cooperation. The examination includes the wide range of related explanatory factors, including demographic and economic homogeneity, political fragmentation, cluster industry concentration, and the statutory environment governing economic development activity.

My primary data sources include the survey responses and follow-up interviews with regional stakeholders in the selected metropolitan areas. The secondary data sources include the legal documents covering multiple-jurisdictional cooperation, census data on demographics, and published reports on industries and regional cooperation in the selected metropolitan areas. During the research process, I took careful steps to avoid the circular tautological argument about the influence of social capital: the reason people in the region are cooperative is because the people in the region are cooperative. This dissertation identifies the most significant factors that influence and activate regional economic development cooperative initiatives in the study area.

Chapter three outlines the research methods used in the dissertation. Following a discussion of the research questions and the criteria for selecting the subject regions of this study, the ranking of the regions in order of progress in effectuating regional economic development cooperation is provided. The observations utilized to determine the ordered rankings, and the dependent variables affecting the status of cooperation is 
then presented. An explanation of the social capital matrix and related survey questions then follows. This chapter concludes with a brief review of the site visits and interviews.

\subsection{The Research Questions}

Drawing from the literature review in the previous chapter, there are two main research questions and related hypotheses in this study. As explained in the last chapter, these questions have not yet been dealt with in the existing literature. The first question of the study is: Is accumulated social capital essential for regional economic development cooperation to occur? This question is important to ask since the specifics of how social capital is important for regional cooperation is not yet understood. The hypothesis to be tested for this question is: For regional economic development cooperation to occur, a reserve of social capital among the stakeholders is essential. If social capital matters for regional economic development, the specifics of how social capital enabled or hindered the regional cooperation need to be identified.

The second question in the study is: Is regional economic development cooperation an endeavor that requires the consent and approval of local public officials and civic leaders? This question deals with the role of local officials in establishing regional agreements. The hypothesis is that regional economic development programming is only possible if the local public officials and civic leaders reach an agreement to cooperate.

I examine the two questions in the context of three metropolitan areas that are similar in terms of population size and other economic characteristics, but are different in terms of achieving regional cooperation for economic development. The selected 
Metropolitan Statistical Areas (MSAs) are: Houston-Sugar Land-Baytown, Texas; Atlanta-Sandy Springs-Marietta, Georgia; and Miami-Fort Lauderdale-Pompano Beach, Florida. These MSAs are similar in their population sizes and their economic characteristics. However, the extent of regional cooperation in economic development varies among the metropolitan areas. Whereas Houston has achieved a great degree of regional cooperation, Miami has not; Atlanta is in the mid-range, having some aspects of regional cooperation. My dissertation uses the lens of social capital to examine why these differences emerged over time.

\subsection{The Empirical Case Study Regions}

This section explains the dissertation's empirical focus on the three MSAs of Houston, Atlanta, and Miami. In light of the view that the competitive advantages of a region are maximized through cooperative efforts, and that the prevailing federal economic development policy encourages cooperation to increase the productivity of the regional economies, this dissertation examines regional cooperation from a national perspective. Towards this end, I first considered all of the most populated MSAs in the United States. There are sixteen large MSAs in the country with a population of over 3 million. I chose three regions from these MSAs that are similar in population size and other economic characteristics (i.e., similar in independent variables), but are remarkably different in terms of their achievement of regional cooperation (i.e., dissimilar dependent variables). Two other criteria for selecting the MSAs were that they should not straddle state boundaries, and should not be located in the same state. 
I decided to eliminate those MSAs that straddle state boundaries from

consideration in order to maintain the same broader economic policy context within each region. Variations in economic development policies set by different state legislatures present a formidable challenge to regional cooperation efforts in metropolitan areas that straddle state boundaries. The reconciliation of differing state economic development policies across an MSA is an added impediment to cooperation that would strain direct comparisons to other MSAs that are wholly contained within the boundaries of a single state.

It was important for this study to select MSAs from different states in order to avoid compounding the effects of a particular state's economic development policies. If two of the three MSAs were in the same state, and both were beneficiaries of state policies that improved the likelihood of regional cooperation, the findings would be skewed. If a particular state chose to offer inducements or incentives for its regions to cooperate, they may distort the study results. For this reason, only MSAs from different states were selected for this comparative study.

Following the procedures outlined in Chapter 1 (Section 2), I chose three metropolitan areas of Atlanta, Houston, and Miami. The population sizes of the MSAs are comparable, each MSA is wholly within the boundaries of a single state, and they are each located in different states (Georgia, Texas, and Florida respectively).

\begin{tabular}{|c|r|}
\hline MSA & Population \\
\hline Houston-Sugarland-Baytown, TX & $5,867,489$ \\
\hline Miami-Fort Lauderdale-Pompano Beach, FL & $5,547,051$ \\
\hline Atlanta-Sandy Springs-Marietta, GA & $5,475,213$ \\
\hline
\end{tabular}

Table 2. The Selected MSAs 


\subsection{The Dependent Variable}

Among the three MSA regions, Houston has clearly attained the greatest level of regional economic development cooperation. Atlanta has regional entities and resources that show evidence of regional economic development cooperation. In Miami, regional economic development cooperation remains an elusive prospect. In the Miami MSA there are some instances of regional economic development cooperation that occurred several years ago, and there is occasionally an industry specific pronouncement, but there is no sustained effort to note.

The ranking the degree of regional cooperation for economic development purposes within the three MSAs is based upon the observations noted during site visits to each of the jurisdictions, published materials from each jurisdiction, and historical data from the three areas. The nature of cooperation among officials from counties and their respective economic development organizations (EDOs) in each MSA could take many forms. Multiple counties within an MSA often engage in collective action to satisfy federal eligibility requirements for economic development grants. In certain instances, two or more counties establish an organizational entity to coordinate economic development activities. In some instances, the entire MSA could be served by public, private, or hybrid partnerships engaged in economic development planning and coordination. An inventory of the EDOs in each MSA was developed and categorically defined.

To establish the inventory, I conducted county-by-county searches for countyaffiliated EDOs. I did searches through internet search engines, which were then supplemented with phone calls to county offices asking for referrals to EDOs serving 
their area. Once the EDOs were identified, I determined their official affiliation with the county for regional cooperation purposes through telephone inquiries or a search of public records. If the EDO for the county participated in regional efforts, I noted the associated multi-county organization. I spoke with representatives of the regional EDOs within each MSA to determine the source of support for the organizations (e.g. public, private, or both resources). For each MSA, I noted the top five industrial employers with the highest location quotients. I used this information to examine the private industries' influence on regional economic development planning and policies.

I did not simply rank the three regions based on the existence of a regional organizational structure for cooperation. A regional entity might exist for the sole purpose of complying with federal or state grant eligibility requirements. Site visits and interviews provided the necessary insight to assess the nature of engagement in regional cooperation by these entities. I arrived at the ranking of the degree of regional economic development cooperation for each MSA based on the cataloging of the full range of efforts of regional cooperation by all the stakeholder organizations in the MSAs.

\subsection{Demographic Context}

It is important to take into account the demographic context of the regions to examine the emergence of regional cooperation in economic development. As already mentioned, the overall population sizes of the three selected regions are comparable. However, the population distribution among the county jurisdictions could differ, affecting the dynamics of how the jurisdictions position themselves for cooperating with others. Hence, I took into account the jurisdictions within each MSA that had larger 
population concentrations than other jurisdictions. Similarly, I took into account the disparities in median household income among the jurisdictions, since this could affect the power dynamics between them for cooperation purposes.

I paid special attention to ethnic diversity within each region, since this is likely to influence the regional cooperation efforts. Feiock, Steinacker, and Park (2009) did not take into account the significance of ethnic diversity in their study of regional cooperation. However, diversity cannot be downplayed for establishing social networks and relationships. I used the Herfindahl Index to measure racial and ethnic diversity (Rhoades, 1993). The Herfindahl Index (HI) is given by the sum of the squares of the racial/ ethnic percentages $(E P)$ in the region:

$$
H I=\sum_{i=1}^{n}\left(E P_{i}\right)^{2}
$$

Low HI values (below 0.50$)$ indicate diverse population and high $\mathrm{HI}$ values $(0.50$ or above) indicate homogenous communities. There are four primary categories of ethnicity reported in the census: White (Non-Hispanic), Black (Non-Hispanic), Asian and Hispanic.

\subsection{Political and Legal Contexts}

The political and legal contexts of the MSAs are important considerations for attaining regional cooperation. With respect to the political contexts, the number of municipalities within each county of a MSA is important for regional cooperation since the tangible or intangible costs of such cooperation could rise with larger number of jurisdictions. Olberding (2002 a) noted that the political fragmentation because of a larger 
number of municipalities is a counter-productive factor in attaining regional cooperation.

To arrive at the measure of political fragmentation, I used a two-tiered approach. The first tier comprised of calculating the per capita political fragmentation, determined by dividing the MSA population by the number of counties. The second tier of per capita fragmentation is comprised of the tier 1 result divided by the total number of municipalities incorporated within the MSA. Though there are more complex methods of computing political fragmentation, I selected these simple measures since they suffice the dissertation's purposes of measuring political fragmentation for comparative ranking purposes (Morgan, 1999). Lower calculated values reflect greater fragmentation.

$$
\text { Political_Fragmentation }=\frac{M S A(\text { population }) / \#(\text { counties })}{\#(\text { cities })}
$$

With respect to the legal context, the importance of the statutory incentives and limitations relative to regional economic development initiatives were recurring themes during the site visits and stakeholder interviews. In order to develop legitimate comparisons of regional cooperation in the three selected MSAs, it is imperative to understand the statutory environment that governs economic development activity within each MSA. State constitutional provisions and statutes not only define the parameters of cooperation, they may also induce or inhibit regional economic development cooperation. I documented the state tax incentives and economic inducements, if they were different from the federal ones. I paid attention to state mandates pertaining to the authority of local governments or EDOs to engage cooperatively, or any incentives to encourage cooperation between municipalities. 
At the federal government level, the Economic Development Administration (EDA), an agency under the Department of Commerce, has repeatedly emphasized the importance of regional councils established by states for the purposes of planning and coordination. The EDA has subsequently designated economic development districts, through which federal funds are allocated. The composition and physical alignment of these federally recognized economic development districts are important since they also encourage regional thinking. Hence, I took into account any overlaps of geographic boundaries between the multi-county economic development organizations and the federal economic development districts in influencing regional cooperation for economic development.

\subsection{The Survey Instrument}

I designed a survey instrument to compare the level of social capital among the regional stakeholders in the three MSAs. The survey was administered online using Survey Monkey. The survey was short, consisting of nine questions, which could have been completed in approximately three minutes. The survey instrument was short in recognition of the time constraints of the officials and civic leaders who were to take the survey.

The survey was designed to measure social capital variables at each of the different stages of transaction model presented by Coase (1988). The survey questions were based on the $3 \times 3$ matrix, reflecting the three phases of a transaction and three elements of social capital. Responses for each question were thus tabulated for the three 
social capital elements (reciprocity, trust, and reputation) at each stage of a collective action transaction (discovery, negotiation and conclusion) (Table 3).

\begin{tabular}{|c|c|c|c|}
\hline \multicolumn{4}{|c|}{ The Social Capital Transaction Matrix } \\
\hline & Reciprocity & Reputation & Trust \\
\hline Discovery & $\begin{array}{l}\text { The expectations } \\
\text { associated with the } \\
\text { exchange of } \\
\text { information }\end{array}$ & $\begin{array}{l}\text { The perceptions of } \\
\text { the process involved } \\
\text { in the exchange of } \\
\text { information }\end{array}$ & $\begin{array}{l}\text { The validity of the } \\
\text { information } \\
\text { exchanged }\end{array}$ \\
\hline Negotiation & $\begin{array}{l}\text { The expectation that } \\
\text { the terms of an } \\
\text { agreement will be } \\
\text { reasonable and fair }\end{array}$ & $\begin{array}{l}\text { The perceptions of } \\
\text { the negotiating } \\
\text { process and } \\
\text { procedures }\end{array}$ & $\begin{array}{l}\text { The integrity of the } \\
\text { negotiators }\end{array}$ \\
\hline Conclusion & $\begin{array}{l}\text { The expectation that } \\
\text { all parties will ratify } \\
\text { an agreement }\end{array}$ & $\begin{array}{l}\text { The perceptions of } \\
\text { the process for } \\
\text { approving } \\
\text { cooperative } \\
\text { agreements }\end{array}$ & $\begin{array}{l}\text { The confidence that } \\
\text { all parties will } \\
\text { adhere to the terms } \\
\text { of an agreement }\end{array}$ \\
\hline
\end{tabular}

Table 3. Social Capital Matrix

The survey questions were on a five-point Likert scale, where stakeholders were asked to indicate whether they strongly disagree, disagree, have no opinion, agree, or strongly agree with a series of statements. The statements were specifically designed to gauge the levels of reciprocity, the strength of reputation, and the degree of trust associated at each stage of a cooperative transaction. My research design allowed for the collection of metrics for the three components of social capital as they are manifested at the discovery, negotiation and conclusion stages of cooperative transaction.

The survey questions were designed such that the responses would provide valuable insights into testing the research hypotheses that social capital is indeed the key ingredient that makes possible regional economic development cooperation. The nine statements for the five-point Likert scale responses correlate to the intersecting boxes found in Table 3 above. Questions 1-3 relate to the Discovery stage; questions 4-6 relate 
to the Negotiation stage; and questions 7-9 relate to the Conclusions stage. The questions are presented below:

1. I have regular communications with my colleagues from other jurisdictions in the region (Discovery, Reciprocity)

2. When it comes to sharing information, my colleagues in the region have been very cooperative to (Discovery, Reputation)

3. Information I receive from my colleagues in the region is reliable and dependable (Discovery, Trust)

4. Working across jurisdictional boundaries, regional problems get resolved in a fair and reasonable way (Negotiation, Reciprocity)

5. I am confident in the way our local jurisdictions come together to handle regional issues (Negotiation, Reputation)

6. In discussions about regional issues, my colleagues from other jurisdictions do their best to truly represent the views of their communities (Negotiation, Trust)

7. If a regional approach is necessary to address a particular situation, our local jurisdictions will participate (Conclusion, Reciprocity)

8. Once a regional plan of action is negotiated, getting the local jurisdictions to ratify a plan is relatively easy (Conclusion, Reputation)

9. The local jurisdictions of our region can be trusted to honor any commitments they make (Conclusion, Trust)

I distributed the surveys to stakeholders in each MSA region. I sent the survey directly to the elected officials through their offices of published email accounts, and to 
the professionals and board members of the EDOs of each county, either directly or through the primary contacts of each organization. The response levels varied among the three regions. Although the differences in response levels limited the use of the data, it was still useful in giving comparative data and in providing a focus for subsequent stakeholder interviews.

\subsection{Site Visits, Interviews and Personal Conversations}

The other components of this research project involved site visits, interviews and personal conversations with the executives, elected leaders, and professional staff directly engaged in the economic development activity of each region. Site visits involved several days of interviews, meetings, and related events in each of the MSAs. The direct contact with influential leaders within each MSA afforded a depth of understanding of the regional aspirations and challenges of the region. 


\section{CHAPTER 4. \\ ECONOMIC DEVELOPMENT COOPERATION IN THE ATLANTA REGION}

\subsection{Overview of the Atlanta MSA}

The Atlanta MSA has achieved moderate success in regional economic development cooperation, despite being a complex mosaic of regional, county and municipal jurisdictions served by numerous municipal, county and multi-county economic development organizations. Regional cooperation is not an aspirational goal in the Atlanta MSA. There is substantial evidence of collaborative, organized efforts to advance and coordinate economic development initiatives throughout the region.

There are 28 counties that comprise the Atlanta MSA, covering an area of $8,393.7$ square miles (American fact finder, 2010). The Atlanta MSA is the ninth largest population center in the nation with an estimated annual Gross Domestic Product of $\$ 270$ billion (Metro Atlanta chamber of commerce, 2012). The Atlanta MSA is a major logistics hub served by three interstate highways, the primary rail hub of the American South, the world's busiest passenger airport, and is only 250 miles away from a critical eastern seaboard, the Port of Savannah. The Atlanta region is also a preferred location for corporate headquarters, ranking third in the nation for hosting Fortune 500 and Global 500 companies, including Coca-Cola, Delta Airlines, Home Depot and UPS (Metro Atlanta chamber of commerce, 2012).

Industry clusters for the Atlanta MSA showing positive location quotient indicators for the number of establishments, employment opportunity and wages span a variety of sectors. Based on the relative economic performance of these sectors, as

depicted in the Table 4, the Metro Atlanta Chamber of Commerce (MACOC) chose to 
concentrate its targeted efforts on developing the following sectors: Supply Chain \& Advanced Manufacturing (transportation \& logistics); Technology (information technology); Bioscience \& Health IT (biomedical / biotechnical); and Corporate Operations and Business Services (business services) (Metro Atlanta chamber of commerce.2012).

\begin{tabular}{|l|c|}
\multicolumn{1}{|c|}{ Description } & Employment LQ \\
\hline Information Technology \& Telecommunications & 1.27 \\
\hline Business \& Financial Services & 1.23 \\
\hline Transportation \& Logistics & 1.22 \\
\hline Biomedical/Biotechnical (Life Sciences) & 1.17 \\
\hline Chemicals \& Chemical Based Products & 0.89 \\
\hline
\end{tabular}

Table 4. The Industry Clusters of the Atlanta MSA

Source: StatsAmerica, 2012

A number of organizations facilitate economic development cooperation in the Atlanta MSA. There are five Regional Commissions and fourteen Joint Development Authorities that strive to coordinate community and economic development programming within the Atlanta MSA (Georgia department of community affairs, 2012a). The Georgia Resource Center, a collaboration of utilities and the Georgia Department of Economic Development, coordinates economic development site selection services throughout the MSA and the State of Georgia (Staples, 2012). The economic development professionals of the region collaborate through their participation in the Georgia Economic Development Association. There is even one entity that expressly defines its coverage area for economic development initiatives as the 28-county Atlanta MSA: the Metro Atlanta Chamber of Commerce (Metro Atlanta chamber of commerce.2012; Sydney, 2012). 
Though the parameters of this research initially excluded chambers of commerce as subject entities in the investigation of regional economic development cooperation, an exception has been made for the MACOC. More than one official acknowledged the role of the MACOC as a major contributor to regional economic development initiatives (Kendrick, 2012; Martin, 2012; Staples, 2012). A subsequent interview with one of the principles of the MACOC confirmed a robust regional engagement in economic development activity in the Atlanta MSA (Sydney, 2012).

The U.S. Census Bureau includes 28 Georgia counties within the Atlanta region, pursuant to MSA criteria developed by the Office of Management and Budget (OMB). The OMB defines an MSA as an area that contains an urban core of 50,000 or more population, plus "any adjacent counties that have a high degree of social and economic integration with the central county or counties as measured through commuting" (United States Census Bureau, 2012). Even though an MSA designation delineates a region with a high degree of economic integration, it does not necessarily translate into collaborative economic development programming for the public officials and EDO leaders of the counties within the region.

In fact, the OMB cautions that MSAs "are not designed to serve as a generalpurpose geographic framework applicable for non-statistical activities or for use in program funding formulas." The purpose for the MSA designation is "to provide nationally consistent delineations for collecting, tabulating and publishing Federal statistics for a set of geographic areas" (Federal register, vol. 752010).

Though the MSA designation is not derived from operational collaboration among the subject counties, there are organizations that define their operational jurisdiction 
according to the MSA boundaries. As noted earlier, in the Atlanta MSA, the MACOC defines its jurisdiction according to the MSA designation. In order to facilitate the research and programmatic mission of the MACOC, the boundaries are adjusted decennially according to the census MSA designation (Sydney, 2012).

\subsection{Demographics of the Atlanta MSA}

The Atlanta MSA includes 28 counties with a combined population of 5,238,964 residents covering an area of 8,394 square miles resulting in a regional density of 624 residents per square mile. The City of Atlanta, the State Capitol of Georgia, lies mostly in Fulton County, with a portion of the Atlanta municipal boundaries extending into DeKalb County. Fulton County is the most heavily populated county in the MSA with a population of 987,148 (American fact finder.2010).

In the Atlanta MSA, four (4) counties have populations greater than 500,000 (Cobb, DeKalb, Fulton and Gwinnett). At the other extreme, there are seven counties with less than 25,000 residents (Butts, Dawson, Heard, Jasper, Lamar, Meriwether, and Pike). The population densities across the MSA range from only 37 residents per square mile in Jasper County to a density of 2733 residents per square mile in DeKalb County. Though this mix of sparsely and densely populated counties may seem incongruous with the metropolitan designation, the OMB makes no distinction between urban and rural counties when delineating the boundaries for an MSA (American fact finder.2010) .

The Atlanta MSA, though comparable in population to the Houston MSA and Miami MSA, has the greatest number of member counties. The table below provides an overview of the counties within the Atlanta MSA, in rank order by population (American 
fact finder.2010). Though there are many counties in this MSA, it is clear that there is a population concentration within the core urban counties of the MSA. The table also provides the square-mile coverage area and population densities; a sense of the political fragmentation within the MSA relative to municipal incorporations; a diversity index to depict ethnic concentrations in each county; and the different forms of government: Council-Manager [CM]; County Executive [CE]; or Commission [C].

Recall that Feiock (2009) found that the likelihood of cooperation is enhanced when the government structure among the jurisdictions takes the Council-Manager form. In the Atlanta MSA, only 16 of the 28 counties (57\%) are structured as Council-Manager governments, with the remaining 12 counties evenly split as either County Executive or Commission forms of government (Georgia department of community affairs.2012a).

The political fragmentation of the Atlanta MSA presents another serious challenge to the likelihood of regional cooperation. The most obvious distinction of the Atlanta MSA relative to the MSAs of Houston and Miami is the higher number of county governments. The relative compactness of the Georgia counties, compared to the physical dimensions of the typical counties in Texas and Florida, is the attribute that explains the high number of counties in the Atlanta MSA. "According to anecdotal history, Georgia established enough counties so that a farmer traveling by mule-drawn buggy could go to the county seat, take care of business, and return to his farm in the same day" (Georgia Humanities Council, 2012). Extending this same logic forward to the modern day, the Census Bureau has utilized daily commuting patterns in the metropolitan Atlanta region to designate the Metropolitan Statistical Area. 


\begin{tabular}{|l|c|c|c|c|c|c|}
\hline \multicolumn{7}{|c|}{ Atlanta MSA Summary Table } \\
\hline \multicolumn{1}{|c}{ County } & \multicolumn{1}{c}{ Pop. } & Sq. Miles & Density & Cities & Diversity & Gov. \\
\hline Fulton & 987,148 & 528.7 & 1867 & 14 & 0.38 & CM \\
\hline Gwinnett & 766,912 & 437.0 & 1755 & 15 & 0.35 & CM \\
\hline DeKalb & 733,060 & 268.2 & 2733 & 8 & 0.39 & CE \\
\hline Cobb & 690,430 & 340.2 & 2029 & 6 & 0.42 & CM \\
\hline Clayton & 271,652 & 142.6 & 1905 & 6 & 0.42 & CE \\
\hline Cherokee & 201,233 & 423.7 & 475 & 7 & 0.69 & CM \\
\hline Henry & 182,952 & 322.7 & 567 & 4 & 0.49 & CM \\
\hline Forsyth & 157,514 & 225.8 & 698 & 1 & 0.70 & CE \\
\hline Paulding & 125,780 & 313.6 & 401 & 3 & 0.69 & CE \\
\hline Douglas & 122,657 & 199.3 & 615 & 1 & 0.44 & CM \\
\hline Coweta & 118,531 & 443.1 & 268 & 7 & 0.59 & CM \\
\hline Carroll & 110,641 & 498.93 & 222 & 7 & 0.61 & CE \\
\hline Fayette & 105,303 & 197.4 & 533 & 5 & 0.55 & CM \\
\hline Newton & 94,076 & 276.4 & 340 & 5 & 0.49 & CM \\
\hline Bartow & 92,490 & 470.1 & 197 & 8 & 0.69 & C \\
\hline Walton & 82,243 & 329.3 & 250 & 7 & 0.68 & C \\
\hline Rockdale & 81,444 & 130.7 & 623 & 1 & 0.44 & CE \\
\hline Barrow & 66,458 & 162.8 & 408 & 6 & 0.62 & CM \\
\hline Spalding & 63,073 & 198.0 & 318 & 3 & 0.52 & CM \\
\hline Pickens & 30,021 & 232.1 & 129 & 3 & 0.90 & C \\
\hline Haralson & 28,559 & 282.2 & 101 & 4 & 0.83 & C \\
\hline Butts & 23,596 & 186.6 & 126 & 3 & 0.56 & CM \\
\hline Meriwether & 22,858 & 503.4 & 45 & 7 & 0.50 & CM \\
\hline Dawson & 21,300 & 211.0 & 101 & 1 & 0.88 & CM \\
\hline Pike & 17,012 & 218.4 & 78 & 5 & 0.73 & CM \\
\hline Lamar & 17,010 & 184.8 & 92 & 3 & 0.56 & CM \\
\hline Jasper & 13,588 & 370.5 & 37 & 2 & 0.61 & C \\
\hline Heard & 11,423 & 296.1 & 39 & 3 & 0.76 & C \\
\hline TOTAL & $\mathbf{5 , 2 3 8 , 9 6 4}$ & $\mathbf{8 3 9 3 . 7}$ & $\mathbf{6 2 4}$ & $\mathbf{1 4 5}$ & $\mathbf{0 . 4 0}$ & \\
\hline
\end{tabular}

Table 5. Atlanta MSA Profile Summary

Further devolving the political unity of the MSA, there are 145 incorporated municipalities within the 28-county MSA. The trend to create additional, smaller governments has not subsided. In the northern reaches of Fulton County, there has been a burst of incorporation activity in recent years. "Balkanization" is the descriptive term 
used by an Emory University law professor in reference to the creation of the new cities of Sandy Springs, Johns Creek, Milton, Dunwoody, Brook Haven, and Chattahoochee Hills (Ross, 2012).

According to Ross (2012), politics, race and issues of local control have motivated the current incorporation movement in northern Fulton County. Ross also expects the new city leaders from this area, predominantly white and Republican, will be successful in lobbying the Georgia Legislature for authorization to separate from Fulton County and become their own county. By all measures, it would appear that political fragmentation is a growing challenge in the Atlanta MSA that dims the prospects for achieving regional economic development cooperation. For MSA comparisons in this case study, the fragmentation value for the MSA is derived by dividing the population by the number of counties and the number of cities. The resulting ratio of residents / local government entities for the Atlanta MSA is:

$$
\frac{5,238,964 \text { (population) } / 28(\text { counties })}{145(\text { cities })}=1,290
$$

Though Feiock (2009) did not find ethnic heterogeneity to be a factor influencing the likelihood of regional cooperation in the large-N study he conducted, the racial and ethnic composition of the 28 counties of Atlanta certainly must be noted. The "marketshare" dominance by a particular ethnic group in all but three (3) counties exceeds, greatly in some cases, the Herfindahl Index (HI) findings of .40 for the aggregate MSA. As race is noted to be a factor that energizes the civic pursuit of creating new cities (Ross, 2012), in the course of my research the topic was not avoided. 
The state of race relations in the Atlanta MSA has always been a factor influencing economic development. Race relations energize a social current that can influence regional economic development initiatives both positively and negatively. According to one prominent local legal scholar (Ross, 2012), the relative tranquility of Atlanta during the Civil Rights Movement of the 1950s and 1960s may have contributed to the rise of Metro Atlanta as the business capital of the South. Ross further noted that the lack of sensational civil rights confrontations in Atlanta might have been by design of the movement leaders, who were concerned for the safety and welfare of their families.

As evidence of the positive impact of the relatively peaceful race relations in Atlanta during the Civil Rights Movement, Ross compares the growth and development of Birmingham, Alabama. He contends that the two cities emerged from this period on different economic trajectories because Atlanta was largely spared the racial strife and conflict that became synonymous with places like Birmingham (Ross, 2012).

Ross points out that Birmingham, AL and Atlanta, GA were cities of nearly equal population before the Civil Rights Movement. Indeed, the U.S. Census data for 1950 indicates Atlanta had a population of 331,314 and Birmingham had a population of 326,057 (1960 census. 1960). At the time, the two cities were ranked $33^{\text {rd }}$ and $34^{\text {th }}$ in the nation, respectively. Today, Birmingham has only 211,458 residents and the City of Atlanta has 432,425 residents (American community survey 2009.).

The counterfactual of this theory cannot be known, but the stories of the freedom riders being severely beaten at the bus station in Birmingham are ingrained in the American psyche (J. O. Horton \& Horton, 2001). It is entirely plausible that those incidents in Birmingham chilled the interests of site selection consultants during the 
ensuing decades of smokestack chasing, when so many northern firms moved south. In a similar vein, it is reasonable to speculate that had the freedom riders been severely beaten in Atlanta, the street address and zip code for a host of Fortune 500 company headquarters might be different today.

In deference to the complexity, subtleness and persistence of the issue of race relations, this case study explores the diversity scores of the subject jurisdictions and searches for patterns of cooperation. To illustrate the diversity, and lack of diversity, for the member counties of the Atlanta MSA, the counties are grouped by increments of 10point ranges in the reported $\mathrm{HI}$ scores.

As the series of tables below depict, the HI diversity score groupings for the member counties illustrate, in some cases, nearly monolithic, homogenous White counties within the Atlanta MSA. Haralson, Dawson and Pickens Counties are at the outer edges of the MSA and have populations that are over $90 \%$ White. At the other end of the spectrum, Gwinnett, Fulton and DeKalb Counties, the core urban counties of the MSA, report the lowest HI scores and reflect the greatest diversity. Reference to these diversity groupings will facilitate the discussion about the composition of the Regional Commissions established by the State of Georgia Department of Community Affairs and the composition of the Joint Development Authorities that are voluntarily established by county EDOs.

\begin{tabular}{|l|c|r|r|c|c|c|}
\hline \multicolumn{7}{|c|}{ Diverse Communities } \\
\hline County & $\begin{array}{l}\text { HI } \\
\text { Score }\end{array}$ & Population & $\begin{array}{l}\text { \% } \\
\text { White }\end{array}$ & $\begin{array}{l}\text { \% } \\
\text { Black }\end{array}$ & $\begin{array}{l}\text { \% } \\
\text { Hispanic }\end{array}$ & $\begin{array}{l}\text { \% } \\
\text { Asian }\end{array}$ \\
\hline Gwinnett & 0.35 & 766,912 & 51.9 & 19.8 & 16.8 & 9.4 \\
\hline Fulton & 0.38 & 987,148 & 43.7 & 42.5 & 8.1 & 4.1 \\
\hline DeKalb & 0.39 & 733,060 & 30.7 & 53.6 & 10.1 & 4.1 \\
\hline
\end{tabular}

Table 6. Atlanta MSA Diverse Communities 


\begin{tabular}{|l|c|r|r|r|r|c|}
\hline \multicolumn{7}{|c|}{ Somewhat Diverse Communities } \\
\hline County & $\begin{array}{l}\text { HI } \\
\text { Score }\end{array}$ & Population & $\begin{array}{l}\text { \% } \\
\text { White }\end{array}$ & $\begin{array}{l}\text { \% } \\
\text { Black }\end{array}$ & $\begin{array}{l}\text { \% } \\
\text { Hispanic }\end{array}$ & $\begin{array}{l}\text { \% } \\
\text { Asian }\end{array}$ \\
\hline Clayton & 0.42 & 271,652 & 21.6 & 59.8 & 11.4 & 5.1 \\
\hline Cobb & 0.42 & 690,430 & 60.0 & 22.3 & 11.3 & 4.1 \\
\hline Douglas & 0.44 & 122,657 & 57.6 & 33.1 & 5.8 & 1.6 \\
\hline Rockdale & 0.44 & 81,444 & 54.6 & 37.0 & 9.4 & 2.8 \\
\hline Henry & 0.49 & 182,952 & 62.7 & 30.5 & 4.7 & 2.7 \\
\hline Newton & 0.49 & 94,076 & 61.5 & 33.9 & 3.6 & 1.1 \\
\hline
\end{tabular}

Table 7. Atlanta MSA Somewhat Diverse Counties

\begin{tabular}{|l|c|r|r|c|c|c|}
\hline \multicolumn{7}{|c|}{ Somewhat Homogenous Communities } \\
\hline County & $\begin{array}{l}\text { HI } \\
\text { Score }\end{array}$ & Population & $\begin{array}{l}\text { \% } \\
\text { White }\end{array}$ & $\begin{array}{l}\text { \% } \\
\text { Black }\end{array}$ & $\begin{array}{l}\text { \% } \\
\text { Hispanic }\end{array}$ & $\begin{array}{l}\text { \% } \\
\text { Asian }\end{array}$ \\
\hline Meriwether & 0.50 & 22,858 & 58.3 & 40.5 & 1.3 & 0.0 \\
\hline Spalding & 0.52 & 63,073 & 64.3 & 32.0 & 2.6 & 0.8 \\
\hline Fayette & 0.55 & 105,303 & 71.9 & 18.3 & 4.2 & 3.8 \\
\hline Butts & 0.56 & 23,596 & 69.7 & 27.1 & 2.2 & 0.4 \\
\hline Lamar & 0.56 & 17,010 & 69.0 & 29.4 & 1.6 & 0.0 \\
\hline Coweta & 0.59 & 118,531 & 74.7 & 17.2 & 5.6 & 1.0 \\
\hline
\end{tabular}

Table 8. Atlanta MSA Somewhat Homogenous Counties

\begin{tabular}{|l|c|r|r|r|c|c|}
\hline \multicolumn{7}{|c|}{ Homogenous Communities } \\
\hline County & $\begin{array}{l}\text { HI } \\
\text { Score }\end{array}$ & Population & $\begin{array}{l}\text { \% } \\
\text { White }\end{array}$ & $\begin{array}{l}\text { \% } \\
\text { Black }\end{array}$ & $\begin{array}{l}\text { \% } \\
\text { Hispanic }\end{array}$ & $\begin{array}{l}\text { \% } \\
\text { Asian }\end{array}$ \\
\hline Carroll & 0.61 & 110,641 & 75.8 & 17.1 & 4.8 & 0.8 \\
\hline Jasper & 0.61 & 13,588 & 74.6 & 22.6 & 3.4 & 0.0 \\
\hline Barrow & 0.62 & 66,458 & 77.3 & 11.2 & 7.2 & 3.1 \\
\hline Walton & 0.68 & 82,243 & 81.0 & 15.5 & 3.0 & 0.1 \\
\hline Bartow & 0.69 & 92,490 & 82.1 & 9.6 & 5.9 & 0.8 \\
\hline Cherokee & 0.69 & 201,233 & 82.3 & 5.4 & 8.8 & 1.7 \\
\hline Paulding & 0.69 & 125,780 & 81.5 & 14.4 & 4.3 & 1.0 \\
\hline
\end{tabular}

Table 9. Atlanta MSA Homogenous Counties 


\begin{tabular}{|l|c|r|r|r|c|c|}
\hline \multicolumn{7}{|c|}{ Very Homogenous Communities } \\
\hline County & $\begin{array}{l}\text { HI } \\
\text { Score }\end{array}$ & Population & $\begin{array}{l}\text { \% } \\
\text { White }\end{array}$ & $\begin{array}{l}\text { \% } \\
\text { Black }\end{array}$ & $\begin{array}{l}\text { \% } \\
\text { Hispanic }\end{array}$ & $\begin{array}{l}\text { \% } \\
\text { Asian }\end{array}$ \\
\hline Forsyth & 0.70 & 157,514 & 83.3 & 2.9 & 8.2 & 4.1 \\
\hline Pike & 0.73 & 17,012 & 84.8 & 12.5 & 1.6 & 0.2 \\
\hline Heard & 0.76 & 11,423 & 86.6 & 10.1 & 1.0 & 0.8 \\
\hline
\end{tabular}

Table 10. Atlanta MSA Very Homogenous Counties

\begin{tabular}{|l|c|r|c|c|c|c|}
\hline \multicolumn{7}{|c|}{ Extremely Homogenous Communities } \\
\hline County & $\begin{array}{l}\text { HI } \\
\text { Score }\end{array}$ & Population & $\begin{array}{l}\text { \% } \\
\text { White }\end{array}$ & $\begin{array}{l}\text { \% } \\
\text { Black }\end{array}$ & $\begin{array}{l}\text { \% } \\
\text { Hispanic }\end{array}$ & $\begin{array}{l}\text { \% } \\
\text { Asian }\end{array}$ \\
\hline Haralson & 0.83 & 28,559 & 90.9 & 5.2 & 1.2 & 0.2 \\
\hline Dawson & 0.88 & 21,300 & 93.6 & 0.5 & 2.9 & 0.4 \\
\hline Pickens & 0.90 & 30,021 & 94.8 & 2.3 & 2.5 & 0.3 \\
\hline
\end{tabular}

Table 11. Atlanta MSA Extremely Homogenous Counties

Another demographic factor that Feiock (2009) found to be detrimental to collective action agreements across jurisdictions is the issue of economic heterogeneity. A broad disparity of median household incomes among the counties of the MSA might suggest a greater degree of difficulty in achieving a cooperative agreement for the purposes of economic development. In the Atlanta MSA, the average median household income is $\$ 53,997$ (American community survey 2009.2009). The lack of homogeneity in median household incomes is reflected in the findings for Forsyth County $(\$ 88,040)$ and Lamar County $(\$ 35,835)$. This is a percentage differential of $153 \%$ in median household incomes among the jurisdictions.

\subsection{Economic Development Authorities}

Every county in the Atlanta MSA has an Economic Development Organization (EDO) established to facilitate growth within their jurisdiction. The EDO is known invariably as the (Name of County) Development Authority, the (Name of County) 
Industrial Development Authority, or the Development Authority of (Name of County). As a general rule, if the name of the county appears first, the authority is derived directly from the Georgia Constitution as a local constitutional amendment; if the name of the county appears in a following clause, the authority is derived from a General Statute.

Ten (10) of the counties in the Atlanta MSA have Development Authorities established through the local Constitutional Amendment process: Barrow, Butts, Cherokee, Coweta, Heard, Henry, Meriwether, Newton, Paulding, and Spalding Counties (Georgia department of community affairs.2012b). Of these ten (10) counties, five (5) also have Development Authorities that derive their authority from the General Statutes of the Georgia Code. All of the remaining 18 counties have a statutorily authorized Development Authority (Georgia department of community affairs.2012b).

The operational distinction between a Constitutional and Statutory Development Authority is limited in most instances. Both forms of Development Authority have the ability to exercise broad corporate powers to accomplish the economic development purposes of a development authority (Official code of georgia.2012). The significant difference between the two types of entities lies in the ability to update, revise and amend the board composition and purpose. The provisional language of a local Constitutional Development Authority is fixed, and not subject to any future referendum amendments short of full repeal. A Statutory Development Authority may amend its board composition or reconstitute itself with relative ease, without any need of a referendum (Official code of georgia.2012). This greater flexibility for the Statutory Development Authority allows for adaptation when new municipal corporations or chambers of commerce are formed. 
The justification for retaining a local Constitutional Development Authority lies in special provisions adopted at the time of inception. Some Constitutional Development Authorities include language authorizing the levy of additional property taxes. For development authorities created pursuant to the Georgia Code, there is no such express provision for levying additional millage (Official code of georgia.2012) .

A quick look at the governing language for the Heard County Development Authority confirms one such exceptional taxing power: "Heard County is authorized to levy an annual tax as may be determined by the governing authority, but not to exceed two mills, on all taxable property within the County for the support of the Authority and for its use and purposes..." (Municode, 2012) . This taxing power is vested in Heard County, whether it chooses to exercise it or not. In fact, the most recent audit of the finances for Heard County reveals there is no special millage levied for the Heard County Development Authority (Kimmel, 2012). But the possibility of imposing the tax remains. Without exception, every county in the Atlanta MSA has formed a development authority that is organized according to the Georgia Code or the Constitution of the State of Georgia. Many counties have established both forms of development authority. The county governments are directly involved in the formation, operation and support of these entities. The development authorities act on behalf of the county governing bodies they represent. For the purpose of attracting, recruiting and retaining employers, every county of the Atlanta MSA has organized a development authority to solidly engage in economic development competition. As the next section illustrates, the development authorities also serve as building blocks for regional economic development cooperation. 


\subsection{Joint Development Authorities}

The Georgia Business Expansion and Support Act grants county officials the authority to offer job tax credits to enterprises creating new jobs. Each jurisdiction is designated as a Tier 1, 2, 3, or 4 county based upon a formula of equally weighted factors: “(A) highest unemployment rate for the most recent 36 month period; (B) lowest per capita income for the most recent 36 moth period; and $(C)$ highest percentage of residents whose incomes are below the poverty level according to the most recent data available" (Revenue and Taxation, 2012).

Tier 1 counties are authorized to grant job tax credits "equal to $\$ 3,500.00$ annually per eligible new full-time employee job for five years beginning with the first taxable year in which the new full-time employee job is created and for the four immediately succeeding taxable years" (Revenue and Taxation, 2012). In descending order, the Georgia Code grants Tier 2 counties a $\$ 2,500.00$ job tax credit; Tier 3 counties a $\$ 1,250.00$ job tax credit; and the Tier 4 counties a $\$ 750.00$ job tax credit. For every county, regardless of the particular job tax credit tier assigned, the Georgia Legislature allows another mechanism to increase the job tax credit amount offered by an additional $\$ 500$.

The Georgia Code provides that an enterprise "located within the jurisdiction of a joint authority established by two or more contiguous counties shall qualify for an additional \$500.00 tax credit for each new full-time employee position created” (Joint Development Authorities, 2012). For those counties that wish to offer this additional job tax credit, they must enter into a Joint Development Agreement with contiguous counties. 
There are specific provisions that must be met in order to become a Joint Development Authority: “A joint authority created by two or more contiguous counties pursuant to this Code section must be an active, bona fide joint authority; must have a board of directors; must meet at least quarterly; and must develop an operational business plan. A county may belong to more than one such joint authority" (Joint Development Authorities, 2012).

The requirements that the authority must have an operational business plan, and the board must meet at least quarterly, are conditions that must be met in order to qualify for the additional $\$ 500.00$ job tax credit. As the list below reveals, every county within the Atlanta MSA belongs to at least one joint development authority, and several belong to more than one. There are ten (14) multi-county joint development authorities active in the Atlanta MSA (Georgia department of community affairs.2012b). Included in the list are the diversity ratings for individual counties (HI Score) and the range of scores reported across each JDA.

1. Butts (.56), Henry (.49), Lamar (.56) and Spalding County (.52) Joint Development Authority (JDA). [.7 HI Score Range]

2. Coweta (.59), Fayette (.55), and Meriwether (.50) JDA. [.9 HI Score Range]

3. Georgia Bioscience JDA - Gwinnett (.35), Barrow (.62), Clarke (.41) and Oconee (.74) Counties. [.39 HI Score Range]

4. JDA of Bartow County (.69) and Pickens County (.90). [.21 HI Score Range]

5. JDA of Carroll (.61), Douglas, Paulding, Haralson (.83), Polk (.56), Heard (.76) and Troup (.36) Counties. [.47 HI Score Range]

6. JDA of Metropolitan Atlanta - Clayton (.42), DeKalb (.39), Fulton (.38), Henry (.49) and Rockdale (.44) Counties. [.11 HI Score Range] 
7. Lanier JDA - Cherokee (.69), Forsyth (.70) and Hall (.47) Counties. [.22 HI Score Range]

8. The JDA of Cherokee County (.69) and Cobb (.42) County. [.27 HI Score Range]

9. West Central Georgia JDA - Lamar (.56), Pike (.73) and Upson (.54) Counties. [.19 HI Score Range]

10. West Point Lake Development Authority-Heard (.76) and Troup (.36) Counties [.40 HI Score Range]

11. JDA of Dawson (.88), Lumpkin and White Counties. [NA]

12. JDA of DeKalb (.39), Newton (.49) and Gwinnett (.35) Counties. [.14 HI Score Range]

13. West Georgia JDA of Douglas (.44) and Paulding (.69) Counties. [.25 HI Score Range]

14. JDA of Jasper (.61), Morgan, Newton (.49), and Walton (.68) Counties. [.19 HI Score Range]

Each JDA listed above is an example of a public multi-county EDO. It is important to note that these are 'voluntary' associations. There is no mandate to participate in a Joint Development Authority. There is an incentive to participate, but it is a free association to be entered into with any contiguous county. While contiguous counties are likely to share rural or urban characteristics, and population attributes in some instances, the HI Scores of the JDA member counties within the Atlanta MSA reveal a mixed composition of diversity scores.

Only six (6) of the 14 JDAs show a pattern of proximate, compact (separation $<$ .20) HI Scores: the JDA of Butts, Henry, Lamar and Spalding; the JDA of Coweta, Fayette and Meriwether; the JDA of Metropolitan Atlanta; the JDA of West Central Georgia; the JDA of DeKalb, Newton and Gwinnett; and the JDA of Jasper, Morgan, 
Newton and Walton. The majority of the JDAs are composed of counties that reflect a wider range of HI Scores. The majority of JDAs in the Atlanta MSA do not appear to be organized according to shared diversity values.

\subsection{Job Tax Credits and the Tier Rating System}

For JDA member counties, the baseline job tax credits within each county is adjusted by $\$ 500$ above the amounts set according to the Tier Rating System in Georgia. The Tier Rating System determines the baseline amount of job tax credits a county may offer to enterprises based upon unemployment, per capita income, and poverty rate data in each county (Georgia department of community affairs.2012b). This baseline job tax credit amount is then supplemented with the additional $\$ 500$ if the county belongs to a multi-county JDA. Every county in the Atlanta MSA is a member of a multi-county JDA.

The state incentive for the counties to join a JDA, the additional $\$ 500$ of job tax credit, has been a very effective tool for encouraging cooperation. In the Atlanta MSA, $100 \%$ of the counties have entered into JDA agreements. There are only three (3) counties out of the 159 counties in the State of Georgia that have not chosen to participate in a JDA (Georgia department of community affairs.2012b) . Table 12 below illustrates the net effect of this JDA incentive adjustment (Georgia USA, 2012). 


\begin{tabular}{|c|c|c|c|}
\hline \multicolumn{2}{|c|}{ Atlanta MSA } & \multirow{2}{*}{$\begin{array}{l}\text { Tier Rating Job } \\
\text { Tax Credit }\end{array}$} & \multirow{2}{*}{$\begin{array}{c}\text { JDA Adjusted } \\
\text { Job Tax Credit }\end{array}$} \\
\hline County & Tier & & \\
\hline DeKalb & 3 & $\$ 1,250$ & $\$ 1,750$ \\
\hline Cobb & 4 & $\$ 750$ & $\$ 1,250$ \\
\hline Clayton & 1 & $\$ 3,500$ & $\$ 4,000$ \\
\hline Fulton & 3 & $\$ 1,250$ & $\$ 1,750$ \\
\hline Gwinnett & 4 & $\$ 750$ & $\$ 1,250$ \\
\hline Forsyth & 4 & $\$ 750$ & $\$ 1,250$ \\
\hline Rockdale & 3 & $\$ 1,250$ & $\$ 1,750$ \\
\hline Douglas & 3 & $\$ 1,250$ & $\$ 1,750$ \\
\hline Henry & 3 & $\$ 1,250$ & $\$ 1,750$ \\
\hline Fayette & 4 & $\$ 750$ & $\$ 1,250$ \\
\hline Cherokee & 4 & $\$ 750$ & $\$ 1,250$ \\
\hline Barrow & 3 & $\$ 1,250$ & $\$ 1,750$ \\
\hline Paulding & 3 & $\$ 1,250$ & $\$ 1,750$ \\
\hline Newton & 2 & $\$ 2,500$ & $\$ 3,000$ \\
\hline Spalding & 1 & $\$ 3,500$ & $\$ 4,000$ \\
\hline Coweta & 4 & $\$ 750$ & $\$ 1,250$ \\
\hline Walton & 3 & $\$ 1,250$ & $\$ 1,750$ \\
\hline Carroll & 2 & $\$ 2,500$ & $\$ 3,000$ \\
\hline Bartow & 2 & $\$ 2,500$ & $\$ 3,000$ \\
\hline Pickens & 3 & $\$ 1,250$ & $\$ 1,750$ \\
\hline Butts & 2 & $\$ 2,500$ & $\$ 3,000$ \\
\hline Dawson & 3 & $\$ 1,250$ & $\$ 1,750$ \\
\hline Haralson & 2 & $\$ 2,500$ & $\$ 3,000$ \\
\hline Lamar & 1 & $\$ 3,500$ & $\$ 4,000$ \\
\hline Pike & 3 & $\$ 1,250$ & $\$ 1,750$ \\
\hline Meriwether & 1 & $\$ 3,500$ & $\$ 4,000$ \\
\hline Heard & 1 & $\$ 3,500$ & $\$ 4,000$ \\
\hline Jasper & 2 & $\$ 2,500$ & $\$ 3,000$ \\
\hline
\end{tabular}

Table 12. Tax Credit Enhancement for JDA Participation

In order to qualify for the additional Job Tax Credit, one of the state requirements is that the JDA must adopt a business plan for the organization. The additional requirement of a business plan ensures that the principles are not simply forming the organization to qualify for the additional economic incentives, but are thoughtfully engaged in a collaborative effort to engage in economic development cooperation. In a 
similar vein, the federal government requires the Regional Commissions, the state jurisdictions that are recognized by the federal government as Economic Development District, to formulate a Comprehensive Economic Development Strategy (CEDS).

\subsection{Comprehensive Economic Development Strategies (CEDS)}

The number one priority of the EDA is Collaborative Regional Innovation (Economic development administration.2012). In the process of awarding grants, the EDA first evaluates whether a grant proposal supports "the development and growth of innovation clusters based on existing regional competitive strengths." It is further clarified that "initiatives must engage stakeholders; facilitate collaboration among urban, suburban, and rural (including tribal) areas; provide stability for economic development through long-term intergovernmental and public/private collaboration; and support he growth of existing and emerging industries" (Economic development administration.2012).

In order for the political subdivisions of a state government to qualify for federal grants administered by the EDA, multiple jurisdictions must collaborate to produce a report outlining the regional Comprehensive Economic Development Strategy (CEDS). The federal code is very specific that any "Planning Investments" administered by the EDA may only be offered to a State or its political subdivisions if a CEDS has been prepared for the Economic Development District (Planning Investments and CEDS, 2012) .

In the most recent announcement of available planning grants, applicants were clearly advised that the EDA provides grants "to the designated Economic Development 
Districts throughout the Nation." Further, it is explained that these "planning organizations are typically recognized by the State in which they reside as multi-

jurisdictional councils of governments, regional commissions, or planning and development centers." In the State of Georgia, the regional commissions carry out this responsibility.

\subsection{Regional Commissions}

The State of Georgia has been subdivided into twelve (12) distinct regions; each numerically designated and nominally identified (Georgia association of regional commissions.2012). The 28 counties of the Atlanta MSA have been sorted and assigned to five (5) different Regional Commissions: the Atlanta Regional Commission; the Three Rivers Regional Commission; the Northwest Georgia Regional Commission; the Georgia Mountains Regional Commission; and the Northeast Georgia Regional Commission.

Pursuant to Georgia law, the definition of a region "means the territorial area within the boundaries of operation for any regional development center, as such boundaries shall be established from time to time by the board of the department" of community affairs (Georgia Planning Act, 1981). The law grants broad discretion to the department to set the boundaries of a region, ostensibly to ensure the efficient administration of programs through its offices. "The number of regional development centers and the region within which each regional development center shall operate and shall be established from time to time by the board of community affairs" (Georgia Planning Act, 1981). The current maps for the regional commissions reflect changes that were put into effect on July 1, 2009 (Georgia Department of Community Affairs, 2010). 
While the Atlanta Regional Commission appears to have counties with positive diversity scores, the other regions do not fare as well in terms of diversity.

The Regional Commissions of Georgia are each managed by an appointed board of directors. "Amended by HB 1216, each Council is now comprised of the chairman of each county commission (or his/her designee), a municipal representative from each county, three appointees named by the governor, and one each by the lt. governor and speaker of the House of Representatives" (Willis, 2009). As Willis points out, the membership may be expanded if necessary to comply with the specific regional membership requirements of the U.S. Economic Development Administration (EDA), the federal agency that provides grant funding for local government public works projects and economic development planning. The Regional Commissions conduct a broad scope of duties to facilitate effective and efficient local government services. According to Section 50-8-30 of the Official Code of Georgia:

The purpose of this article is to provide for regional commissions to develop, promote, and assist in establishing coordinated and comprehensive land use, environmental, transportation, and historic preservation planning in the state, to assist local governments to participate in an orderly process for coordinated and comprehensive planning, to assist local governments to prepare and implement comprehensive plans which will develop and promote the essential public interests of the state and its citizens and advance positive governmental relations among the state, regional, and local levels, and to prepare and implement comprehensive regional plans which will develop and promote the essential public interests of the state and its citizens. 
This article shall be construed liberally to achieve its purpose (Regional Commissions, 2011).

As noted above, one of the duties is to prepare and implement comprehensive regional plans. To assist local governments, and to qualify the member jurisdictions for federal grant opportunities, each Regional Commission accepts the responsibility to produce a Comprehensive Economic Development Strategy (CEDS). The economic development activities and the status of the CEDS process for each of the five (5) regional commissions operational within the Atlanta MSA are presented in the following sections.

\subsubsection{The Atlanta Regional Commission}

The Atlanta Regional Commission (ARC) is also known as Region 3. The ARC includes ten (10) of the 28 counties that constitute the Atlanta MSA. The board of the ARC has a total of 41 members: 23 of the members are elected officials from the counties and cities of the region, 17 are appointed citizens, and there is one (1) representative from the Georgia Department of Community Affairs. An appointed citizen currently chairs the ARC (Atlanta regional commission.2012).

Table 14 below illustrates the HI scores, population and ethnic characteristics for the ARC member counties. The diversity score range for the regional commission is relatively compact with a differential of only $20 \%$. As will be noted later, this relatively compact range in the diversity score for the regional commission does not reflect any bias on the part of the member counties. The grouping of counties within regional commissions is a matter determined by the Georgia Department of Community Affairs. 


\begin{tabular}{|l|c|r|r|c|c|c|}
\hline \multicolumn{7}{|c|}{ Atlanta Regional Commission } \\
\hline County & $\begin{array}{l}\text { HI } \\
\text { Score }\end{array}$ & Population & $\begin{array}{l}\text { \% } \\
\text { White }\end{array}$ & $\begin{array}{l}\text { \% } \\
\text { Black }\end{array}$ & $\begin{array}{l}\text { \% } \\
\text { Hispanic }\end{array}$ & $\begin{array}{l}\text { \% } \\
\text { Asian }\end{array}$ \\
\hline Gwinnett & 0.35 & 766,912 & 51.9 & 19.8 & 16.8 & 9.4 \\
\hline Fulton & 0.38 & 987,148 & 43.7 & 42.5 & 8.1 & 4.1 \\
\hline DeKalb & 0.39 & 733,060 & 30.7 & 53.6 & 10.1 & 4.1 \\
\hline Clayton & 0.42 & 271,652 & 21.6 & 59.8 & 11.4 & 5.1 \\
\hline Cobb & 0.42 & 690,430 & 60.0 & 22.3 & 11.3 & 4.1 \\
\hline Douglas & 0.44 & 122,657 & 57.6 & 33.1 & 5.8 & 1.6 \\
\hline Rockdale & 0.44 & 81,444 & 54.6 & 37.0 & 9.4 & 2.8 \\
\hline Henry & 0.49 & 182,952 & 62.7 & 30.5 & 4.7 & 2.7 \\
\hline Fayette & 0.55 & 105,303 & 71.9 & 18.3 & 4.2 & 3.8 \\
\hline
\end{tabular}

Table 13. County Profiles in the Atlanta Regional Commission

The National Association of Regional Councils has recognized the leadership of the ARC for its efforts to encourage regional cooperation. Its past chairman, Commissioner Sam Olens, received a 2008 national leadership award for being a consensus builder in metro Atlanta, working for the adoption of a $\$ 51$ billion transportation plan and creating a Transit Planning Board (Miles, 2009) .

The ARC is the core of the Atlanta MSA, consisting entirely of counties from within the MSA. As already mentioned, the counties of the ARC are the most highly populated and diverse counties of the MSA. More than one thousand business and community leaders attended the "2012 State of the Region" breakfast, held at the Georgia World Congress Center.

Tad Leithead, the Chairman of the Atlanta Regional Commission, lamented the failure of the July, 2012 sales tax referendum for regional transportation and infrastructure, but encouraged everyone to "disenthrall from parochial thinking" (Leithead, 2012) . Leithead's message was clear: 'It's mandatory that we cooperate as a 
region. We cannot address our problems or implement a vision individually as a county or a city. We need to agree on a regional vision" (Leithead, 2012).

Letihead was referring to the failed $\$ 7.2$ billion transportation plan that the voters of Metro Atlanta rejected on July 31, 2012 (Hart, 2012). The Special Local Option Sales Tax, a percent sales tax to support capital infrastructure needs of the region, failed to win approval in every regional commission of the Atlanta MSA (Hart, 2012) . Leithead, in the State of the Region address, remained optimistic about the future of regional cooperation, noting that 22 elected officials had unanimously concurred with a project list for the Atlanta Regional Commission (Leithead, 2012).

The ARC is currently engaged in a nine-month process to create the Metro Atlanta Regional Economic Development Strategy. Expressly stated in the publication announcing this initiative is the statement that the roadmap will "meet the Economic Development Administration's requirements for a Comprehensive Economic Development Strategy (CEDS)" (Metro Atlanta chamber of commerce.2012) . To ensure compliance with the federal requirements, a Steering Committee of leaders from the private, public and non-profit sectors was appointed, and a working group of economic development officials from organizations throughout the 10-county Metro Atlanta region are participating in the process (Metro Atlanta chamber of commerce.2012).

Though the ARC is the organizing entity responsible for the production of a CEDS, there is no evidence that the ARC is posturing to assume a greater role as a regional entity to coordinate economic development activity. As the ARC is currently organized, it does not serve such a purpose. The committee structure of the ARC does not expressly include economic development as a function of the organization. The existing 
committees include: Executive, Aging Advisory, Aging Services, Budget Audit Review, Communications / Public Involvement, Environment and Land Use, Transportation and Air Quality, Transportation Coordinating, and Regional Transit Committee (Atlanta regional commission.2012). Though the $\mathrm{ARC}$ is actively working on the publication of a CEDS, which will qualify the member counties for EDA grant funding, the ARC will likely remain as a resource and facilitator for EDOs within the region, and will not become an active agent for the implementation of economic development programming.

\subsubsection{Three Rivers Regional Commission}

The Three Rivers Regional Commission (TRRC), which is on the southern border of the ARC. There are eight (8) Atlanta MSA counties in the Three Rivers Region, and two (2) counties from outside the Atlanta MSA, Upton (population 27,153) and Troup (population 67, 044) (American community survey 2009.2009). As illustrated in the table below, all of the counties in the Three Rivers Regional Commission have a HI Score of .50 or greater. The diversity range score is .26 , largely due to the outlier score attributed to Heard County (.76 HI Score).

\begin{tabular}{|l|c|r|r|r|c|c|}
\hline \multicolumn{7}{|c|}{ Three Rivers Regional Commission } \\
\hline County & $\begin{array}{l}\text { HI } \\
\text { Score }\end{array}$ & Population & $\begin{array}{l}\text { \% } \\
\text { White }\end{array}$ & $\begin{array}{l}\text { \% } \\
\text { Black }\end{array}$ & $\begin{array}{l}\text { \% } \\
\text { Hispanic }\end{array}$ & $\begin{array}{l}\text { \% } \\
\text { Asian }\end{array}$ \\
\hline Meriwether & 0.50 & 22,858 & 58.3 & 40.5 & 1.3 & 0.0 \\
\hline Spalding & 0.52 & 63,073 & 64.3 & 32.0 & 2.6 & 0.8 \\
\hline Fayette & 0.55 & 105,303 & 71.9 & 18.3 & 4.2 & 3.8 \\
\hline Butts & 0.56 & 23,596 & 69.7 & 27.1 & 2.2 & 0.4 \\
\hline Lamar & 0.56 & 17,010 & 69.0 & 29.4 & 1.6 & 0.0 \\
\hline Coweta & 0.59 & 118,531 & 74.7 & 17.2 & 5.6 & 1.0 \\
\hline Carroll & 0.61 & 110,641 & 75.8 & 17.1 & 4.8 & 0.8 \\
\hline Heard & 0.76 & 11,423 & 86.6 & 10.1 & 1.0 & 0.8 \\
\hline
\end{tabular}

Table 14. County Profiles of the Three Rivers Regional Commission 
When the Georgia DCA modified the regional commission boundaries in 2009, the federally designated Economic Development Districts (EDD's) were also impacted (Three rivers regional economic development district annual progress report.2010) . The McIntosh Trail Regional Development Center (MTRDC) was merged with the Chattahoochee-Flint Regional Development Center (CFRDC) to form the TRRC. "Both the MTRDC and CFRDC are grant recipients of 301.b Planning Investments from the Economic Development Administration (EDA), under the U.S. Department of Commerce" (Three rivers regional economic development district annual progress report.2010). The significance of this statement is clarified further in the executive summary of the 2010 annual update of the CEDS prepared by the TRRC:

"In order to be eligible for grant funding by EDA, a Comprehensive Economic Development Strategy must be established as a regional economic tool which focuses on job creation, economic initiatives and incentives to assist business and industry, and workforce training and education as priorities in the region. The Comprehensive Economic Development Strategy (CEDS) is a five-year plan, which serves as a guide for those efforts. This plan is based upon a specific set of goals and objectives designed to address the various economic challenges of the District. The CEDS provides a foundation that helps create additional jobs, attract public and private investment, foster a more stable and diversified economy and improves living conditions. Having this plan allows for better coordination among individuals, organizations, local governments and private industry concerned with economic development (Three rivers regional economic development district annual progress report.2010). 
The TRRC recognizes that the importance of the CEDS is to provide a foundation for coordination among the counties and EDOs within the region. The TRRC is representative of the region, with 20 public officials, 10 private officials, and five at-large officials. The TRRC does comply with the EDA and State of Georgia membership requirements (Three rivers regional economic development district annual progress report.2010). However, the TRRC does not serve as an official entity with the responsibility of implementing economic development policy.

\subsubsection{Northwest Georgia Regional Commission}

The Northwest Georgia Regional Commission (NWGRC) occupies the northwest corner of the State of Georgia. A majority of the counties within the NWGRC are not included in the Atlanta MSA. The eleven (11) non-Atlanta MSA counties within the Northwest Georgia region are: Dade, Caloosa, Fannin, Walker, Whitfield, Murray, Gilmer, Chattooga, Gordon, Floyd and Polk. As the table below indicates, the Atlanta MSA counties within the NWGRC (Bartow, Haralson, Paulding and Pickens Counties) all have White populations above $80 \%$ and very high HI Scores that indicate a lack of diversity. The HI Score range across these Atlanta MSA counties is .21.

\begin{tabular}{|l|c|r|l|c|c|c|}
\hline \multicolumn{7}{|c|}{ Northwest Georgia Regional Commission } \\
\hline County & $\begin{array}{l}\text { HI } \\
\text { Score }\end{array}$ & Population & $\begin{array}{l}\text { \% } \\
\text { White }\end{array}$ & $\begin{array}{l}\text { \% } \\
\text { Black }\end{array}$ & $\begin{array}{l}\text { \% } \\
\text { Hispanic }\end{array}$ & $\begin{array}{l}\text { \% } \\
\text { Asian }\end{array}$ \\
\hline Bartow & 0.69 & 92,490 & 82.1 & 9.6 & 5.9 & 0.8 \\
\hline Paulding & 0.69 & 125,780 & 81.5 & 14.4 & 4.3 & 1.0 \\
\hline Haralson & 0.83 & 28,559 & 90.9 & 5.2 & 1.2 & 0.2 \\
\hline Pickens & 0.90 & 30,021 & 94.8 & 2.3 & 2.5 & 0.3 \\
\hline
\end{tabular}

Table 15. County Profiles of the Northwest Georgia Regional Commission 
As designated counties within the NWGRC, the Atlanta MSA counties do stand to benefit by being included in the federally recognized Economic Development District. According to the NWGRC, “ The Economic Development Administration (EDA) funds public works and planning projects for local governments to support creating and/or retaining private sector jobs. Since 1976, EDA has invested approximately $\$ 17$ million in the Coosa Valley region" (Northwest Georgia regional commission.2012).

The NWGRC, as designated by the Georgia DCA in 2009, has been in continuous existence as a regional cooperation entity for over 50 years. In 1960, it was known as the Coosa Valley Planning and Development Association. What was once a local initiative for multi-county cooperation has become the model for multi-county coordination throughout the state.

\subsubsection{Georgia Mountains Regional Commission}

The Georgia Mountains Regional Commission (GMRC), which lies northeast of the ARC, is comprised of 13 counties, but only two (2) counties are listed as part of the Atlanta MSA, Dawson County and Forsyth County. As listed in the table below, Dawson and Forsyth Counties have a notable lack of diversity in the composition of the populations. The HI Score range of .18 is noted for these two (2) Atlanta MSA member counties.

\begin{tabular}{|l|r|r|c|c|c|c|}
\hline \multicolumn{7}{|c|}{ Georgia Mountains Regional Commission } \\
\hline County & $\begin{array}{l}\text { HI } \\
\text { Score }\end{array}$ & Population & $\begin{array}{l}\text { \% } \\
\text { White }\end{array}$ & $\begin{array}{l}\text { \% } \\
\text { Black }\end{array}$ & $\begin{array}{l}\text { \% } \\
\text { Hispanic }\end{array}$ & $\begin{array}{l}\text { \% } \\
\text { Asian }\end{array}$ \\
\hline Forsyth & 0.70 & 157,514 & 83.3 & 2.9 & 8.2 & 4.1 \\
\hline Dawson & 0.88 & 21,300 & 93.6 & 0.5 & 2.9 & 0.4 \\
\hline
\end{tabular}

Table 16. County Profiles of the Georgia Mountains Regional Commission 
As member counties of the GMRC, Dawson County and Forsyth County stand to benefit from the services provided by this regional organization. The GMRC is recognized as an Economic Development District by the federal agencies, and a Comprehensive Economic Development Strategy (CEDS) report has been properly filed with the EDA. The GMRC economic development department "assists local governments and development authorities in pursuing sound economic development through a variety of technical assistance, including: preparation of federal and state grant and loan applications, preparation of redevelopment plans, and grant administration" (Georgia mountains regional commission.2012).

The GMRC has clarified its role is to assist the EDOs of the region, and is not an entity responsible for implementing economic development policy. "The Department meets with the 13-county Economic Development Directors as needed to discuss economic development issues, project sharing, and best management practices" (Georgia mountains regional commission.2012). Again, this distinction regarding the role of the GMRC is important for the purpose of assessing economic development cooperation within the Atlanta MSA.

\subsubsection{Northeast Georgia Regional Commission}

\begin{tabular}{|l|c|r|l|l|l|l|}
\hline \multicolumn{7}{|c|}{ Northeast Georgia Regional Commission } \\
\hline County & $\begin{array}{l}\text { HI } \\
\text { Score }\end{array}$ & Population & $\begin{array}{l}\text { \% } \\
\text { White }\end{array}$ & $\begin{array}{l}\text { \% } \\
\text { Black }\end{array}$ & $\begin{array}{l}\text { \% } \\
\text { Hispanic }\end{array}$ & $\begin{array}{l}\text { \% } \\
\text { Asian }\end{array}$ \\
\hline Newton & 0.49 & 94,076 & 61.5 & 33.9 & 3.6 & 1.1 \\
\hline Jasper & 0.61 & 13,588 & 74.6 & 22.6 & 3.4 & 0.0 \\
\hline Barrow & 0.62 & 66,458 & 77.3 & 11.2 & 7.2 & 3.1 \\
\hline Walton & 0.68 & 82,243 & 81.0 & 15.5 & 3.0 & 0.1 \\
\hline
\end{tabular}

Table 17. County Profiles of the Northeast Georgia Regional Commission 
The Northeast Georgia Regional Commission (NEGRC) lies due east of the ARC and is composed of 12 counties. There are eight (8) counties in the NEGRC that lie outside the Atlanta MSA: Jackson, Madison, Elbert, Oconee, Clark, Oglethorpe, Morgan, and Greene Counties. As identified in table 19 above, three (3) of the four (4) counties that fall within the Atlanta MSA (Barrow, Walton, and Jasper) recorded HI Scores above .60; Newton County was the exception, reporting a .49 HI Score. An HI Score range of only .19 is recorded for these four (4) Atlanta MSA member counties.

As member counties of the NEGRC, the local governments and EDO officials benefit from the services provided by the economic development professionals. The Economic Development division notes that the "NEGRC serves as the Local Economic Development District (EDD) in coordination with the Economic Development Administration (EDA), and encourages cooperation between local government officials, community-based organizations, and the private sector" (Northeast Georgia regional commission.2012). The role of the NEGRC is to encourage cooperation; it is not vested with any authority to manage economic development cooperation among the counties.

\subsection{One Georgia}

In conversations with economic development professionals in the Atlanta region there are occasional references to the concept of two Georgias - one Georgia is Metro Atlanta, and the other Georgia is the rest of the state. The concept is attributed to the late Jimmy Gray, who was once editor of the Albany Herald. In a speech two decades ago, Gray spoke of one Georgia, Atlanta, as "prosperous, with high incomes, good schools 
and educational opportunities, good healthcare, plentiful job opportunities and a high quality of life" (Young, 2010). "The other Georgia, Gray said, was mired in poverty, with poor schools, inadequate healthcare, high unemployment, high crime rates and a poor quality of life" (Young, 2010).

While the particular economic conditions that prompted Gray to make those remarks back in the 1990s have been modified with the passage of time, the power of his commentary has not necessarily waned. There remains a pervasive sentiment that Metro Atlanta is capable of providing for itself. According to a senior economic development official with DeKalb County, the State of Georgia is more than keen to allow the local officials of the Metro Atlanta region opportunities to demonstrate their prowess in solving problems without state intervention or assistance (Whatley, 2012).

Examples of officials from the Metro Atlanta area engineering solutions to major problems, without any notable assistance from the state government, include the construction of the commuter rail and the stabilization of Grady Hospital. Both the transit system and the public safety-net hospital are supported primarily from local taxes and dedicated revenues from the City of Atlanta and Fulton and DeKalb Counties (Grady hospital.2012).

On the other hand, the other Georgia, outside Metro Atlanta, is often the beneficiary of legislation intended to address the perceived disparity between the successful urban State Capitol and the struggling rural regions of the state. Even within the Atlanta MSA, it is possible to see how the results of the Tier system for awarding Job Tax Credits puts the urban core counties at a disadvantage. The most populated urban counties (Fulton, Gwinnett and DeKalb) are authorized to offer Job Tax Credits of \$1,250 
and $\$ 1,750$; while the least populated rural counties (Lamar, Jasper and Heard) may offer Job Tax Credits of $\$ 3,000$ and $\$ 4,000$. The structural inequity of this particular program likely traces its genesis to Gray's observations two decades ago, and it remains is an issue that concerns economic development professionals today (Martin, 2012).

Perhaps the strongest evidence of the lasting impact of Gray's commentary about "Two Georgias" is a program adopted by the Legislature to allocate settlement proceeds of a tobacco lawsuit that is entitled "One Georgia." As one economic development professional lamented, the One Georgia program seems to reinforce the division and expressly excludes the Metro Atlanta region from accessing any of the proceeds of the settlement (Whatley, 2012). The summary of the grants and loan programs found on the website for The One Georgia Authority confirms the assertion:

Utilizing one-third of Georgia's share of the Tobacco Master Settlement Agreement to assist the State's most economically challenged areas, the One Georgia Authority anticipates spending \$1.6 billion on investments in Georgia's rural counties over the 25-year term of the settlement. The goal of the One Georgia Authority is to offer financial partnerships with rural communities to create strong economies in all business sectors, allowing new and existing industries, both large and small, to flourish. One Georgia is bridging Georgia's economic divide by ensuring balanced growth across the state helping to guarantee that all Georgians have access to economic opportunities in their own communities (One Georgia authority.2012).

This section is included to provide context to the challenges that confront the economic development professionals working to facilitate cooperation in the Atlanta MSA. This pervasive sense that the Metro Atlanta area is capable of promoting economic 
growth and development, despite disadvantages incorporated into the economic development programs of the State of Georgia, does not enhance opportunities for regional economic cooperation across urban and rural counties of the MSA.

There is also the confounding problem of defining the "Metro Atlanta" boundaries. One senior economic development official from DeKalb County noted that the definition of Metro Atlanta changes depending on the topic (Whatley, 2012). The boundaries of the Metro Atlanta Rapid Transit Authority include DeKalb and Fulton Counties (Metropolitan Atlanta regional transit authority.2012). The Metro Atlanta JDA consists of Clayton, DeKalb, Fulton, Henry and Rockdale Counties (Georgia Department of Community Affairs, 2010). Clayton, Cobb, DeKalb, Fulton, Gwinnett and Henry Counties support the Metro Atlanta Arts \& Culture Coalition (Metro Atlanta arts.2012). The Metro Atlanta Chamber of Commerce includes all 28 counties of the MSA (Metro Atlanta chamber of commerce.2012).

\subsection{Cooperative Organizations of the Atlanta MSA}

As a counterbalance to the numerous entities that subdivide the region, and the many governmental jurisdictions that fragment the political leadership of the MSA, there are several entities that do endeavor to provide cohesive support for economic development in the Atlanta MSA. The MACOC provides "one-stop-site selection assistance for the 28-county metro Atlanta area" (Metro Atlanta chamber of commerce.2012). The Georgia Economic Development Association (GEDA), headquartered in Midtown Atlanta, is an association that strives to improve the relationships among the economic development professionals who are active on behalf of 
the cities and counties of the Atlanta MSA and the State of Georgia (Georgia economic development association.2012). The Georgia State Economic Development Office (GSEDO) is another critical institution that provides support to regional collaborations. The GSEDO is co-located in Midtown Atlanta with the Georgia Resource Center, which is owned and operated by Georgia Power. The Resource Center dedicates its services to business attraction and expansion throughout the Atlanta MSA and the entire State of Georgia (Georgia resource center.2012).

The Metro Atlanta Chamber has over 4,000 members representing firms from throughout the 28-county MSA. The board of advisors for the Chamber is composed of the 400-500 members who contribute a premium. These individuals qualify for the Leadership Councils that have been created to provide support for the targeted industry clusters (Sydney, 2012). With assistance from Bain Consulting, the Metro Atlanta Chamber has selected four (4) clusters of economic activity to develop: Bioscience, Technology, Supply Chain and Clean Tech (Metro Atlanta chamber of commerce.2012).

The Leadership Councils for each of these targeted clusters each have between 50-80 board members of the Chamber participating (Sydney, 2012). Board members are assigned to Leadership Councils according to their professional affiliation and cluster interests (Sydney, 2012). The Leadership Councils enhance communications and linkage among the industry representatives of the Atlanta Region in order to strengthen capacity and foster innovation and growth. The Chamber also works with the Atlanta Convention \& Visitors Bureau to host receptions by the Leadership Councils when related international trade shows are held in Atlanta (Sydney, 2012). The Chamber initiatives to encourage industry specific networking across the MSA region are very much in accord 
with the concepts advanced by Michael Porter and endorsed by the U.S. Department of Commerce.

The Georgia Economic Developers Association (GEDA) was established "to provide and promote networking and professional development opportunities and to shape economic development public policy" (Georgia economic development association.2012). GEDA is a statewide organization headquartered in Atlanta that is currently led by Misti Martin of the Cherokee Office of Economic Development (Georgia economic development association.2012). For fifty years, GEDA has been instrumental in shaping the economic development policies of Georgia by encouraging its members to provide input to their legislators (Martin, 2012). GEDA is not a lobbying organization, but the members are educated, informed and engaged in matters important to their profession (Martin, 2012). It is an important network for economic development professionals in the Atlanta MSA and the State of Georgia (Kendrick, 2012).

According to the Chair of the GEDA, the County Development Authorities and Joint Development Authorities all report their available sites and facilities to the Georgia State Economic Development Office (Martin, 2012). The inventory of available sites and facilities is utilized to match the preferences of site selection consultants and corporate relocation professionals interested in expanding operations in the State of Georgia. The State Economic Development Office plays an important role in centralizing the data and supporting the efforts of economic development professionals across the MSA (Martin, 2012).

The GEDA, the GSEDO, the Georgia Power economic development team and a business incubator center are all co-located in the Georgia Resource Center in Midtown 
Atlanta, near the Georgia Tech campus. The ground floor of the building is a suite of conference rooms with theatre-style meeting space to provide tailored presentations to prospective employers. Depending on the site specifications being sought, every location in Georgia that meets the client's criterion can be presented on the big screen. Once the satellite search zooms in, software applications are utilized to visually transform the landscape of the site to buildable surfaces, with parking and traffic circulation modeling instantly incorporated. The Resource Center staff then uses advanced 'augmented reality' programming to allow patrons to 'see' their facilities on the selected location (Staples, 2012).

While every EDO in Georgia has access to the Georgia Resource Center facilities, the central location within the Atlanta MSA gives every county development official in the region easy access to this incredible asset. The topographical modeling software allows the board members of any Development Authority or JDA the ability to evaluate the site preparation expenses instantaneously. Before acquiring a property for an industrial development park, the software provides development officials with an informed estimate of the volume of earthmoving required to transform hilly countryside properties into flat buildable surfaces (Staples, 2012). Whether it is a site for potential employer, or an investment site to lure future employers, the Resource Center provides decision makers with critical development information in a timely fashion - instantly.

The multiple cohesive organizational assets mentioned above are all indicators of a region that is capable of collective action for economic development purposes. The tools for cooperation are in place, and the Metro Chamber is organized structurally to respond to the regional interests. Though a formal economic development agreement 
across the entire Atlanta MSA has not emerged, the willing participation of every county in at least one JDA reveals a willingness to engage in collective action. To measure the strength of the social capital available to support a region-wide economic development endeavor, a survey process was utilized.

\subsection{Social Capital Survey}

The preliminary results of the survey suggest the key stakeholders of the Atlanta MSA possess reasonable reserves of social capital to facilitate collective action for regional economic development. However, it must be noted, the response rates do not afford adequate data to draw conclusions relative to the other MSAs of this study.

Only 28 of the 117 elected officials contacted eventually submitted responses. There were 48 direct contacts with the executives of the EDOs in the Atlanta MSA, many of whom offered to distribute the survey to board members, but would not provide email contact information. A total of 26 responses were received from EDO officials. The combined response rate was at best $33 \%$, discounting the offer to further distribute the survey material, based upon 54 respondents /165 direct survey recipients.

\subsubsection{The Discovery Phase}

In the Atlanta MSA, there are very positive responses to statements designed to measure the various elements of social capital within the discovery phase of a collective action transaction. The tables below report the metrics of reciprocity, reputation and trust within the discovery phase. 
The vast majority of respondents reported engaging in regular communications with their colleagues from other counties in the region. Only $13.1 \%$ indicated that they do not engage in regular information exchanges with individuals from outside their county.

\begin{tabular}{|c|c|c|}
\hline \multicolumn{3}{|c|}{$\begin{array}{l}\text { Statement \#1: I have regular communications with my colleagues } \\
\text { from other counties in the region. }\end{array}$} \\
\hline Answer Options & $\begin{array}{l}\text { Response } \\
\text { Percent }\end{array}$ & $\begin{array}{l}\text { Response } \\
\text { Count }\end{array}$ \\
\hline strongly disagree & $1.9 \%$ & 1 \\
\hline disagree & $5.6 \%$ & 3 \\
\hline somewhat disagree & $5.6 \%$ & 3 \\
\hline somewhat agree & $29.6 \%$ & 16 \\
\hline agree & $37.0 \%$ & 20 \\
\hline strongly agree & $20.4 \%$ & 11 \\
\hline \multicolumn{2}{|c|}{ answered question } & 54 \\
\hline \multicolumn{2}{|c|}{ skipped question } & 0 \\
\hline
\end{tabular}

Table 18. Response \#1, Atlanta MSA

The reputation for cooperation in sharing information is rated highly by most of the respondents. Even though $7.5 \%$ of the respondents in the prior question indicated they do not have regular communications with their colleagues from outside the county, only $5.6 \%$ had no opinion on the quality of those communications. As the table below indicates, the vast majority of respondents $(89 \%)$ believe their colleagues have been very cooperative in providing information.

\begin{tabular}{|l|c|c|}
\hline \multicolumn{3}{|l|}{$\begin{array}{l}\text { Statement \#2: When it comes to sharing information, my colleagues } \\
\text { from other counties in the region have been very cooperative. }\end{array}$} \\
\hline Answer Options & $\begin{array}{c}\text { Response } \\
\text { Percent }\end{array}$ & $\begin{array}{c}\text { Response } \\
\text { Count }\end{array}$ \\
\hline strongly disagree & $0.0 \%$ & 0 \\
\hline disagree & $1.9 \%$ & 1 \\
\hline somewhat disagree & $3.7 \%$ & 2 \\
\hline no opinion / non-applicable & $5.6 \%$ & 3 \\
\hline somewhat agree & $16.7 \%$ & 9 \\
\hline agree & $59.3 \%$ & 32 \\
\hline strongly agree & $13.0 \%$ & 7 \\
\hline & answered question & $\mathbf{5 4}$ \\
\hline \multicolumn{2}{|c|}{ skipped question } & $\mathbf{0}$ \\
\hline
\end{tabular}

Table 19. Response \#2, Atlanta MSA 
There is a high level of trust among the respondents that their colleagues from other counties in the region provide reliable and dependable information. In fact, there was not even one respondent who was inclined to express doubts about the veracity of their colleagues from other counties. Among those who expressed an opinion, $100 \%$ somewhat agreed, agreed or strongly agreed their colleagues were to be trusted to provide reliable information. Table 22 below illustrates these survey results.

\begin{tabular}{|l|c|c|}
\hline \multicolumn{3}{|l|}{$\begin{array}{l}\text { Statement \#3: Information I receive from my colleagues in other } \\
\text { counties of our region is reliable and dependable. }\end{array}$} \\
\hline Answer Options & $\begin{array}{c}\text { Response } \\
\text { Percent }\end{array}$ & $\begin{array}{c}\text { Response } \\
\text { Count }\end{array}$ \\
\hline strongly disagree & $0.0 \%$ & 0 \\
\hline disagree & $0.0 \%$ & 0 \\
\hline somewhat disagree & $0.0 \%$ & 0 \\
\hline no opinion / non-applicable & $9.3 \%$ & 5 \\
\hline somewhat agree & $24.1 \%$ & 13 \\
\hline agree & $61.1 \%$ & 33 \\
\hline strongly agree & $5.6 \%$ & 3 \\
\hline \multicolumn{2}{|c|}{ answered question } & $\mathbf{5 4}$ \\
\hline skipped question & $\mathbf{0}$ \\
\hline
\end{tabular}

Table 20. Response \#3, Atlanta MS

\subsubsection{The Negotiation Phase}

Among the survey respondents in the Atlanta MSA, the metrics for reciprocity in the negotiation phase of a transaction reveal $84.7 \%$ maintain a positive view of equitable give and take among the regional jurisdictions. As the Table 23 below reveals, among the 52 leaders who responded, only $15.3 \%$ expressed reservations about equitable reciprocity between and among the county jurisdictions. 


\begin{tabular}{|c|c|c|}
\hline $\begin{array}{l}\text { Statement \#4: Worl } \\
\text { get resolved in a fai }\end{array}$ & ries, regiona & problems \\
\hline Answer Options & $\begin{array}{l}\text { Response } \\
\text { Percent }\end{array}$ & $\begin{array}{c}\text { Response } \\
\text { Count }\end{array}$ \\
\hline strongly disagree & $0.0 \%$ & 0 \\
\hline Disagree & $1.9 \%$ & 1 \\
\hline somewhat disagree & $13.5 \%$ & 7 \\
\hline somewhat agree & $48.1 \%$ & 25 \\
\hline Agree & $30.8 \%$ & 16 \\
\hline strongly agree & $5.8 \%$ & 3 \\
\hline Other (please specify & & 3 \\
\hline & red question & 52 \\
\hline & ed question & 2 \\
\hline
\end{tabular}

Table 21. Response \#4, Atlanta MSA

The respondents indicated community leaders had a generally favorable reputation for cooperative action in solving problems of the region. By slightly more than a 3:1 margin, respondents noted a favorable response regarding the capacity for leaders to negotiate effectively to resolve regional issues. The fact that several respondents 'strongly disagreed' (5.7\%) does suggest some leaders have experienced unsuccessful cooperative outcomes and are less than confident in the ability of their counterparts to successfully negotiate solutions to regional issues. Notably, $24.5 \%$ of respondents registered unfavorable responses.

\begin{tabular}{|l|c|c|}
\hline $\begin{array}{l}\text { Statement \#5: Working across county boundaries, regional problems } \\
\text { get resolved in a fair and reasonable way. }\end{array}$ & $\begin{array}{c}\text { Response } \\
\text { Percent }\end{array}$ & $\begin{array}{c}\text { Response } \\
\text { Count }\end{array}$ \\
\hline Answer Options & $0.0 \%$ & 0 \\
\hline strongly disagree & $1.9 \%$ & 1 \\
\hline disagree & $13.5 \%$ & 7 \\
\hline somewhat disagree & $48.1 \%$ & 25 \\
\hline somewhat agree & $30.8 \%$ & 16 \\
\hline agree & $5.8 \%$ & 3 \\
\hline strongly agree & & 3 \\
\hline Other (please specify) & answered question & $\mathbf{5 2}$ \\
\hline \multicolumn{2}{|c|}{ skipped question } & $\mathbf{2}$ \\
\hline
\end{tabular}

Table 22. Response \#5, Atlanta MSA 
Though the table above suggests that the regional leaders may have not always succeeded in negotiating favorable outcomes, there is no sentiment that the leaders do not trust their colleagues to advocate in an honest and forthright manner. In response to the query designed to elicit opinion regarding the level of trust during the negotiating process, the respondents were overwhelmingly positive. As the Table 25 below reveals, only two (2) respondents indicated some degree of doubt about the trustworthiness of their colleagues from other counties.

\begin{tabular}{|l|c|c|}
\hline \multicolumn{3}{|l|}{$\begin{array}{l}\text { Statement \#6: In discussions about regional issues, my colleagues } \\
\text { from other counties do their best to accurately represent the views of } \\
\text { their community. }\end{array}$} \\
\hline Answer Options & $\begin{array}{c}\text { Response } \\
\text { Percent }\end{array}$ & $\begin{array}{c}\text { Response } \\
\text { Count }\end{array}$ \\
\hline strongly disagree & $1.9 \%$ & 1 \\
\hline disagree & $0.0 \%$ & 0 \\
\hline somewhat disagree & $1.9 \%$ & 1 \\
\hline no opinion / non-applicable & $5.6 \%$ & 3 \\
\hline somewhat agree & $14.8 \%$ & 8 \\
\hline agree & $64.8 \%$ & 35 \\
\hline strongly agree & $11.1 \%$ & 6 \\
\hline & answered question & $\mathbf{5 4}$ \\
\hline skipped question & $\mathbf{0}$ \\
\hline
\end{tabular}

Table 23. Response \#6, Atlanta MSA

\subsubsection{The Conclusion Phase}

Opinion regarding the likelihood of leaders to conclude cooperative agreements to resolve regional problems is very positive (85.2\%). As the table below indicates, $<10 \%$ somewhat disagree or disagree with the notion that counties will cooperate to effectively respond to regional challenges. These high metrics for reciprocity in the conclusion phase of a collective transaction are noteworthy for the Atlanta MSA. 


\begin{tabular}{|l|c|c|}
\hline \multicolumn{3}{|l|}{$\begin{array}{l}\text { Statement \#7: If a regional approach is the best way to address a } \\
\text { particular situation, our counties will cooperate to get the job done. }\end{array}$} \\
\hline Answer Options & $\begin{array}{c}\text { Response } \\
\text { Percent }\end{array}$ & $\begin{array}{c}\text { Response } \\
\text { Count }\end{array}$ \\
\hline strongly disagree & $0.0 \%$ & 0 \\
\hline disagree & $5.6 \%$ & 3 \\
\hline somewhat disagree & $3.7 \%$ & 2 \\
\hline no opinion / non-applicable & $5.6 \%$ & 3 \\
\hline somewhat agree & $35.2 \%$ & 19 \\
\hline agree & $27.8 \%$ & 15 \\
\hline strongly agree & $22.2 \%$ & 12 \\
\hline \multicolumn{2}{|c}{ answered question } & $\mathbf{5 4}$ \\
\hline skipped question & $\mathbf{0}$ \\
\hline
\end{tabular}

Table 24. Response \#7, Atlanta MSA

The negative metrics for the reputation of officials successfully, formally concluding agreements in the Atlanta MSA presents cause for concern. The survey results reveal considerable doubts $(40.8 \%)$ about the reputation of officials' ability to readily conclude collective action agreements. On the other hand, as the table below suggests, a clear majority of respondents $(59.2 \%)$ believe it is relatively easy to get the officials to bless a fair solution to a regional problem.

\begin{tabular}{|c|c|c|}
\hline \multicolumn{3}{|c|}{$\begin{array}{l}\text { Statement \#8: Once a fair solution to a regional problem has been } \\
\text { found, getting all the officials from the different local jurisdictions to } \\
\text { bless it is relatively easy }\end{array}$} \\
\hline Answer Options & $\begin{array}{c}\text { Response } \\
\text { Percent }\end{array}$ & $\begin{array}{c}\text { Response } \\
\text { Count }\end{array}$ \\
\hline strongly disagree & $9.3 \%$ & 5 \\
\hline disagree & $9.3 \%$ & 5 \\
\hline somewhat disagree & $22.2 \%$ & 12 \\
\hline somewhat agree & $40.7 \%$ & 22 \\
\hline agree & $18.5 \%$ & 10 \\
\hline strongly agree & $0.0 \%$ & 0 \\
\hline \multicolumn{2}{|l|}{ Other (please specify) } & 3 \\
\hline \multicolumn{2}{|c|}{ answered question } & 54 \\
\hline \multicolumn{2}{|c|}{ skipped question } & $\mathbf{0}$ \\
\hline
\end{tabular}

Table 25. Response \#8, Atlanta MSA 
Within the conclusion phase of a collection action agreement, the overwhelming favorable response to this survey question (88.7\%) reveals a depth of trust among the leaders of the Atlanta MSA that should serve the region well. This level of confidence in the ability to conclude agreements that will be respected and honored by all parties is perhaps the most critical element of social capital within this survey. The table below reveals a strong reservoir of social capital within the Atlanta MSA.

\begin{tabular}{|c|c|c|}
\hline \multicolumn{3}{|c|}{$\begin{array}{l}\text { Statement \#9: The local jurisdictions of our region can be trusted to } \\
\text { honor any commitments they make }\end{array}$} \\
\hline Answer Options & $\begin{array}{l}\text { Response } \\
\text { Percent }\end{array}$ & $\begin{array}{c}\text { Response } \\
\text { Count }\end{array}$ \\
\hline strongly disagree & $0.0 \%$ & 0 \\
\hline disagree & $1.9 \%$ & 1 \\
\hline somewhat disagree & $9.4 \%$ & 5 \\
\hline somewhat agree & $39.6 \%$ & 21 \\
\hline agree & $45.3 \%$ & 24 \\
\hline strongly agree & $3.8 \%$ & 2 \\
\hline \multicolumn{2}{|l|}{ Other (please specify) } & 3 \\
\hline \multicolumn{2}{|c|}{ answered question } & 53 \\
\hline \multicolumn{2}{|c|}{ skipped question } & 1 \\
\hline
\end{tabular}

Table 26. Response \#9, Atlanta MSA

\subsection{The Dependent Variable: Regional Economic Development Cooperation}

Regional cooperation for economic development purposes is not an elusive concept, nor simply an aspirational goal in the Atlanta MSA. There is ample evidence of regional cooperation in the Atlanta MSA among the economic development professionals, and there are institutional manifestations of cooperation as well. While it is relatively easy to identify impediments and obstacles to cooperation, the weight of the evidence gathered in this study reveals the Atlanta MSA to be a region with cooperative attributes that are very much aligned with the national policies for strengthening the performance of the regional economies. Most importantly, there is evidence of a regional 
database of economic development information that is being used to promote the region. By the definition utilized in this study, regional economic development cooperation is occurring in the Atlanta MSA.

In the Atlanta MSA, the Metro Chamber serves as the primary organizing entity that provides economic development services throughout the 28 -counties of the region. The boundaries of the MSA are the boundaries of the Metro Chamber. It is the policy of the Metro Chamber to adjust their boundaries every ten (10) years to align with the MSA designation determined by the U.S. Census Bureau (Sydney, 2012).

The Metro Chamber not only publishes a strategic plan every five years for the Atlanta MSA, the organization serves as a coordinating entity to strengthen the ties among business leaders in the targeted industry clusters of the region (Sydney, 2012). And while many economic development professionals note that the Metro Chamber is unable to close on a deal with prospective employers, the Metro Chamber is recognized for its role in disseminating regional promotional material and for distributing information to local EDOs about prospects, trends and opportunities (Kendrick, 2012; Martin, 2012).

There are two (2) other organizations that are major contributors to enabling cohesive economic development action in the Atlanta MSA. Even though the Georgia Economic Development Association and the Georgia Resource Center are constituted to serve statewide interests, both are physically located in Atlanta and both organizations provide critical services that enhance opportunities for collaboration among their stakeholders throughout the Atlanta MSA. The fact that both entities are co-located in the 
same building is further evidence of the collaboration between them (Georgia resource center.2012) .

Not to be overlooked, the five (5) Regional Commissions in the Atlanta MSA have engaged in developing planning documents for economic development coordination. Though the Regional Commissions do not serve as EDOs for the purpose of implementing the Comprehensive Economic Development Strategy reports, the preparation of the CEDS reports is an important step in advancing cooperation among the member counties of the Atlanta MSA.

The Atlanta MSA does have numerous multi-county EDOs that serve a portion of the MSA. The formation of the 14 Joint Development Authorities involving multiple counties within the MSA is a clear indication of cooperative economic development activity within the Atlanta MSA. The fact that $100 \%$ of the counties in the Atlanta MSA have entered into cooperative agreements with adjoining counties is a strong indicator of a willingness to cooperate for the purpose of advancing economic development opportunities beyond the county jurisdictional boundaries. The incentives offered by the State of Georgia can be credited for much of this collaboration.

\subsection{Conclusion}

The 28 counties of the Atlanta MSA have not formally adopted a collective action agreement to advance economic development programming for the entire region, but the economic development professionals of the Atlanta MSA have access to a robust database of regional information managed by the Georgia Resource Center, and the MSA 
is effectively promoted by the Metro Atlanta Chamber of Commerce. Regional economic development cooperation does occur in the Atlanta MSA.

From the interviews and office visits during this research, it is clear that the local jurisdictions are entirely capable of simultaneously seeking opportunities for their respective communities while advancing the interests of the region. Actively engaging with peers and colleagues throughout the region to share and assimilate information, while working very closely with neighboring counties, seems to be the norm among the Atlanta MSA economic development professionals. It is fair to label economic development cooperation in the Atlanta MSA as decentralized cooperation. There is deference to the urban core when association is advantageous, while every local EDO and JDA pursues their own interests.

The results of the survey suggest there is a reservoir of social capital that could be expended to successfully conclude a cooperative transaction, if one were necessary. The need for a formal agreement among the key stakeholders may be eclipsed by the regional mechanisms that have emerged to facilitate economic development cooperation. The contributions from the Georgia Resource Center in Atlanta, the Metropolitan Atlanta Chamber of Commerce, the association for economic development professionals, and the extensive network of Joint Development Authorities may render the need for a more formal governance structure moot.

An initiative to advance a more formal governance structure might not be able to overcome the obstacles outlined in the inventory of community profile characteristics. The governments of the counties in the region are a mixed bag of structures, with only $57 \%$ percent being council-manager governments. The economic disparity among the 
counties of the region is indeed wide, with the median household income in Lamar County at only $\$ 33,835$ and Forsyth County with median household income of $\$ 88,040$. The political fragmentation in the Atlanta region, with 28 counties and 145 cities, is not conducive to effectuating a formal cooperative agreement.

Rather than challenge the body politic to suppress the preference for autonomy and local control in a quest for a formal regional cooperative agreement for economic development, the business community and economic development professionals in the Atlanta MSA engage in informal regional collaboration. The common database support of the Georgia Resource Center, the industry cluster programming focus and the regional promotional efforts of the Metro Atlanta Chamber of Commerce obviates the need for a formal cooperation agreement.

There are possible actions that might benefit the regional economic development efforts of the Atlanta MSA. Legislators could enhance the incentives for cooperation among county economic development organizations to encourage even greater expansion of the Joint Development Authorities. The incremental $\$ 500$ incentive associated with the formation of a JDA has been very effective in facilitating cross-county economic development cooperation. Perhaps JDAs with ten counties or more could become eligible for even greater Job Tax Incentives.

The other matter that deserves attention is the number of regional commissions that intersect and divide the Atlanta MSA. It might benefit the economic development planning $n$ the Atlanta MSA if the Department of Community Affairs realigned the regional commission boundaries to minimize the divisions of the MSA. This might allow 
the Comprehensive Economic Development Strategy documents to have greater applicability to the actual economic development policies and programs of the MSA.

A review of the diversity of the member counties within each regional commission reveals groupings within a relatively tight range of .18 to .26 Herfindahl Index scores. These groupings are not decided locally. The Georgia Department of Community Affairs organizes the regional commissions. Unlike the locally initiated JDA formations that do not demonstrate a pattern of similar diversity scores, the regional commissions reflect the possibility of grouping by common diversity factors. These patterns are worth noting and should be considered by the DCA when shaping the boundaries in the future. 


\section{CHAPTER 5}

\section{ECONOMIC DEVELOPMENT COOPERATION IN THE HOUSTON REGION}

\subsection{An Overview of the Houston MSA}

The Houston MSA has achieved a level of regional economic development cooperation that is notably superior to the other two (2) regions of this study. A single organizational entity has emerged to conduct economic development activities on behalf of the entire MSA. The Greater Houston Partnership (GHP) is a private organization with an 85-member professional staff dedicated to conducting regional economic research and ensuring the Houston region is recognized globally as a destination for international business and commerce (Greater Houston partnership.2012). As one county economic development official aptly stated, "The Greater Houston Partnership is the mother ship" (Texas conversations 2012).

The GHP was formed in the 1980s by a merger of the World Trade Organization of Houston, the Economic Development Council of Houston and the Houston Chamber of Commerce (Richard, 2012). The impetus to combine the efforts of the various economic development institutions was economic recession. In 1982-1983, the national unemployment rate hit double-digits for ten (10) months in a row (Texas conversations2012). In Houston, the impact of the recession seemed deeper and wider due to the downturn in the energy sector (Wilkins, 2012). Though the energy sector remains a dominant economic force in the Houston economy, great strides have been made to balance the economic activity with growth in other sectors (Richard, 2012).

The energy sector is the major industry cluster in the Houston MSA economy. "More than 3,000 energy-related establishments are located within the Houston MSA, 
including more than 500 exploration and production firms, more than 150 pipeline transportation establishments and hundreds of manufacturers and wholesalers of energy sector products" (FY 2012 budget houston.2011). While Houston prides itself on being the "US energy headquarters and a world center for virtually every segment of the petroleum industry," economic development professionals emphasize the continuing efforts to diversify the Houston MSA economy, which began in earnest following the atypical decline of the energy sector in the late 1980s (FY 2012 budget houston.2011)(Rendeiro, 2012).

Using 2009 employment location quotient data to compare the Houston MSA to the national economy, the dominance of the energy sector is evident, complemented by growth across a number of related sectors. Within several sectors of the economy, the Houston MSA has outperformed the national average, reflected as a Location Quotient greater than 1.0, in terms of employment (StatsAmerica.2012) :

\begin{tabular}{|l|c|}
\hline \multicolumn{2}{|c|}{ Houston MSA Industry Clusters } \\
\hline Description & $\begin{array}{c}\text { Employment } \\
\text { LQ }\end{array}$ \\
\hline Energy (Fossil \& Renewable) & 2.74 \\
\hline Machinery Manufacturing & 2.11 \\
\hline Fabricated Metal Products & 1.96 \\
\hline Chemicals \& Chemical Based Products & 1.62 \\
\hline Transportation \& Logistics & 1.42 \\
\hline Manufacturing Super cluster & 1.17 \\
\hline
\end{tabular}

Table 27. Industry Clusters of the Houston MSA

The intense concentration of energy related business in the Houston MSA is certainly a defining characteristic of the local economy, and may account for the relative strength in employment data when comparing unemployment rates among the three (3) metropolitan areas of this study. The Houston MSA generally posts the lowest 
unemployment numbers among the three regions in recent years. To suggest the more favorable unemployment numbers are directly related to the issue of regional economic development cooperation is not supported by the mixed unemployment results in Atlanta and Miami. The seasonally adjusted unemployment rates reported by the U.S. Bureau of Labor Statistics for the month of August from 2007 to 2012 are listed in the table below.

\begin{tabular}{|r|r|r|r|}
\hline \multicolumn{5}{|c|}{ Seasonally Adjusted Unemployment Rates } \\
\hline & Houston & \multicolumn{1}{|l|}{ Atlanta } & \multicolumn{1}{l|}{ Miami } \\
\hline Aug-07 & 4.2 & 4.6 & 4.0 \\
\hline Aug-08 & 4.9 & 6.4 & 6.4 \\
\hline Aug-09 & 8.0 & 10.3 & 10.9 \\
\hline Aug-10 & 8.3 & 10.0 & 11.3 \\
\hline Aug-11 & 8.2 & 9.7 & 10.4 \\
\hline Aug-12 & 7.0 & 8.8 & 8.7 \\
\hline
\end{tabular}

Table 28. Unemployment History for all three (3) MSAs

The Port of Houston and the Houston Airport System are major economic drivers for the Transportation \& Logistics sector. The Port of Houston Authority and more than 150 private industrial companies operate along 25 miles of shipping channel with direct access to the Gulf of Mexico. The Port of Houston has been ranked number one for U.S. imports for the past 19 years and is second for U.S. export tonnage (FY 2012 budget houston.2011). The George Bush Intercontinental Airport and two other aviation facilities "position Houston as the international and cargo gateway to the south central Unites States and a primary gateway to Latin America" (FY 2012 budget houston.2011).

In the 2005-2015 strategic plan adopted by the GHP, industries are targeted that demonstrate a capacity to grow and prosper in the region. The ten (10) industries identified in strategic plan include: Aerospace, Alternative Energy, Biotechnology, Education, Energy, Entrepreneurial Enterprises, Health Care, Information Technology, 
Nanotechnology, and Petrochemical (Greater Houston partnership 2005-2012 strategic plan.2005). The decision of the GHP to nurture the competitive advantages of particular industries in the region comports with the federal economic development policies outlined in the literature review (Porter, 2001).

The GHP functions as a resource and coordinating entity for the sub-regional and county EDOs of the Houston MSA. Organizations constituted to serve the economic interests of more than one county include The Economic Alliance - Port Region and the Bay Area Houston Economic Partnership (Gulf Coast Economic Development District, 2009) . The active county-level EDOs in the Houston MSA include: Sealy EDC (Austin County), ED Alliance for Brazoria County, Baytown West Chambers County ED Foundation, Chambers County EDD, Chambers-Liberty Counties Navigation District EDC, Greater Fort Bend EDC, Galveston County Economic Alliance, Galveston ED Partnership, University of Houston SBD Centers (Harris County), Liberty County ED Alliance, South Montgomery County ED Partnership, Greater Conroe EDC (Montgomery County) and Waller county EDP (Gulf Coast Economic Development District, 2009).

Though there are a number of active sub-regional and county level EDOs in the Houston MSA, it is not necessarily a detriment to economic development cooperation. Many of these organizations gained their footings as active and robust agencies working alongside the GHP. The functional relationship between the GHP and these organizations will be described later in this chapter.

Cooperation among the local officials in the Houston region is advanced through a public sector organization. The State Legislature in Texas has long held the view that 
cooperation is vital among the local governments of a region. For many decades, the State has supported regional councils dedicated to developing and maintaining transportation infrastructure, transit services, water supply, public safety and emergency response networks (TSHA, 2012) .

The Houston Galveston Area Council (H-GAC) was formed in 1966. Its boundaries span 13 counties, including all of the Houston MSA counties with the exception of San Jacinto County. The H-GAC reaches beyond the perimeter of the Houston MSA to include the sparsely populated counties of Matagorda (36,717), Wharton $(41,225)$, Colorado $(20,831)$ and Walker $(67,641)$ (American community survey, 2009) . The H-GAC "mission is to serve as the instrument of local government cooperation, promoting the region's orderly development and the safety and welfare of its citizens" (Houston-Galveston Area Council, 2008) .

The H-GAC is also the entity responsible for producing the Gulf Coast Economic Development District Comprehensive Economic Development Strategy (CEDS) report for the federal government. Publication of the CEDS is a qualifying event for the member counties of the H-GAC to be eligible for federal economic development grants. The CEDS is informative and reflective of the regional economic development strategy, but does not necessarily serve as an instrument of policy to be enacted for the purpose of economic development in the region (Gulf Coast Economic Development District, 2009). 


\subsection{Demographics and Characteristics of the Houston MSA}

The Houston MSA includes ten counties, 144 municipalities, and a combined population of 5.86 million people (United states census bureau, 2012). There are 66 independent school districts serving the Houston MSA (FY 2012 budget houston, 2011). The City of Houston has over 2 million residents and is the county seat of Harris County. Harris County is the largest and most densely populated county in the Houston MSA, home to more than $70 \%$ of residents in the Houston MSA (American community survey, 2009). The table below provides an overview of the counties within the Houston MSA, in rank order by population (American community survey, 2009).

A Commission form of government is uniformly found in the counties of the Houston MSA as prescribed in the Texas Constitution. Each County elects a presiding Judge and a Court of Commissioners to "exercise such powers and jurisdiction over all county business, as is conferred by this Constitution and the laws of the State, or as may be hereafter prescribed" (Texas Constitution, 2012). Pursuant to the findings of Feiock (2009), this consistency in the form of county government, though not the more preferred Council-Manager form, could favorably influence the likelihood of economic development cooperation among county officials. For reasons that will be explained in the section devoted to the legal history of economic development policy in Texas, county officials do not have an entrenched, historical familiarity with the intricacies of local economic development practices. 


\begin{tabular}{|l|r|r|r|r|r|c|}
\hline \multicolumn{7}{|c}{ Houston MSA Summary Data } \\
\hline \multicolumn{1}{|c}{ County } & \multicolumn{1}{c}{ Pop. } & \multicolumn{1}{c|}{$\begin{array}{c}\text { Miles } \\
\text { Harris }\end{array}$} & \multicolumn{1}{c|}{ Density } & Cities & Diversity & Gov. \\
\hline Fort Bend & 556,870 & 861.5 & 646 & 20 & 0.27 & C \\
\hline Montgomery & 447,718 & 1041.7 & 430 & 17 & 0.57 & C \\
\hline Brazoria & 309,208 & 1357.7 & 228 & 23 & 0.40 & C \\
\hline Galveston & 286,814 & 378.4 & 758 & 14 & 0.42 & C \\
\hline Liberty & 74,941 & 1158.4 & 65 & 13 & 0.54 & C \\
\hline Waller & 35,552 & 513.4 & 69 & 7 & 0.36 & C \\
\hline Chambers & 29,198 & 597.1 & 49 & 9 & 0.54 & C \\
\hline Austin & 26,567 & 646.5 & 40 & 4 & 0.52 & C \\
\hline San Jacinto & 24,645 & 569.2 & 43 & 3 & 0.64 & C \\
\hline Total & $\mathbf{5 , 8 6 2 , 5 0 2}$ & $\mathbf{8 8 2 7 . 4}$ & $\mathbf{6 6 4}$ & $\mathbf{1 4 4}$ & $\mathbf{0 . 3 3}$ & \\
\hline
\end{tabular}

Table 29. County Profile Summary in the Houston MSA

Historically, the commissioners' court in most counties has deferred to the private EDOs and municipal leaders to shape the economic development agenda of the county (Tollett, 2012). This lack of direct involvement by county officials somewhat diminishes the importance of political fragmentation at the county level as a factor influencing economic development cooperation in the region. Valid arguments could arise that the formula should be weighted to reflect this functional difference. For the integrity of this comparative case study, the method for calculating the value for political fragmentation will not be modified.

The chosen method for calculating the value for political fragmentation in this study is to divide the population of the region by the number of counties, then divide the results by the number of cities. A lower score indicates a relatively higher degree of political fragmentation. The value for political fragmentation in the Houston MSA is a score of 4,071. By comparison, the Houston MSA is less politically fragmented than the 
Atlanta MSA, which reported a score of 1,290. The calculation for the Houston MSA is presented below:

$$
\frac{5,862,502 \text { (pop.) } / 10(\text { cou }}{144(\text { cities })}
$$

The ethnic diversity of the population in the Houston MSA was evaluated utilizing the Herfindahl Index, which produces a percentage scale to measure the extent any particular ethnic demographic (Non-Hispanic White, Hispanic, Black or Asian) enjoys a relative advantage. The index is stated in percentages, with a lower percentage indicating greater diversity. A higher percentage suggests one particular ethnic group has a more dominant representation in the jurisdiction.

The Herfindahl Index rating overall for the Houston MSA is 33\%. This rating suggests the population is diverse, and no particular demographic is disproportionately represented at the level of the MSA. Harris County, the most populous county in the region, has a slightly lower diversity index of $32 \%$. Harris County is also the only county in the MSA with a Hispanic population $(1,620,254)$ greater than the number of White non-Hispanic residents $(1,428,917)$.

However, the diversity ratings among several counties in the MSA reveal that certain jurisdictions do exceed a $50 \%$ rating. A rating of $>50 \%$ indicates one ethnic demographic has disproportionate representation, or greater market share of influence, in a county. Five (5) of the ten counties in the Houston MSA fall into the category of having a diversity score above $50 \%$ due to the dominance of the Non-Hispanic White population: Austin (52\%), Chambers (54\%), Liberty (54\%), Montgomery (57\%) and San Jacinto (64\%). It should be noted however that, with the exception of Montgomery 
County, these counties are the least populated counties in the MSA. Montgomery County, with a population of 447,718 , is further distinguished as an affluent metropolitan suburban community with a mean family income of $\$ 100,457$ (American fact finder.2010).

As the findings above suggests, the lower $(<50 \%)$ diversity rating for the Houston MSA can be traced to the more densely populated urban counties: Harris (32\%), Galveston (42\%), Fort Bend (27\%), and Brazoria (40\%). Waller County (36\%) is an exception with a population of only 35,552 . Waller County is also the only county in the Houston MSA with a population of Black, non-Hispanic residents $(9,101)$ greater than the number of Hispanic residents $(8,532)$. Fort Bend County has the lowest Herfindahl Index score in the Houston MSA, reflecting the highest diversity rating. This result can be attributed to the fact that Fort Bend County has the highest percentage of Asian residents (15.5\%) of any county in the MSA. The spike in percentage of Asian residents in Fort Bend County serves to balance the 'market share' of White, non-Hispanics (38.7\%), Black, non-Hispanics (20.8\%) and Hispanics (23.8\%) (American community survey. 2009).

The overall median household income for the Houston MSA is $\$ 55,532$ a year (American fact finder.2010) . Among the three (3) MSAs of this comparative case study, the Houston MSA has the highest median household income. As expected, some counties within the Houston MSA are more prosperous than others.

The degree of differential in the household incomes is notable. The median household ranges from a low of $\$ 42,043$ in San Jacinto County to a high of $\$ 80,638$ a year in Fort Bend County (American community survey 2009.2009). This is a 91.8\% 
differential in median household incomes across these counties of the MSA. Recall, Feiock (2009) found that economic disparity among the member jurisdictions is a factor that decreases the likelihood of cooperation.

\subsection{The Constitutional and Statutory History}

The history of economic development policy in Texas is strikingly different than the historic pattern of 'smokestack chasing' that was found in Georgia and Florida. The state and the local governments of Texas were effectively prohibited from participating in the 'smokestack chasing' practices. The Constitution of Texas did not allow the state or local governments to expend any public funds to promote private business activity. Until 1987, it was essentially illegal for any governmental body in Texas to offer incentives, rebates, or tax breaks to attract or retain firms considering relocation (Abbot, 2008) .

In the wake of the 1982 national recession, Texas experienced prolonged high unemployment rates due to the deep and lingering impacts on the energy sector. To recover fully, consensus emerged in the business community that the economic development laws needed to be changed in order to attract and expand business in Texas. By and large, it was private business interests that pushed for the change. The GHP considered this change crucial to ensuring Texas could compete in the global marketplace and was instrumental in getting a referendum question to amend the Constitution approved (Houston interviews, 2012) .

"In November 1987, the voters of Texas approved an amendment to the Texas Constitution providing that expenditures for economic development serve a public purpose and were therefore permitted under Texas law" (Abbot, 2008). This 
Constitutional amendment finally opened the door for legislation that would authorize local officials to expend public resources on economic development initiatives. According to a recent New York Times series, the public officials in Texas have entered into the 'smokestack chasing' fray with complete abandonment and are now provide more public assistance to private firms on an annual basis than any other state in the nation (Story, 2012).

This relatively recent change in economic development policy in Texas helps to explain why public officials at the county level have not historically been involved in economic development affairs. Other than cheering from the sidelines, they could not expend one dollar of public funds to impact private business decisions. Even with the Constitutional change that made it possible for local governments to expend public monies for economic development purposes, the county officials of Texas were not the primary actors on the local level. The State Legislature of Texas has delegated to cities the leading role in the local economic development arena.

Prior to the passage of the 1987 Constitutional amendment, the Texas Legislature adopted the Development Corporation Act of 1979 (the ACT). Development corporations could be established by cities and were authorized to promote local business development. Until the Constitution was amended in 1987, these development corporations were entirely dependent upon private contributions (Abbot, 2008). In the 1989 Legislative Session, following the passage of the Constitutional amendment, the Act was amended to allow for cities to ask voters to approve a sales tax to fund the initiatives of the development corporations (Abbot, 2008). 


\begin{tabular}{|l|l|c|l|l|c|}
\hline \multicolumn{5}{|c|}{ Municipal Incentive Programs in Houston MSA } \\
\hline City & County & 4A/4B & \multicolumn{1}{c|}{ City } & \multicolumn{1}{c|}{ County } & 4A/4B \\
\hline Arcola & Brazoria & 4B & Montgomery & Montgomery & 4B \\
\hline Baytown & Fort Bend & 4B & Nassau Bay & Harris & 4B \\
\hline Beasley & Harris & 4A/4B & Needville & Fort Bend & 4B \\
\hline Bellville & Fort Bend & 4A/4B & $\begin{array}{l}\text { Oak Ridge } \\
\text { Aurth }\end{array}$ & Montgomery & 4B \\
\hline Brookshire & Waller & 4B & Orchard & Fort Bend & 4A/4B \\
\hline $\begin{array}{l}\text { Clear Lake } \\
\text { Shores }\end{array}$ & Galveston & 4B & Oyster Creek & Brazoria & 4B \\
\hline Cleveland & Liberty & 4B & Pearland & Harris & 4B \\
\hline Clute & Brazoria & 4B & Prairie View & Waller & 4B \\
\hline Conroe & Montgomery & 4B & Richmond & Fort Bend & 4B \\
\hline Dayton & Liberty & 4B & Rosenberg & Fort Bend & 4B \\
\hline Dickinson & Galveston & 4B & Santa Fe & Galveston & 4B \\
\hline Freeport & Brazoria & 4B & Seabrook & Harris & 4B \\
\hline Galveston & Galveston & 4B & Sealy & Austin & 4B \\
\hline Hempstead & Waller & 4A & Shenandoah & Montgomery & 4B \\
\hline Hitchcock & Galveston & 4A & Stafford & Fort Bend & 4B \\
\hline Kemah & Galveston & 4B & Sugar Land & Fort Bend & 4A/4B \\
\hline La Marque & Galveston & 4A & Sweeny & Brazoria & 4B \\
\hline La Porte & Harris & 4B & Texas City & Galveston & 4A \\
\hline Lake Jackson & Brazoria & 4B & Tomball & Harris & 4B \\
\hline League City & Galveston & 4B & Waller & Waller & 4A \\
\hline Liberty & Liberty & 4B & Wallis & Austin & 4B \\
\hline Manvel & Montgomery & 4A/4B & West Columbia & Brazoria & 4B \\
\hline Magnolia & Fort Bend & 4A & Willis & Montgomery & 4A/4B \\
\hline Meadows & 4B & Webster & Harris & 4B \\
\hline
\end{tabular}

Table 30. Municipal Incentive Programs in the Houston MSA

Cities across Texas took advantage of this sales tax program to fund the initiatives of their development corporations. The legislation amending the Development Corporation Act of 1979 included two sections outlining the eligibility criteria and purposes of the sales tax, sections $4 \mathrm{~A}$ and $4 \mathrm{~B}$. Generally, the $4 \mathrm{~A}$ sales tax could be up to a $1 / 2$ cent and be used for new and expanded industrial and manufacturing activities; the 
4B $1 / 2$ cent sales tax is less restrictive and can be used for a wide range of civic and commercial projects (Abbot, 2008).

According to the Texas Attorney General, 558 cities in Texas have levied an economic development sales tax: "Of these cities, 115 have adopted a Section 4A economic development sales tax, 339 cities have adopted a Section 4B economic development sales tax, and 104 cities have adopted both a Section 4A and a Section 4B sales tax" (Abbot, 2008). The 50 cities within the Houston MSA that have levied an economic development sales tax are listed in Table 31 above (Gulf Coast Economic Development District, 2009).

The Texas Legislature has been clear in its intent to empower cities, and not counties, to levy the sales tax and control the local economic development agenda. This deference to cities, rather than counties, may have naturally flowed from the Legislature's familiarity with city-centric EDOs. Regardless of the origins of the State's predisposition to empower cities with the authority to levy the economic development sales tax, the secondary role of counties seems to persist in the economic development arena. In the opinion of the Texas Attorney General, cities are even authorized to engage in projects beyond their municipal boundaries:

Section 23(a)(1) of the Development Corporation Act provides that an economic development corporation may undertake projects outside of the city limits with permission of the governing body that has jurisdiction over the property. In other words, if the corporation wants to undertake a project that is located completely in the city's extraterritorial jurisdiction or beyond, it should get approval from the governing body of the county, the county commissioners court. The language of the Act, however, does not 
seem to require this approval if the project is located at least partially within the boundaries of the city (Abbot, 2008).

The Texas Legislature has provided opportunities for county officials to take the lead in certain economic development programs. Chapter 312 of the Texas Code authorizes counties the ability to grant tax abatements to attract new business to Tax Reinvestment Zones (TRZs). To grant the tax abatements, unless a county enacts more liberal policies, the business must be located in a TRZ designated by the county (Texas Statute 312, 2012).

According to the most recent report from the Texas Comptroller, between 2006 and 2009, the cities of Texas have taken the lead in establishing 567 TRZs (Combs, 2010) . By comparison, during the same period of time, the counties of Texas acted as the lead in establishing 132 TRZs. Half of the counties in the Houston MSA have not designated their own TRZs (Combs, 2010). The table below reflects the findings of the Texas Comptroller:

\begin{tabular}{|l|c|}
\hline \multicolumn{2}{|c|}{ Houston MSA County TRZs } \\
\hline \multicolumn{1}{|c|}{ County } & Tax Reinvestment Zones \\
\hline Harris & 10 \\
\hline Fort Bend & 3 \\
\hline Montgomery & 0 \\
\hline Brazoria & 1 \\
\hline Galveston & 6 \\
\hline Liberty & 0 \\
\hline Waller & 0 \\
\hline Chambers & 0 \\
\hline Austin & 1 \\
\hline San Jacinto & 0 \\
\hline
\end{tabular}

Table 31. County Tax Reinvestment Zones in the Houston MSA 
Given the history of the legal constraints on expending public resources to advance economic development interests in Texas, and the Legislature's predilection to empower city officials with tax revenues for economic development matters, it is not entirely unexpected that county officials might be remiss in availing themselves of every possible economic development program that is authorized. This is not to suggest that county officials have not been generous in providing tax abatements and other state incentives when called upon.

As reported in a recent New York Times series, the state, county and city governments of Texas have raised the bar for incentive competition. The people of Texas spend more money per capita on economic development incentives than any other state. It is estimated that the annual expenditures on economic development incentive programs amount to $\$ 759$ per capita, costing Texans more than $\$ 19$ billion a year (Story, 2012). For comparison purposes to the other states in this report, the expenditures in Georgia amount to $\$ 144$ per capita, costing Georgians at least $\$ 1.4$ billion a year; the expenditures in Florida amount to $\$ 212$ per capita, costing Floridians at least $\$ 3.98$ billion per year (Story, 2012).

In the short span of 25 years, the governments of Texas have traveled at lightning speed from a position of not offering economic development incentives to being the most generous state in the nation for incentives (Story, 2012). Prior to the 1987 Constitutional amendment that allowed for the expenditure of public funds, the economic development arena was a function of the creativity and resources found in the private sector. With the subsequent introduction of a host of public incentive programs, the private sector continues to lead the economic development process today in an aggressive fashion. The 
EDOs of Texas have been demonstrably successful in persuading public officials to loosen the purse strings. As one former Houston official sized up the situation, "Everything is led by the private sector. They are the brains behind the projects" (Houston interviews, 2012).

\subsection{Greater Houston Partnership}

The GHP emerged as the regional EDO for the Houston MSA at a time of financial crisis. In the 1980s, billboards in downtown Houston were promoting the advantages of locating in other regions (Richard, 2012). The lingering effects of the 1982 national recession were more acute in the Houston MSA than other regions of the country due to the inordinate economic influence of the energy sector. Following the recession, the energy sector of the Houston region continued to struggle due to the reduced demand for fuel, and a contemporary increase in oil and gas production capacity overseas (Houston ED official2012). The business leaders of Houston became alarmed and recognized the need for an institutional response.

Due to the Constitutional constraints on local government, it became imperative that all of the non-governmental economic development resources of the community be unified to address the financial crisis. Before the end of the 1980s, the Houston Chamber of Commerce, the Houston Economic Development Council and the Houston World Trade Association merged to form the GHP. This powerful, centralized agency, housed on several floors in a Houston skyscraper, has worked to de-emphasize its orientation as a tool of downtown business interests. From the outset, the GHP struck a regional posture 
and committed to serving all counties of the Houston MSA (Greater Houston partnership.2012).

The evolution of the GHP transpired during the same period of time that the Legislature was taking steps to secure funding for municipal development corporations. Many of the same individuals responsible for the formation of the GHP were actively working to change the Constitutional restrictions on public economic development expenditures (Houston ED official, 2012). Since its inception, the GHP has maintained an active and influential government advocacy program. The GHP dedicates almost 20\% of their operating budget to government relations (Houston ED official, 2012) .

Though the GHP is a robust agency with a regional agenda, it is committed to ensuring the local EDOs throughout the region are stable partners. Early on, the leadership of the GHP recognized the importance of developing the capacity of the local EDOs throughout the Houston MSA. The GHP has earned lasting goodwill by facilitating opportunities to develop the skill sets and capabilities of the local EDO professionals throughout the region.

The GHP partnered with CenterPoint Energy, the electric company that serves the Houston metropolitan region, to provide economic development training programs for the staff of the local EDOs. The partnership with CenterPoint was a natural fit, as the utility is an accredited economic development organization with a notable history of community involvement in the Houston MSA (CenterPoint energy, 2012). The GHP-sponsored training programs effectively assuaged concerns of the local EDOs that the GHP would usurp their functions and dominate the economic development realm throughout the 
Houston MSA. The educational outreach program was very effective in demonstrating to the local EDO professionals that the GHP was intent on cooperation (Richard, 2012).

The partnership with CenterPoint has been lasting and beneficial to the GHP. CenterPoint Energy is one of the nine (9) Executive Partners contributing at the highest levels (\$100,000 and above) to sustain the GHP. The other Executive Partners include BP America, Inc.; Chevron; Conoco Phillips; Exxon Mobil; Shell Oil Company; Reliant, an NRG Company; AT\&T; and JPMorgan Chase (GHP partners list, 2012). As the Executive Partners list reveals, energy sector corporations remain at the top of the GHP hierarchy. The table below depicts the constitution of the membership roster for the GHP.

\begin{tabular}{|l|l|r|}
\hline \multicolumn{3}{|c|}{ GHP Membership Levels } \\
\hline Membership Level & \multicolumn{1}{|c|}{ Dollar Range } & Number of Firms \\
\hline Executive Partner & $\$ 100,000$ and above & 9 \\
\hline Managing Partner & $\$ 50,000-\$ 99,999$ & 21 \\
\hline General Partner & $\$ 25,000-\$ 49,999$ & 44 \\
\hline Partner & $\$ 10,000-\$ 24,999$ & 98 \\
\hline Limited Partner & $\$ 3,000-\$ 9,999$ & 248 \\
\hline Investor & $\$ 550-\$ 29,999$ & 1,000 \\
\hline
\end{tabular}

Table 32. Private Sector Contributors to GHP

In the detailed reports of the GHP membership, the absence of cities and county governments is notable. The GHP is truly a private membership operation. The ability of the GHP to operate an EDO with a staff of 85 personnel is the result of its broad and generous membership base. From membership dues alone, assuming the low end of the possible contributions from the table above, the GHP generates at least $\$ 4,450,000$ annually. The GHP also has an endowment fund known as Opportunity Houston. According to a January 14, 2008 press release, during Phase 1 of the campaign, the GHP 
raised "the largest total raised by any such organization in the U.S.," a record $\$ 30$ million (Greater Houston partnership.2012).

According to a senior economic development official, the GHP has a very positive relationship with the Texas Governor's office. If a prospect has an interest in the Houston region, the Governor's staff will hand off the lead to the GHP, and the GHP will work with the local EDOs to find a good fit for the firm (Richard, 2012). In turn, the GHP often supports foreign missions led by the Governor, and hosts an annual regional luncheon featuring the Governor of Texas.

The GHP has a special program dedicated to promoting events that allow its members to network with business colleagues and prominent officials. The "Signature Events" of the GHP include the following: Regional Delegation Dinner; State of METRO; State of the Airports; State of the City; State of the County; State of the Port; State of the Senate; State of the State; and the World Trade Soirée. All of these events are designed to afford members access to the major public figures of the region (Greater Houston partnership.2012).

The "Signature Events" also provide a forum for the GHP leadership to remind the public officials of the importance of maintaining and improving the infrastructure of the region to ensure Houston remains globally competitive. The purpose and intent of the GHP is always focused on ensuring and increasing the prosperity of the Houston region. According to the strategic plan of the organization, the primary purpose of the GHP is to brand Houston as a Business Magnet. To accomplish this feat, the GHP promotes "specific initiatives by highlighting opportunities and advancements within each industry 
segment to companies and organizations, nationally and globally" (Greater Houston partnership 2005-2012 strategic plan, 2005) .

As evidence of the international cachet of the Houston region, a senior economic development official pointed to the generous gift of \$150 million to the MD Anderson Cancer Center from the United Arab Emirates (Moukheiber, 2011); the May 30, 2012 decision by the City Council to add international flights at Hobby Airport (Moran, 2012); and the fact that Houston has nearly as many foreign consulates as Los Angeles and Chicago (Foreign consular offices in the united states, 2012)(Richard, 2012). The global economic development prowess of the GHP is certainly enhanced by the ability to leverage the working investment fund that exceeds \$30 million (Greater Houston partnership, 2012).

5.5 Sub-regional Economic Development Organizations

There are two (2) multi-county EDOs and ten (10) local EDOs active in the Houston MSA (Gulf Coast Economic Development District, 2009) . The Economic Alliance - Port Region and the Bay Area Houston Partnership serve multi-county jurisdictions.

The Economic Alliance - Port Region is a professional EDO that serves sixteen communities adjacent to the 25-mile long Houston shipping channel. The economic clusters that define the port region effectively bond the 16 communities in the coverage area. The EDO concentrates on two (2) dominant economic clusters: 1) Refining and Petrochemical Manufacturing; and 2) Maritime-International Trade (The economic alliance.2012). 
More than 125 energy companies operate in this industrial region. The EDO reports that Port Region hosts the largest complex of petrochemical-manufacturing facilities in the nation (The economic alliance.2012). The growth of the energy sector in the Houston MSA has not been impeded by environmental protectionist policies. There is a prevailing view among the EDO officials that the environmental risks associated with petrochemical manufacturing are acceptable in light of the extraordinary economic benefits for the region (Wilkins, 2012). The civic motto of one Harris County waterfront community aptly summarizes this sentiment: "The City of Baytown: Where Oil and Water Really Do Mix” (Baytown, texas.2012).

The majority of the municipalities that participate in The Economic Alliance Port Region EDO are located in Harris County. The EDO is supported by the member cities and Harris County to help prospects "navigate through incentive process such as tax abatements and more" (The economic alliance.2012). Indeed, the website for the EDO prominently lists the Harris County tax abatement incentives. In addition to a number of major petrochemical companies, such as Chevron Phillips, Dow Chemical Company, DuPont, Exxon Mobil, and Shell Chemical Company, the membership of the EDO includes CenterPoint Energy, the GHP, and the Bay Area Houston Economic Partnership (The economic alliance.2012).

The Bay Area Houston Economic Partnership is the other multi-county subregional EDO in the Houston MSA. The geographic area for the Bay Area Houston Economic Partnership overlaps much of the coverage area of The Economic AlliancePort Region. The regional focus is on Galveston and Harris counties and the Port of Houston. Several cities within this sub-region are active in both organizations (Pasadena, 
Houston, La Porte, and Seabrook). The primary distinction between these two (2) subregional EDOs is the cluster industry targeting. The target industries for The Bay Area Houston Economic Partnership include: Aerospace Engineering; Bioscience /

Biotechnical Research and Development; Chemicals and Plastics; and Health Care (Bay area Houston economic partnership.2012).

The other major difference in the two sub-regional organizations is the industry membership. In the 2009 Membership Report from The Bay Area Houston Economic Partnership, the petrochemical industries are not dominant. Municipalities provided $45 \%$ of revenues, and Aerospace industries contributed $15 \%$ of revenues. The remaining categories of contributors include: Consumer Products (8\%), Construction (1\%), Education (3\%), Finance (6\%), Healthcare (3\%), Hospitality (3\%), Manufacturing (2\%), Professional (7\%), Real Estate (5\%), and Utilities (1\%) (Bay area Houston economic partnership.2012).

The collaboration among the sub-regional EDOs in the region is evident in examining the membership rosters. Just as the GHP and the Bay Area Houston Economic Partnership are members of The Economic Alliance - Port Region, both the GHP and The Economic Alliance - Port Region are listed as members of the Bay Area Houston Economic Partnership (Bay area Houston economic partnership.2012). And, the local EDOs of the Houston MSA are all identified as Allies of the GHP. The table below lists the local EDOs active in the Houston MSA. The GHP identifies all of these organizations as Economic Development Allies (Greater Houston partnership.2012). 


\begin{tabular}{|l|l|c|}
\hline \multicolumn{3}{|c|}{ GHP Economic Development Allies } \\
\hline County & \multicolumn{1}{|c|}{ Economic Development Organization } & $\begin{array}{c}\text { GHP } \\
\text { Allied }\end{array}$ \\
\hline Multiple & The Economic Alliance - Port Region & Yes \\
\hline Multiple & Bay Area Houston Economic Partnership & Yes \\
\hline Austin & Sealy Economic Development Corporation & Yes \\
\hline Brazoria & $\begin{array}{l}\text { The Economic Development Alliance for Brazoria } \\
\text { County }\end{array}$ & Yes \\
\hline Chambers & Baytown-West Chambers County E.D. Foundation & Yes \\
\hline Fort Bend & Greater Fort Bend Economic Development Council & Yes \\
\hline Galveston & Galveston County Economic Alliance & Yes \\
\hline Galveston & Galveston Economic Development Partnership & Yes \\
\hline Harris & Katy Area Economic Development Council & Yes \\
\hline Montgomery & Economic Development Partnership & Yes \\
\hline Montgomery & Greater Conroe Economic Development Council & Yes \\
\hline Waller & Waller County Economic Development Partnership & Yes \\
\hline
\end{tabular}

Table 33. Allies of the Greater Houston Partnership

The EDOs of the Houston region appear to be truly collaborating with each other. As one member of the Bay Area Houston Economic Partnership put it: "Every community in the region is focused on trying to develop economic activity for their particular jurisdiction, but most folks know it is counterproductive to be territorial. You have to cooperate. If a prospect doesn't work out for your community, you have to try to get them to locate in the region. And if it doesn't work out for the region, you have to try to get them to locate in the state" (Tollett, 2012) .

\subsection{Houston-Galveston Area Council}

Regional cooperation in the public sector has been institutionalized for more than 45 years. In 1966, the local government officials of the 13-county Upper Gulf Coast Region of Texas formed the Houston-Galveston Area Council (H-GAC) (Gulf Coast Economic Development District, 2009). With the exception of San Jacinto County, the 
other nine (9) counties of the Houston MSA are represented on the H-GAC. The nonHouston MSA jurisdictions that are included on the H-GAC are Colorado, Matagorda, Walker and Wharton counties.

The H-GAC counties coordinate local government activities across a full spectrum of service lines: transportation and air quality; community and environmental; public safety and security; human services; cooperative purchasing; and regional data and GIS (Houston-Galveston area council.2012). To meet federal transportation requirements, the $\mathrm{H}-\mathrm{GAC}$ is designated as the Metropolitan Planning Organization for Brazoria, Chambers, Fort Bend, Galveston, Harris, Liberty, Montgomery and Waller counties. In a similar vein, the H-GAC is co-designated to address federal economic development requirements.

The 13-counties of the H-GAC are co-designated as a federal region known as the Gulf Coast Economic Development District (GCEDD). The GCEDD was officially incorporated in the State of Texas in 1988 to formulate the federal Comprehensive Economic Development Strategy (CEDS) (Gulf Coast Economic Development District, 2009). This function is consistent with the purposes of the regional councils, which is to "make studies and plans to guide the unified, far-reaching development of a region, eliminate duplication, and promote economy and efficiency in the coordinated development of a region” (Texas Code Chapter 391, 2012).

The cluster analysis for the 13-county region reported in the CEDS identified several clusters that overlap with the findings of earlier Texas studies and the industry clusters that have been targeted by the Governor's office: business and financial; distribution, transportation and logistics; biotechnology and medical; energy, petroleum 
refining and chemical; information technology and communications; and manufacturing (Gulf Coast Economic Development District, 2009). As noted earlier, these sectors are also covered by the strategic plans of the GHP, the Bay Area Houston Economic Partnership, and the Economic Council- Port Region.

The regional vision and goals of the GCEDD are in keeping with the entity's primary functions to: 1) coordinate the economic development activities of the planning region, 2) provide technical assistance to economic development organizations of the region, and 3) maintain the region's eligibility to apply for economic development grants and assistance from the Economic Development Administration (EDA) The regional vision of the GCEDD is succinctly stated: The Board envisions a healthy regional economy, diversified among a variety of sectors, poised to accommodate economic development of the future, with unprecedented opportunities to the citizens of the Gulf Coast (Gulf Coast Economic Development District, 2009).

The four (4) goals adopted by the GCEDD to achieve the vision are: 1) Promote coordination among local economic development efforts; 2) Advocate economic development projects and programs of benefit to the Gulf Coast region; 3) Facilitate access to relevant economic and business data to support economic development activities; and 4) Work to raise awareness of issues affecting quality growth and development across the region (Gulf Coast Economic Development District, 2009) . As the goals suggest, the GCEDD is dedicated to serving as a collaborative resource to ensure public officials are properly informed of the economic development opportunities and initiatives across the entire region. According to a senior staff member of the H- 
GAC, "Our organization works to enhance cooperation throughout the region. It is the primary purpose of the Council” (Wemple, 2012).

It is important to note that the $\mathrm{H}-\mathrm{GAC}$, though it fulfills critical duties as a regional board, is a voluntary association of local governments. The Texas Code authorizes the association, but does not mandate participation. Funding for the H-GAC is derived from a population formula that is used to assess fees from the participating governments. There are currently 36 local elected officials who serve as the Board of Directors for the H-GAC (Houston-Galveston area council.2012). By virtue of the decision by so many local governments to fund the H-GAC, it is reasonable to infer that the local public officials of the Houston MSA value collaboration.

\subsection{Social Capital Survey Results}

In the Houston MSA, 21 recipients of the two-minute, nine-question electronic survey responded. The survey was sent to 45 elected officials and 58 economic development professionals in the region. Many of the economic development officials had offered to circulate the survey among their peers. Discounting this possible wider audience that may have received the survey, a total of 21 responses for 103 direct recipients is a response rate of $20 \%$. This low response rate is a very generous calculation. The results of this survey are being reported, though the response rate was below expectations. 


\subsubsection{The Discovery Phase}

The respondents in the Houston MSA gave very positive responses to the statements designed to gauge the degree of reciprocity, reputation and trust within the discovery phase of a transaction. This high degree of comfort relative to the free exchange of quality information between and among the respondents suggests a storehouse of social capital available in the Houston MSA.

\begin{tabular}{|l|c|c|}
\hline $\begin{array}{l}\text { Statement \#1: I have regular communications with my colleagues } \\
\text { from other counties in the region. }\end{array}$ & $\begin{array}{c}\text { Response } \\
\text { Percent }\end{array}$ & $\begin{array}{c}\text { Response } \\
\text { Count }\end{array}$ \\
\hline Answer Options & $9.5 \%$ & 2 \\
\hline strongly disagree & $0.0 \%$ & 0 \\
\hline disagree & $4.8 \%$ & 1 \\
\hline somewhat disagree & $19.0 \%$ & 4 \\
\hline somewhat agree & $47.6 \%$ & 10 \\
\hline agree & $19.0 \%$ & 4 \\
\hline strongly agree & answered question & $\mathbf{2 1}$ \\
\hline \multicolumn{2}{|r|}{ skipped question } & $\mathbf{0}$ \\
\hline \multicolumn{2}{|r|}{}
\end{tabular}

Table 34. Response \#1, Houston MSA

An overwhelming majority $(85.6 \%)$ responded positively to the query about reciprocal information exchange. Less than $10 \%$ of the respondents indicated they strongly disagree with the statement about regular communication with their colleagues from other counties in the region. The results for statement \#1 are listed in table 35.

Those surveyed were very favorable when expressing views regarding the reputation of their colleagues for being responsive to requests for information. As the table below reveals, over $90 \%$ gave positive responses to statement \#2. In the Houston MSA, the results suggest there is every expectation that one's colleagues will be 
cooperative in providing information. Given this wealth of social capital in the reputation category, the discovery phase of a transaction should proceed easily.

\begin{tabular}{|l|c|c|}
\hline \multicolumn{3}{|c|}{$\begin{array}{l}\text { Statement \#2: When it comes to sharing information, my colleagues } \\
\text { from other counties in the region have been very cooperative. }\end{array}$} \\
\hline Answer Options & $\begin{array}{c}\text { Response } \\
\text { Percent }\end{array}$ & $\begin{array}{c}\text { Response } \\
\text { Count }\end{array}$ \\
\hline strongly disagree & $4.8 \%$ & 1 \\
\hline disagree & $0.0 \%$ & 0 \\
\hline somewhat disagree & $0.0 \%$ & 0 \\
\hline no opinion / non-applicable & $4.8 \%$ & 1 \\
\hline somewhat agree & $14.3 \%$ & 3 \\
\hline agree & $47.6 \%$ & 10 \\
\hline strongly agree & $28.6 \%$ & 6 \\
\hline & answered question & $\mathbf{2 1}$ \\
\hline & skipped question & $\mathbf{0}$ \\
\hline
\end{tabular}

Table 35. Response \#2, Houston MSA

\begin{tabular}{|l|c|c|}
\hline \multicolumn{3}{|l|}{$\begin{array}{l}\text { Statement \#3: Information I receive from my colleagues in other } \\
\text { counties of our region is reliable and dependable. }\end{array}$} \\
\hline Answer Options & $\begin{array}{c}\text { Response } \\
\text { Percent }\end{array}$ & $\begin{array}{c}\text { Response } \\
\text { Count }\end{array}$ \\
\hline strongly disagree & $4.8 \%$ & 1 \\
\hline disagree & $0.0 \%$ & 0 \\
\hline somewhat disagree & $0.0 \%$ & 0 \\
\hline no opinion / non-applicable & $4.8 \%$ & 1 \\
\hline somewhat agree & $4.8 \%$ & 1 \\
\hline agree & $52.4 \%$ & 11 \\
\hline strongly agree & $33.3 \%$ & 7 \\
\hline \multicolumn{2}{|c}{ answered question } & $\mathbf{2 1}$ \\
\hline skipped question & $\mathbf{0}$ \\
\hline
\end{tabular}

Table 36. Response \#3, Houston MSA

Table 36 above confirms a high level of trust regarding the exchange of

information In the discovery phase, the respondents in the Houston MSA report a regular, reciprocal exchange of information, acknowledge their colleagues have a good reputation for responding to requests for information, and they trust the accuracy of the information 
that is provided. More than $90 \%$ responded favorably to statement \#3 of the survey. This very high rating of trust bodes well for any collective action transactions in the Houston MSA.

\subsubsection{The Negotiation Phase}

The responses to questions 4, 5, and 6 of the survey suggests the Houston MSA leaders hold a favorable amount of social capital (reciprocity, reputation and trust) that would be useful in negotiation phase of a transaction. Question 4 seeks to measure the reciprocity in solving problems that has occurred in the region. While the responses are $90 \%$ favorable, it is worth noting that $35 \%$ only somewhat agree with the statement.

\begin{tabular}{|l|c|c|}
\hline $\begin{array}{l}\text { Statement \#4: Working across county boundaries, regional problems } \\
\text { get resolved in a fair and reasonable way. }\end{array}$ \\
\hline Answer Options & $\begin{array}{c}\text { Response } \\
\text { Percent }\end{array}$ & $\begin{array}{c}\text { Response } \\
\text { Count }\end{array}$ \\
\hline strongly disagree & $0.0 \%$ & 0 \\
\hline disagree & $0.0 \%$ & 0 \\
\hline somewhat disagree & $10.0 \%$ & 2 \\
\hline somewhat agree & $35.0 \%$ & 7 \\
\hline agree & $40.0 \%$ & 8 \\
\hline strongly agree & $15.0 \%$ & 3 \\
\hline Other (please specify) & 2 \\
\hline \multicolumn{2}{|c|}{ answered question } & $\mathbf{2 0}$ \\
\hline \multicolumn{2}{|c|}{ skipped question } & $\mathbf{1}$ \\
\hline
\end{tabular}

Table 37. Response \#4, Houston MSA

The reputation for negotiating solutions to regional problems also scores very high in the survey. As the results in Table 38 show, $90 \%$ of the respondents expressed favorable views regarding the capacity of the region to effectively address problems. This degree of confidence in the ability to work across county lines to address regional issues suggests the Houston MSA has a strong reservoir of social capital to draw upon during the negotiation phase to resolve any possible social dilemma. 
There is also a very high regard for the reputation of community leaders to collaborate to solve regional problems. Statement \#5 [see table 39] reveals more than $90 \%$ of respondents have a favorable opinion of their colleagues' ability to come together and address regional issues.

\begin{tabular}{|c|c|c|}
\hline \multicolumn{3}{|c|}{$\begin{array}{l}\text { Statement \#5: I am confident in the way our communities come } \\
\text { together to handle regional issues. }\end{array}$} \\
\hline Answer Options & $\begin{array}{c}\text { Response } \\
\text { Percent }\end{array}$ & $\begin{array}{c}\text { Response } \\
\text { Count }\end{array}$ \\
\hline strongly disagree & $0.0 \%$ & 0 \\
\hline disagree & $4.8 \%$ & 1 \\
\hline somewhat disagree & $4.8 \%$ & 1 \\
\hline somewhat agree & $23.8 \%$ & 5 \\
\hline agree & $47.6 \%$ & 10 \\
\hline strongly agree & $19.0 \%$ & 4 \\
\hline \multicolumn{2}{|c|}{ answered question } & 21 \\
\hline \multicolumn{2}{|c|}{ skipped question } & $\mathbf{0}$ \\
\hline
\end{tabular}

Table 38. Response \#5, Houston MSA

Perhaps of more importance during the negotiation phase of a transaction is the element of trust. Not one of the survey respondents expressed negative views of the sincerity or trustworthiness of their colleagues. Though $4.8 \%$ registered no opinion on the 'trust' statement, the finding that more than $95 \%$ of the respondents trust their counterparts to negotiate in good faith is a very positive result.

\begin{tabular}{|c|c|c|}
\hline \multicolumn{3}{|c|}{$\begin{array}{l}\text { Statement \#6: In discussions about regional issues, my colleagues from } \\
\text { other counties do their best to accurately represent the views of their } \\
\text { community. }\end{array}$} \\
\hline Answer Options & $\begin{array}{c}\text { Response } \\
\text { Percent }\end{array}$ & $\begin{array}{c}\text { Response } \\
\text { Count }\end{array}$ \\
\hline strongly disagree & $0.0 \%$ & 0 \\
\hline disagree & $0.0 \%$ & 0 \\
\hline somewhat disagree & $0.0 \%$ & 0 \\
\hline no opinion / non-applicable & $4.8 \%$ & 1 \\
\hline somewhat agree & $14.3 \%$ & 3 \\
\hline agree & $52.4 \%$ & 11 \\
\hline strongly agree & $28.6 \%$ & 6 \\
\hline \multicolumn{2}{|c|}{ answered question } & 21 \\
\hline \multicolumn{2}{|c|}{ skipped question } & 0 \\
\hline
\end{tabular}

Table 39. Response \#6, Houston MSA 


\subsubsection{The Conclusion Phase}

In the conclusion phase of the survey, the Houston MSA respondents expressed a very positive view of the accrued social capital elements of reciprocity, reputation and trust. The recorded scores for the series of statements (\#7, \#8 and \#9) relative to the conclusion phase were beyond $80 \%$ favorable across the series. The conclusion phase of a transaction is inherently the most critical, and positive findings in this phase of the survey are of particular interest.

The respondents expressed very favorable views of the ability of the counties in the region to interact to address regional concerns. The degree of confidence in the ability of jurisdictions to engage in reciprocal exchanges for the greater good of the region is certainly high. Over $90 \%$ of those surveyed noted favorable responses to the statement (\#7) about reciprocity in the conclusion phase of a transaction.

\begin{tabular}{|l|c|c|}
\hline \multicolumn{3}{|l|}{$\begin{array}{l}\text { Statement \#7: If a regional approach is the best way to address a } \\
\text { particular situation, our counties will cooperate to get the job done. }\end{array}$} \\
\hline Answer Options & $\begin{array}{c}\text { Response } \\
\text { Percent }\end{array}$ & $\begin{array}{c}\text { Response } \\
\text { Count }\end{array}$ \\
\hline strongly disagree & $0.0 \%$ & 0 \\
\hline disagree & $0.0 \%$ & 0 \\
\hline somewhat disagree & $4.8 \%$ & 1 \\
\hline no opinion / non-applicable & $4.8 \%$ & 1 \\
\hline somewhat agree & $23.8 \%$ & 5 \\
\hline agree & $47.6 \%$ & 10 \\
\hline strongly agree & $19.0 \%$ & 4 \\
\hline \multicolumn{2}{|r|}{ answered question } & $\mathbf{2 1}$ \\
\hline \multicolumn{2}{|r}{ skipped question } & $\mathbf{0}$ \\
\hline
\end{tabular}

Table 40. Response \#7, Houston MSA

The officials in the Houston MSA have a very favorable reputation for concluding transactions to benefit the region. While over $81 \%$ expressed a favorable opinion on this 'reputation' statement, it was the lowest scoring response in the entire survey. To the 
extent that almost $20 \%$ of the respondents do not have confidence in the ability of officials to conclude an agreement, there is some minor pause for concern.

\begin{tabular}{|c|c|c|}
\hline \multicolumn{3}{|c|}{$\begin{array}{l}\text { Statement \#8: Once a fair solution to a regional problem has been } \\
\text { found, getting all the officials from the different local jurisdictions to } \\
\text { bless it is relatively easy }\end{array}$} \\
\hline Answer Options & $\begin{array}{c}\text { Response } \\
\text { Percent }\end{array}$ & $\begin{array}{c}\text { Response } \\
\text { Count }\end{array}$ \\
\hline strongly disagree & $4.8 \%$ & 1 \\
\hline disagree & $4.8 \%$ & 1 \\
\hline somewhat disagree & $9.5 \%$ & 2 \\
\hline somewhat agree & $42.9 \%$ & 9 \\
\hline agree & $33.3 \%$ & 7 \\
\hline strongly agree & $4.8 \%$ & 1 \\
\hline \multicolumn{2}{|l|}{ Other (please specify) } & 1 \\
\hline \multicolumn{2}{|c|}{ answered question } & 21 \\
\hline \multicolumn{2}{|c|}{ skipped question } & $\mathbf{0}$ \\
\hline
\end{tabular}

Table 41. Response \#8, Houston MSA

\begin{tabular}{|c|c|c|}
\hline \multicolumn{3}{|c|}{$\begin{array}{l}\text { Statement\#9: The local jurisdictions of our region can be trusted to } \\
\text { honor any commitments they make }\end{array}$} \\
\hline Answer Options & $\begin{array}{c}\text { Response } \\
\text { Percent }\end{array}$ & $\begin{array}{c}\text { Response } \\
\text { Count }\end{array}$ \\
\hline strongly disagree & $0.0 \%$ & 0 \\
\hline disagree & $0.0 \%$ & 0 \\
\hline somewhat disagre & $0.0 \%$ & 0 \\
\hline somewhat agree & $28.6 \%$ & 6 \\
\hline agree & $42.9 \%$ & 9 \\
\hline strongly agree & $28.6 \%$ & 6 \\
\hline \multicolumn{2}{|c|}{ Other (please specify) } & 0 \\
\hline \multicolumn{2}{|c|}{ answered question } & 21 \\
\hline \multicolumn{2}{|c|}{ skipped question } & $\mathbf{0}$ \\
\hline
\end{tabular}

Table 42. Response \#9, Houston MSA

While there is not a unanimous positive opinion regarding the ability of officials to conclude an agreement, $100 \%$ of the respondents trust the counties to honor the terms of any agreement that reaches a favorable conclusion. The final statement of the survey (\#9) did not record anyone registering disagreement. 
To the extent that it can be inferred from these survey respondents that their views reflect the opinion of the key community leaders engaged in economic development cooperation in the Houston MSA, it is reasonable to conclude that there is an abundance of social capital at their disposal. In this survey, at every stage of a transaction (discovery, negotiation, and conclusion) the elements of social capital (reciprocity, reputation, and trust) were recorded to be very high.

5.8 The Dependent Variable: Regional Economic Development Cooperation The Houston MSA is an economic region of the United States that is fueled by cooperation in the economic development arena. The GHP is a private regional EDO with tremendous resources that defines its service area as the 10-counties of the Houston MSA (Greater Houston partnership.2012) . The GHP belongs to, and supports, the two (2) sub-regional multi-county EDOs that are active within its service area (Bay area Houston economic partnership.2012; the economic alliance.2012). The GHP has partnered with CenterPoint Energy to provide training to build professional capacity among the economic development professionals of the region. The GHP refers to the local EDOs of the Houston MSA as Allies (GHP partners list2012).

Public officials of the region voluntarily participate in the regional commission known as the Houston-Galveston Area Council (H-GAC). There are 36 local officials from a 13-county region that overlaps $90 \%$ of the counties in the Houston MSA actively engaged in cooperative efforts to improve the quality of life throughout the region (Houston-Galveston area council.2012) . The H-GAC is the umbrella organization for the Gulf Coast Economic Development District (GCEDD). 
The GCEDD is the entity responsible for production of the Comprehensive Economic Development Strategy (CEDS) for the region. The CEDS is a compilation of the demographics, economic assets, industry cluster data and economic activities occurring in the region. The CEDS is an excellent resource for local officials in the region, and is also a document required by the federal government in order for the member counties to be eligible recipients of federal economic development assistance (Gulf Coast Economic Development District, 2009) .

At the conclusion of the review of all relevant material, a visit to the region, conversations and interviews with a wide range of economic development professionals, and the opportunity to weigh the results of the other two cases, it is clear that the Houston MSA has achieved greater degree of regional economic development cooperation than the MSAs of Atlanta and Miami. This comparative case research study finds the Houston MSA to be a region that has clearly embraced the concept of regional economic development cooperation.

\subsection{Conclusion}

The fundamentals of regional economic development cooperation, the utilization of region-wide economic data in support of a unified marketing strategy, are institutionalized in the operations of the Greater Houston Partnership (GHP). Regional economic development cooperation is definitely occurring in the Houston MSA. A long history of collaboration among the public officials of the region, dating back to the formation of the Houston-Galveston Area Council in 1966, may have provided a template for the private sector to take a regional approach to economic development. 
In the same way that the Texas Legislature ordained the establishment of the Area Council and provided for voluntary membership of local governments, the GHP declared its purview to be the ten counties of the MSA and then sought to ally its operations with the local EDOs in the counties. As a largely private sector initiative, the factors that typically impede such regional cooperation and give rise to social dilemmas had little impact on the formation of the Greater Houston Partnership.

The community profile characteristics revealed various challenges that would be expected to inhibit regional cooperation. Economic heterogeneity throughout the region is one such challenge. There is a $91.8 \%$ median income differential between the low of $\$ 42,043$ in San Jacinto County and the high of $\$ 80,638$ in Fort Bend County. There are no council-manager forms of government among the counties of the region, the form of government that increases the likelihood of cooperation (Feiock, Steinacker, \& Park, 2009). The MSA is also somewhat politically fragmented, first by the ten county governments that constitute the MSA, and again by the 144 cities of the region.

The challenges listed above might have impeded a formal agreement among the public entities, but these factors did not limit the ability of the private sector to move forward with a regional plan. In this particular case, due to the Constitutional prohibition on public subsidies to the private sector development interest that existed at the time, there was no need to engage local governments in the initiative to develop a regional economic strategy. The provisions of the Constitution effectively sidelined local governments from the economic development process. The downtown business community of Houston was largely able to develop a plan and implement it without addressing local political considerations. 
The decision to merge three (3) different economic development organizations that were active in downtown Houston into one entity, and then declare the service area to be the entire 10-county MSA was a bold move by the private sector. The subsequent decision to partner with the regional electric utility to offer services and training to the local economic development organizations of the ten (10) counties in the MSA was a strategy that worked. The GHP, though emanating from the City of Houston in Harris County, where $70 \%$ of the population in the Houston MSA resides, has become an ally of every economic development organization in the region.

The GHP conducts research and distributes information regarding the industry clusters of the region to its allies, uses its corporate endowment to promote the region globally to prospective employers, and acts as a powerful lobby in the State Capitol. In the early years of its operation, the GHP lobbied to have the voters of Texas amend the Constitution and make possible economic development incentives. Local governments, particularly cities and school districts, have since become very cooperative in assembling incentive packages for prospect employers. Now, Texas leads the nation as the most generous source of economic incentives to business (Story, 2012).

According to the survey responses received, social capital among the Houston MSA stakeholders identified in this study is bountiful. The positive responses suggest there are sufficient reserves to overcome difficulties at every stage of a possible collective action transaction. However, given the primacy of the business community in the economic development arena, the need to expend this social capital to overcome the politics of local government jurisdictions may never arise. The foundations for regional 
economic development cooperation were set by the private sector and seem fixed in the Houston MSA.

The interviews and site visits confirmed there is widespread commitment to regional economic prosperity, and a willingness to work together to advance the interests of the local community, the Houston region and the State of Texas (Tollett, 2012). From the interviews that were conducted for this study, there is also a continuing deference to the business community on matters relating to economic development policy.

As of this writing, a formal collective action agreement for the purposes of advancing economic development policies involving public and private sectors does not seem necessary in the Houston MSA. The centralized function of the GHP, in harmony with its allied local and sub-regional EDOs, is a model that has worked well to advance economic development programming for the entire region.

This research is not designed to evaluate the economic outcomes of regional cooperation, but it is worth noting that unemployment is relatively lower in the Houston MSA and the regional approach to economic development is institutionalized. However, it would be a reach to conclude that regionalism is the vehicle that has brought greater prosperity to Houston, relative to the MSAs of Atlanta and Miami.

Recall, the Houston MSA economy is buoyed by the very profitable energy sector and its related industries. And, the efforts to diversity the Houston economy since the recession of the 1980s has been greatly assisted by the advent of generous economic incentives bestowed on the private sector. As mentioned earlier in this chapter, the annual per capita expenditure on private sector incentives is Texas is roughly four (4) times the amount awarded to firms in Georgia or Florida. Excessive generosity that directly 
reduces the cost of operating a business has certainly created a favorable business climate in the Houston MSA. An argument could be made that the combination of regional economic development cooperation and the most generous incentive packages in the nation is a formula for economic prosperity. 


\section{CHAPTER 6 \\ ECONOMIC DEVELOPMENT COOPERATION IN THE MIAMI REGION}

\subsection{An Overview of the Miami MSA}

Regional cooperation for the purposes of economic development remains an elusive concept in the Miami MSA. Though the region has only three (3) counties, it is a rare occasion for the EDOs of the Miami-Dade, Broward and Palm Beach counties to collaborate for the economic benefit of the region. The three (3) counties of the Miami MSA were once unified within the boundaries of a single political division of the State of Florida known as Dade County. This much larger jurisdiction was subdivided by the Legislature early in the $20^{\text {th }}$ century (Annual report to bondholders.2010) .

In 1909, the Florida Legislature designated the northern portions of Dade County as Palm Beach County. Then, in 1915, Palm Beach County and Dade County each conceded equal sections between them to form Broward County (Annual report to bondholders 20102010). Since then, the name of Dade County has been changed to Miami-Dade County (Finefrock, 1997), but the geographic boundaries have remained firmly set. The current mayor of Miami-Dade County often quips, "The only man-made features visible from space are the Great Wall of China and the border between MiamiDade and Broward counties” (Gimenez, 2011).

From an economic development perspective, the wall-like division between the counties does seem firm and is rarely breached. In interviews with the senior staff of the respective county EDOs, there is one memorable incident of formal collective action on behalf of the region. A cooperative effort was underwritten with a grant from Enterprise Florida, the state economic development agency. With the proceeds of the grant, a 
brochure was produced, South Florida: Your Global Business Connection, and one joint promotion event to Canada was undertaken in 2009 (Broward EDO official.2012)(Miami EDO official2012)(Palm beach EDO official.2012). This may be the one and only qualifying event for regional economic development cooperation in the Miami MSA.

Despite the political and operational barriers, a relationship of sorts has evolved among the three EDOs of the region - the Beacon Council in Miami-Dade County; the Greater Fort Lauderdale Alliance in Broward County; and the Palm Beach Business Development Board in Palm Beach County. For many years, these agencies were in a very competitive posture, pilfering prospects across the county lines. In the late 1990s, the three (3) EDOs finally agreed to cooperate and abide by a regional détente on the practice of luring employers from within the region (Targeted Job Tax Incentives, 2012). Building upon this thin foundation of minimal cooperation, the three (3) EDOs have ventured forth to a state of constrained, limited collaboration.

The county EDOs of the Miami MSA have agreed to share information whenever a firm from another county expresses a desire to relocate (Miami EDO official2012). In essence, if one of the EDOs is approached to 'bid' for the relocation of a firm from within the three-county region, the EDO is to refer the firm back to the home-county EDO for a retention offer (Miami EDO official2012). This courtesy of notifying an EDO of the potential loss of an employer is an informal type of collaboration.

A more formal collaboration along these lines is reflected in the adoption of implementing Ordinances by the respective county governments for the Targeted Job Tax Incentive Program. In each case, there is protective language to deter firms from seeking incentives by merely changing their address within the Miami MSA. This formal 
collaboration in restricting the eligibility of firms will be discussed further in the following section of this Chapter (Targeted Job Tax Incentives, 2012).

The executives from the three (3) county EDOs do meet on a quarterly basis to share information and discuss regional opportunities (Greater Fort Lauderdale alliance.2012). In conversations with EDO officials, there is consistent reference to a Life Sciences Corridor running from the Scripps complex in Palm Beach, through Broward County and reaching the medical research facilities of the University of Miami in Miami-Dade County (Palm beach EDO official2012). The Public and Private Universities of the region, the Research Parks, and Research Institutes of the region are the formal leaders of this collaborative effort (Life sciences corridor.2012).

The President of Florida International University and the CEO of the Beacon Council of Miami-Dade County instigated the creation of Life Sciences South Florida, as the Life Science Corridor project is now known (Life sciences corridor.2012). It is worth noting that this fledgling regional exercise in economic development cooperation has no local politicians participating. The mission statement of Life Sciences South Florida appears to be carefully crafted to shield the county EDOs from being criticized for spending local resources on regional collaboration:

"Universities, state colleges, research institutes, and research parks will utilize our collective assets and facilitate collaborations with economic development councils and regional, state, national, and international industries, governments, and communities to promote innovation investment, entrepreneurship and economic growth in the areas of biotechnology, pharmaceuticals, diagnostics, and information technology to generate high-technology and high-paying employment" (Life sciences corridor.2012). 


\begin{tabular}{|l|c|}
\hline \multicolumn{2}{|c|}{ Miami MSA Industry Clusters } \\
\hline $\begin{array}{l}\text { Description } \\
\text { Arts, Entertainment, Recreation \& Visitor } \\
\text { Industries }\end{array}$ & $\begin{array}{c}\text { Lmployment } \\
\text { Transportation \& Logistics }\end{array}$ \\
\hline Business \& Financial Services & 1.33 \\
\hline Biomedical/Biotechnical (Life Sciences) & 1.20 \\
\hline Printing \& Publishing & 1.02 \\
\hline Apparel \& Textiles & 0.96 \\
\hline
\end{tabular}

Table 43. Industry Clusters of the Miami MSA

The industry cluster assessment for the region does indicate there is a location quotient advantage (1.02) for the Life Sciences sector in the Miami MSA (StatsAmerica.2012) . The real strength in the Miami MSA lies in the trade and tourism sectors. As the table above indicates, the location quotient advantage for the Visitor Industries, Transportation \& Logistics, and Business \& Financial Services sectors are all 1.20 or better. However, by sheer volume of employment opportunities, the Life Sciences sector plays a prominent role in the economy of the Miami MSA.

Coordinating economic development strategy among the three (3) counties is complicated by the legacy Regional Planning Councils that bisect the MSA region. The South Florida Regional Planning Council (SFRPC) and the Treasure Coast Regional Planning Council (TCRPC) are the responsible Florida agencies that formulate the Comprehensive Economic Development Strategy (CEDS) documents for U.S. Economic Development Agency within the Miami MSA (Treasure coast CEDS 2007-2012. 2007)(South Florida CEDS 2012-2017.2012). Miami-Dade and Broward counties are joined by Monroe County to form the SFRPC. Palm Beach County is within the 
jurisdiction of the TCRPC and is joined by Indian River, Martin and St. Lucie Counties (Florida regional planning councils.2012).

As expected, the determination of cluster industry configurations for the different groupings of counties yields divergent recommendations for economic development strategy. A comparison of the CEDS documents guiding the Miami MSA counties will be provided in a later section.

A recent initiative supported by both the SFRPC and the TCRPC to provide a common regional strategic plan for the entire seven-county Southeast Coast of Florida will also be discussed (Seven50: SE Florida prosperity.2012). The decision to merge the geographic coverage areas of these two historic Economic Development Districts for the purposes of the federally funded study is not an academic exercise only. Enterprise Florida, the state economic development agency, has now identified the seven-county Southeast Region as one of its eight (8) key regions (Enterprise florida.2012).

\subsection{Demographics and Characteristics of the Miami MSA}

The Miami MSA consists of three large counties stacked along the southeastern coast of Florida covering a combined land area of 5,077 square miles. The MSA hosts a population of 5,547,051 residents. At the bottom of the stack, Miami-Dade County is home to $45 \%$ of the population of the MSA; going north, Broward has $32 \%$ of the MSA population; and, at the northern end, the Palm Beach County, the largest county by square miles, is home to $23 \%$ of the MSA population (American community survey.2009). Table 45 below reflects the geographic top-to-bottom alignment of the counties within the Miami MSA. 


\begin{tabular}{|l|c|r|r|r|r|r|}
\hline \multicolumn{7}{|c|}{ Miami MSA Summary Table } \\
\hline County & \multicolumn{1}{c|}{ Pop. } & $\begin{array}{c}\text { Mq. } \\
\text { Miles }\end{array}$ & Density & Cities & Diversity & Gov. \\
\hline Palm Beach & $1,279,950$ & 1969.8 & 650 & 37 & 0.44 & CM \\
\hline Broward & $1,766,476$ & 1209.7 & 1460 & 31 & 0.33 & CM \\
\hline Miami-Dade & $2,500,625$ & 1897.7 & 1318 & 34 & 0.45 & CE \\
\hline Totals & $\mathbf{5 , 5 4 7 , 0 5 1}$ & $\mathbf{5 0 7 7 . 2}$ & $\mathbf{1 0 9 3}$ & $\mathbf{1 0 2}$ & $\mathbf{0 . 3 3}$ & \\
\hline
\end{tabular}

Table 44. County Summary Profiles of the Miami MSA

This stacked population distribution for the MSA is unlike the central urban core configuration found in the Houston MSA, and to a lesser degree in the Atlanta MSA. The urban centers of the Miami MSA appear as rungs in a stepladder. There are "downtown business interests" found in multiple downtowns: Miami, Fort Lauderdale, and West Palm Beach. Regional coordination on any issue is often hindered by an extensive discussion about where to meet.

Until the voters of Miami-Dade County approved a change in the Home Rule Charter in 1992, the Council-Manager form of government was common across the region. Effective in 1996, Miami-Dade County shifted to an Executive Mayor, hybrid form of government that continued to rely on the professional services of a County Manager. Then, January 23, 2007, the voters approved a referendum in Miami-Dade County conferring Strong Mayor authority on the elected mayor and eliminating the need for a professional manager (Miami-Dade charter.2012).

It is considered a favorable condition for regional cooperation to have the Council-Manager form of government across the jurisdictions, according to Feiock (2009). With the advent of the change to a strong mayor form of government in MiamiDade County, there is no uniformity in government structure across the region. It is worth noting that only evidence of collaboration among the three governments in the arena of 
economic development, the legislation adopted to prevent firms from qualifying for job tax credits by changing locations within the region (Targeted Job Tax Incentives, 2012), occurred before Miami-Dade County transitioned to a strong mayor form of government.

To the extent that common government structure may benefit collaborative efforts to achieve regional economic development cooperation, there is a possibility that strong mayors may govern all three (3) counties. Broward County has tried unsuccessfully to shift to a strong mayor form of government in the past, and civic interest in making the change has apparently not waned (Wallman, 2010). Even if future civic efforts result in a common government form across the three (3) counties, there is no guarantee that regional economic development cooperation would become a common governing priority for three (3) strong mayors.

Political fragmentation is another factor that is taken into consideration when evaluating the prospects for cooperation within a region. The findings of Feiock (2009) indicated the likelihood of cooperation is inversely related to the degree of fragmentation. The method for calculating the value is to divide the MSA population by the number of counties, and then divide that result by the number of cities within the MSA.

For comparison purposes, the higher the value indicates the MSA is relatively less fragmented. As noted earlier in the previous chapters, the Atlanta MSA reported a Fragmentation Value of 1,290 (the most fragmented) and the Houston MSA had a Fragmentation Value of 4,071 (less fragmented than the Atlanta MSA). The value calculated for the Miami MSA $(18,127)$ reveals the region is the least politically fragmented of the three MSAs in this study. In ranking the political fragmentation across the MSA regions using the formula for this research, Miami $<$ Houston $<$ Atlanta. 


$$
\frac{5,547,051(\text { pop. }) / 3(\text { cout }}{102(\text { cities })}
$$

The ethnic diversity of the population in the entire Miami MSA and among the member counties is another factor explored in this study. The Herfindahl Index, a mathematical formula utilized to gauge market share dominance within jurisdictions, is adapted for this study to assess the diversity of a region by ethnic demographic (NonHispanic White, Hispanic, Black or Asian). The index is stated in percentages, with a lower percentage indicating greater diversity - or less dominance by any particular ethnic class.

The Herfindahl Index rating overall for the Miami MSA is $33 \%$. Similar to the rating for the Houston MSA, this result suggest the population of the region is diverse, with no particular demographic disproportionately represented at the MSA level. Broward County has the exact same rating of $33 \%$ as the entire Miami MSA (see Table 45). Miami-Dade County has a rating of $45 \%$ and Palm Beach County has a score of $44 \%$. Though the diversity scores for Miami-Dade County and Palm Beach County are similar, the formula results are derived from a very different ethnic composition in each county.

In many ways, the counties of Miami-Dade and Palm Beach are at opposite ends of the spectrum in the composition of their diverse communities. Miami-Dade has a $62.5 \%$ Hispanic population. The Hispanic population of Palm Beach is only $18.5 \%$. The White, Non-Hispanic population constitutes $61.8 \%$ of Palm Beach. In Miami-Dade the White, Non-Hispanics are only $17.4 \%$ of the population. In both counties, the Black, 
Non-Hispanic population is between $15 \%$ and $18 \%$ and the Asian population is single digit percentages (American community survey.2009).

The middle county, Broward, has the most diverse population with a score of $33 \%$. The White, Non-Hispanic population of Broward is $45.5 \%$; Black, Non-Hispanics constitute 24.4\%; Hispanics make up 24.6\% of the population; and Asians constitute the remaining 3.1\% of the population (American community survey.2009). As the crossroads county within the MSA, Broward clearly has a population composition that reflects the greatest diversity.

The overall median household income for the Miami MSA is $\$ 47,350$ annually. Miami-Dade reports the lowest median household income among the three (3) counties: $\$ 42,969$ annually. Broward is in the middle, with a median household income of $\$ 51,731$ annually. Palm Beach is at the top for the region, reporting a median household income of $\$ 53,538$ (American community survey, 2009). From the perspective of economic heterogeneity, the differential in annual earnings for household across the three (3) counties of the MSA is a matter of $\$ 10,569$ annually, or a $19.7 \%$ difference. Feiock (2009) found that economic heterogeneity is a factor that diminishes the likelihood of cooperation. Relative to the findings of economic heterogeneity in the Houston MSA $(153 \%)$ and the Atlanta MSA (93\%), this is not a factor that challenges cooperation in the Miami MSA (19.7\%).

\subsection{Statutes, Regulations and Politics}

The most significant legislative action that has impacted regional cooperation in the Miami MSA can be traced to the funding mechanism for economic development 
organizations (EDOs). In 1986, the State Legislature authorized an additional Local Business Tax that could be collected in certain counties, with the proceeds dedicated to an EDO serving the county (Local Business Taxes, 2012). Two county EDOs in the Miami MSA benefit from this dedicated funding mechanism. One does not. The two county EDOs that receive these dedicated funds, the Beacon Council of Miami-Dade County and the Greater Fort Lauderdale Alliance (the Alliance) of Broward County, have a direct and dependent affiliation with their respective county governments.

The Business Development Board (the BDB) of Palm Beach County does not receive dedicated funding from the Palm Beach County government, but there is a publicprivate partnership involving the transfer of funds. This partnership did not emerge under the auspices of the State Legislature. This economic development public-private partnership is a voluntary association between the BDB and the Palm Beach County government, negotiated as an arm's length contract to further mutual interests (Miami EDO official.2012).

The county-centric funding mechanisms, and the subordinate affiliation of the EDOs with the governing bodies of the counties, is a possible factor that constrains the opportunities for regional collaboration in the Miami MSA. Several senior EDO officials expressed the importance of having the political leadership out front on the issues of regional economic development cooperation (Miami EDO official, 2012)(Palm beach EDO official, 2012)(Broward EDO official, 2012).

There was one period of time during the years 1999-2000 where the elected officials of all three counties embraced a policy regarding economic cooperation and the use of incentives. Miami-Dade County Commissioner Jimmy Morales spearheaded an 
initiative to get all three counties to "agree not to use county funds as incentives to cause a business to relocate from one county to another county" (Morales, 1999). Working with the leadership of the three (3) county EDOs, regional cooperation was embraced, for a moment, by the elected leadership of the counties.

As a result of the Morales initiative, all three (3) counties inserted language into the legislation implementing the Quality Targeted Industry (QTI) program that excludes firms from qualifying for the incentives by simply changing their regional address (Targeted Job Tax Incentives, 2012). Though the resolution sponsored by Morales and adopted by the Miami-Dade County Commission contained aspirational language suggesting the counties would "agree to encourage cooperative initiatives related to the regional economy," there has been no marked progress to note in the decade since (Morales, 1999). Without the political leadership, the financially dependent county EDOs of the region have been cautious in making regional overtures.

The Legislature had the best of intentions when it took action to authorize public funding of for certain EDOs in Florida. The Miami MSA was in dire economic straits and the civic leaders were clamoring for an institutional response during the critical juncture of the early 1980s. In November of 1981, the cover of TIME magazine asked the question that the civic leaders of the Miami MSA were struggling with: Paradise Lost? (Kelly, 1981). A sampling of the excerpts from this 1981 TIME cover story reveals the depth of the South Florida region's troubles:

- When the FBI issued its annual list of the ten most crime-ridden cities in the nation last September, three of them were in South Florida: Miami (pop. 347,000) was in first place, West Palm Beach (pop. 63,000) was fifth and Fort Lauderdale (pop. 153,000) was 
eighth. Miami last year had the nation's highest murder rate, 70 per 100,000 residents, and this year's pace has been even higher.

- An estimated $70 \%$ of all marijuana and cocaine imported into the U.S. passes through South Florida. Drug smuggling could be the region's major industry, worth anywhere from $\$ 7$ billion to $\$ 12$ billion a year (vs. \$12 billion for real estate and \$9 billion for tourism, the area's two biggest legitimate businesses). Miami's Federal Reserve branch has a currency surplus of \$5 billion, mostly in drug-generated $\$ 50$ and $\$ 100$ bills, or more than the nation's twelve Federal Reserve banks combined. Drug money has corrupted banking, real estate, law enforcement and even the fishing industry, whose practitioners are abandoning the pursuit of snapper and grouper for the transport of bales of marijuana ("square grouper, " as fishermen call it) from freighters at sea to the mainland.

- Since the spring of 1980, when Cuban President Fidel Castro opened the port of Mariel to those who wanted to leave, about 125,000 "Marielitos" have landed in South Florida. In addition, 25,000 refugees have arrived from Haiti; boatloads of half-starved Haitians are washing up on the area's beaches every week. The wave of illegal immigrants has pushed up unemployment, taxed social services, irritated racial tensions and helped send the crime rate to staggering heights. Marielitos are believed to be responsible for half of all violent crime in Miami (Kelly, 1981).

Beginning on May $17^{\text {th }}$ of 1980 , race riots wracked the region. Following the decision by an all white jury that City of Miami Police officers were not guilty in the beating death of Arthur McDuffie, an African American former U.S. Marine and successful salesman who had led the police on a high speed chase, the urban core went up 
in flames (Hampton, 1987). Businesses were burned to the ground. From an economic development perspective, the situation was a nightmare.

While other regions of the nation were contending with an economic recession in the earl 1980s, the Miami MSA was processing thousands of desperate refugees, tamping down racial tensions, and working with law enforcement to wean the regional economy off the profits of a lucrative illegal drug trade. It took civic leaders several years to grapple with this situation. As with any disaster, there is a period of rescue and recovery before the rebuilding begins. The request to the Florida Legislature for authorization to secure a revenue stream for economic development activities was eventually presented, and approved, during the 1986 Legislative Session (Feldstein Soto, 1986).

To aid the counties in the Miami MSA, the Florida Legislature adopted House Bill 453 allowing Home Rule Counties recognized in Section 125.011 of Chapter 125 of the Florida Statutes, "or any county adjacent thereto" to "levy and collect, by ordinance enacted by the governing body of the county, an additional business tax up to 50 percent of the appropriate business tax imposed under section (1)" (Local Business Taxes, 2012). Within the Miami MSA, the eligible counties were the Home Rule County of MiamiDade and the adjacent county of Broward. Both counties imposed the additional tax (Broward.org.2012).

The law further provided that: "Proceeds from the additional business tax must be placed in a separate interest-earning account, and the governing body of the county shall distribute this revenue, plus accrued interest, each fiscal year to an organization or agency designated by the governing body of the county to oversee and implement a comprehensive economic development strategy through advertising, promotional 
activities, and other sales and marketing techniques" (Local Business Taxes, 2012). In Miami-Dade County, the governing body designated the Beacon Council as the recipient of these funds; in Broward County, the Greater Fort Lauderdale Alliance (the Alliance) is the recipient of the additional business tax proceeds (Broward.org.2012).

The additional Local Business Tax proceeds provide vital, sustaining contributions to the Beacon Council and the Alliance. In 2011, the Broward County Commission negotiated a new five-year public / private economic development partnership agreement with the Alliance. Pursuant to the new agreement, Broward County allocated a base annual budget amount of $\$ 874,650$ to support the Alliance (Broward Economic Development Partnership Agreement, 2011). According to an audit published in $2011,38 \%$ of the Alliance's annual revenues $(\$ 2,048,500)$ are derived from the additional Local Business Tax proceeds collected and distributed by Broward County (Lukic, 2011).

Miami-Dade County has not updated the public / private partnership agreement with the Beacon Council since it was executed back on July $19^{\text {th }}$ of 1988 . The agreement remains in its original form pursuant to the terms of the ordinance enacting the additional Local Business Tax (Additional Tax on Local Business Tax, 2012). The agreement has been automatically renewed every year since 1988. During each annual budget cycle, the County Commission approves a single-line allocation of the proceeds from the additional local business. In 2012, as a routine matter associated with adopting the annual county budget, the Miami-Dade County Commission conveyed \$3,375,000 of Local Business Tax revenue to the Beacon Council (Gimenez, 2012). 
News reports about the Beacon Council have suggested that "more than half of the agency's annual budget" is derived from the additional local business tax (Mazzei, 2012). This is a very conservative representation of the amount of public funding that props up the Beacon Council. The information about the private sector support for the agency is very guarded and not normally published in the public domain. During the course of this research, one exception was discovered.

According to a report by the Miami-Dade County Commission Auditor, public funding constitutes between 78-80\% of the Beacon Council's annual budget. In FY 20072008 , the additional Local Business Tax contribution was $\$ 3,940,000$ and the overall annual budget for the agency was $\$ 5,026,000$. Public funds were $78.3 \%$ of the agency's annual budget. In the FY 2008-2009, the additional Local Business Tax contribution was $\$ 3,893,000$ and the agency's overall budget was $\$ 4,862,000$. That amounts to exactly $80 \%$ of the annual budget (Anderson, 2010).

The Business Development Board of Palm Beach County (the BDB) also receives substantial public funding support. The BDB does not receive any funding from an additional Local Business Tax. Palm Beach County, at the northern end of the stack, does not qualify as an "adjacent county" under the Statute that authorized the collection of the additional Local Business Tax (Local Business Taxes, 2012). Palm Beach County funds the BDB with general funds of the county.

In 2011, the BDB entered into a five (5) year agreement to provide "business recruitment, expansion and retention services and general marketing for Palm Beach County" worth an aggregate amount of $\$ 4,657,350$ (Agreement with BDB of Palm Beach County, 2011). In 2010, Palm Beach County allocated $\$ 1,049,750$ from the 
general funds of the county to support the programming of the BDB (Palm beach county budget 2010.2012). In 2010, the Palm Beach Post reported the other half of the BDB's $\$ 2.2$ million annual budget comes from the contributions of its 400 dues-paying corporate members (Eyman, 2010).

The three (3) EDOs that serve the three (3) counties of the Miami MSA are all dependent to varying degrees upon public funds for their operations. The Beacon Council of Miami-Dade is most dependent on the public sector, leveraging only $20-25 \%$ of its funds from the private sector. The Alliance of Broward County, with almost $40 \%$ of its funds banked from the public sector, raises over $60 \%$ of its support from the private sector. The BDB of Palm Beach has a balanced public-private partnership, operating with roughly $50 \%$ of its funds coming from the public and private sectors.

As a result of the financial dependence on local government, regional economic development cooperation among the counties of the Miami MSA is, for the most part, a decision that rests with the governing bodies of the counties. Absent a regional economic development cooperation accord entered into by the county commissions, it is unreasonable to expect the professional EDOs to advance beyond the county boundaries and expend resources to develop the regional industry clusters or promote the competitive advantages of the entire region. After all, the elected leadership of the counties controls a substantial portion of the resources that fund the operations of the county EDOs. Even though many of the EDO professionals expressed support for regional economic development cooperation, it is considered primarily a policy issue for the elected officials (Miami EDO official2012). In a way, it seems public funding serves as a policy leash restraining cooperation among the three (3) county economic development organizations. 
Evidence of this restraint in acting regionally is writ large by the recent One Community, One Goal strategic planning initiative undertaken by the Beacon Council in Miami-Dade County. The purpose of this project was to develop a targeted industries strategy to more effectively compete in the global economy. The executive summary of the report declares: Miami-Dade County is a truly international community with global brand recognition as the "Gateway to the Americas." Comparative communities and competitors include the likes of Rio De Janeiro, Toronto, Singapore, Hong Kong, Panama, Los Angeles, New York, Houston and Atlanta (One community, one goal.2012). The global competitors identified in the project are all regional economies.

In the benchmarking section of the One Community, One Goal report, it is clearly stated that "in most circumstances Miami-Dade County metrics were compared to US Census defined Metropolitan Statistical Areas (MSAs) or Metropolitan Divisions, which include central cities and surrounding counties considered an integrated part of the metro" (One community, one goal.2012). To the consultants responsible for preparing the assessment, it made eminent sense to select the economies of regional MSAs for benchmarking purposes. Yet there is no explanation offered for limiting the scope of this effort to one county within the Miami MSA.

A guest editorial that ran in the Miami Herald following the announcement of this one-county initiative urged the political leadership of Miami-Dade County to elevate the initiative to a regional level: "A coordinated effort with Broward and Palm Beach Counties to make this region more competitive in the global economy is urgently needed" (Murphy, 2011). The current mayor of Miami-Dade County, who serves as a co-chair of 
the One Community, One Goal program, was not persuaded (One community, one goal.2012).

\subsection{Regional Public Organizations}

There is not a single institution that has been identified by the local governments to coordinate economic development programming across the three (3) counties of the Miami MSA. In the absence of any such regional EDO, other regional public organizations of the MSA were reviewed to provide context for the assessment of the dependent variable in this case study region. The South Florida Regional Transportation Authority (SFRTA) is the best example of regional cooperation in the Miami MSA. The Comprehensive Economic Development Strategy (CEDS) developed by the regional planning councils, the Seven50 project, and the Southeast Florida Climate Change Compact will also be discussed.

The SFRTA provides a commuter rail service that connects the three (3) counties of the MSA. The authority was created on July 1, 2003. The (9) nine-member governing board includes one commissioner and one designee appointed from Miami-Dade, Broward and Palm Beach counties; a district secretary appointed by the FDOT Secretary, and two appointees by the Governor.

By law, each county is required to allocate several million dollars annually to partially match the FDOT support for this commuter rail service (Regional Transportation and Transit Authorities, 2012). The county contributions have historically accounted for about $20 \%$ of the SFRTA's revenues. Due to the significant financial support from the State of Florida (over $50 \%$ of revenues), the SFRTA is listed as an 
enterprise fund of the FDOT (SFRTA 2011 CAFR.2011). It is important to note that this cooperative regional venture is embedded in Florida Law and is not voluntary in nature. As a mandate that serves the public interests, the SFRTA does present a unique model for regional cooperation.

The Miami MSA has two (2) regional planning councils that serve the southern and northern ends of the region. The Treasure Coast Regional Planning Council (TCRPC) serves Palm Beach County, along with the non-MSA northern coastal counties of Martin, St. Lucie and Indian River. The South Florida Regional Planning Council (SFRPC) serves the MSA counties of Broward and Miami-Dade, along with the nonMSA, southernmost county of Monroe.

Regional councils are established pursuant to Florida Law to, among other purposes, "assist local governments with activities designed to promote and facilitate economic development in the geographic area covered by the council" (Florida Regional Planning Council Act, 2012). The geographic area covered by the council is a decision that rests with the Executive Office of the Governor (Florida Regional Planning Council Act, 2012). The boundaries of the SFRPC have been set since the organization was established in 1969 (Davis, 2009); the boundaries of the TCRPC have been in place since 1976 (McAlpin, Cavalcanti, \& and Lewis, 2009).

From time to time, the Executive Office of the Governor may exercise the authority granted by the Legislature to modify the boundaries of the regional planning councils. In doing so, the Governor is to take into consideration the preferences of local general-purpose governments; the effects of population migration, transportation networks, population increases and decreases, economic development centers, trade 
areas, natural resource systems, federal program requirements, designated air quality nonattainment areas, economic relationships among cities and counties, and media markets; and other data, projects, or studies that it determines to be of significance in establishing district boundaries (Florida Regional Planning Council Act, 2012).

With so many variables in play, it is certainly plausible that a defense of the existing boundaries could be mustered. With the passage of so many decades since the boundaries of the SFRPC and the TCRPC were originally set, valid reasons for making adjustments could also be advanced. The statute does not require a periodic evaluation of the boundaries (Florida Regional Planning Council Act, 2012), and there is no record found of any such exercise occurring.

In sync with the State of Florida designation of the regional planning council boundaries, the federal government has designated each region as an Economic Development District (EDD). With this designation comes the responsibility for submitting and updating a Comprehensive Economic Development Strategy (CEDS). Given the far-flung reaches of the TCRPC and the SFRPC, from the Florida Keys to the grapefruit orchards of Indian River, the CEDS documents for each region present divergent assessments of the industrial clusters.

The 2007-2012 CEDS of the TCRPC advises that the region should focus on the "star" clusters identified in the table below. There is also a recommendation to dedicate attention to certain sectors that are identified as "opportunity" clusters. The opportunity clusters include Biopharmaceuticals, Education and Knowledge Creation, Publishing and Printing, and Transportation and Logistics. 


\begin{tabular}{|l|c|}
\hline \multicolumn{2}{|c|}{ Treasure Coast Region (2004 data) } \\
\hline Description & Employment LQ \\
\hline Agricultural Products & 4.82 \\
\hline Hospitality \& Tourism & 1.49 \\
\hline Power Generation \& Transmission & 1.46 \\
\hline Heavy Construction Services & 1.42 \\
\hline Aerospace Vehicles \& Defense & 1.34 \\
\hline
\end{tabular}

Table 45. Cluster Industries of the Treasure Coast Region

The 2007-2012 CEDS of the SFRPC identifies industry clusters that have performed well in comparison to the national norms, and suggests an economic development strategy grounded in the concept of nurturing and developing certain clusters. The industries that registered LQ employment values above 1.0 are listed in the Table 47 (South Florida regional planning council 2007-2012 CEDS.2007).

\begin{tabular}{|l|c|}
\hline \multicolumn{2}{|c|}{ South Florida Region (2004 data) } \\
\hline Description & Employment LQ \\
\hline Arts, Entertainment and Recreation & 1.3 \\
\hline Hospitality \& Tourism & 1.2 \\
\hline Educational Services & 1.2 \\
\hline Real Estate, Rental, Leasing & 1.2 \\
\hline Retail Trade & 1.2 \\
\hline Utilities & 1.2 \\
\hline
\end{tabular}

Table 46. Cluster Industries of the South Florida Region

In this CEDS report, the "traditional clusters" are identified as Professional and Technical Services, Financial Services, Administrative and Support Services, Tourism and Hospitality Industries, Aviation, Marine, Transportation Activities, Real Estate, and Health Care. There is also reference to "cutting edge" clusters that includes the Life Sciences / Biomedical Sector, a Creative Economy Cluster, and the Homeland Security and Defense Cluster (South Florida regional planning council 2007-2012 CEDS.2007). 
Some of the findings of the cluster industry analysis from the two (2) regions do overlap. There is common reference to sectors such as Hospitality \& Tourism, Transportation \& Logistics, and Biomedical / Life Sciences. The overlap in cluster industries is to be expected, as these sectors are prominent in the analysis of clusters for the greater Miami MSA [See Table 44, page 145]. To bring some cohesion to this divided planning process, a new initiative has been undertaken.

In 2010, the TCRPC and the SFRPC collaborated and won a federal HUD Sustainable Communities Regional Planning Grant. Working in concert with partners from government, education, and the private sector, the application was submitted and the Southeast Florida Regional Partnership secured a $\$ 4.25$ million regional planning grant. The objective of this grant-funded exercise is to divine a broad plan for the entire seven-county region served by the two (2) regional planning councils. If successful, "the Plan will: 1) serve as the framework for future federal investment; 2) support the efforts of individual counties, municipalities and their regional partners whose plans and projects further the implementation of the regional Vision and Plan; and 3) put the Southeast Florida Region in the best position possible to capture future federal funds for critical infrastructure projects designed to improve the region's' sustainability (Seven50: SE Florida prosperity.2012).

Part of the justification for the inclusion of seven (7) counties in this regional plan is the fact that Enterprise Florida, the public / private partnership that provides economic development services for the State of Florida, and the Florida Department of Transportation (FDOT), in their Strategic Intermodal Plan, refer to the area as the “Southeast Region" of Florida (Seven50: SE Florida prosperity.2012). It should be 
noted that FDOT continues to administer their transportation services through separate districts in the "Southeast Region": District 4 (Broward, Palm Beach, Martin, St. Lucie and Indian River) and District 6 (Miami-Dade and Monroe)(Florida DOT.2012).

The Southeast Florida Regional Climate Change Compact (the Compact) is a truly voluntary, multiple-county cooperative effort. The Compact idea was circulated to county representatives of Palm Beach, Broward, Miami-Dade, and Monroe during the Southeast Florida Regional Climate Leadership Summit on October 23, 2009 (Southeast Florida climate change compact.2012). The original summit was organized by Broward County.

The county commissions from the four (4) member counties subsequently adopted resolutions to support this collaborative initiative "to foster sustainability and climate resilience at a regional scale (Southeast Florida compact website.2012). The professional staff from the four (4) member counties has since produced valuable subject matter documents, and there have been annual summits hosted in each of the four member counties. The level of engagement and commitment by the elected officials has been less remarkable. At the most recent summit in Palm Beach, not one county elected official from Miami-Dade attended.

The lack of sustained cooperation among the counties of southeast Florida is an observation shared by the organizers of the Seven 50 project. In their assessment, "The absence of a regional, collaborative partnership and shared vision for Southeast Florida has left our region at a competitive disadvantage when we seek to access needed state and federal resources. Envision Utah, One Bay (Tampa), Portland Metro 2040, Denver Metro Vision 2040, Sacramento Area Blueprint (2004) and Myregion.org (Orlando) are 
examples of regions that have well-established, multi-sector partnerships and regional strategies for quality communities and growth. While Southeast Florida has made progress in many issue areas, including transportation, water supply, and climate change planning with the recent signing of the four-county Southeast Florida Regional Climate Change Compact, these examples are the exception rather than the rule (Seven50.org.2012).

The challenge of shifting the focus of local officials beyond the immediate needs of a particular jurisdiction to the issues of regional concern is more than problematic in South Florida. Even when all of the counties of the MSA are confronted with a similar threat, such as climate change related sea level rise, it is a challenge to maintain a united front. In the arena of economic development, where the threat of global competition should spark a collaborative response across the region, there is no such public agenda.

The collaboration among the three (3) EDOs of the MSA that produced a regional promotional brochure and one joint marketing mission to Canada ended when the Enterprise Florida grant expired. The cooperation among the three (3) counties regarding incentive programs was not the first step on the path towards greater cooperation. It seems to have been another case of "the exception rather than the rule". The results of the social capital survey reflect the relatively weak cooperative state of affairs in the Miami MSA.

\subsection{Social Capital Survey Results}

In the Miami MSA, 31 recipients responded to the two-minute, nine question electronic survey. Due to the configuration of the survey data, it is known that the 
response rate among the elected officials was $19.2 \%(5$ responses $/ 26$ recipients $=19.2)$. The response rate among the potential pool of 322 executives and board members for the three (3) EDOs of the Miami MSA is not known (Report to the community2009)(Greater Fort Lauderdale alliance.2012)(Palm beach BDB.2012).

The three (3) EDOs in the Miami MSA each provided a single point of contact for distribution of the survey to their respective board members. The receipt of 26 responses from EDO board members does confirm the survey was circulated. However, it is not known how widely the anonymous survey was circulated. Assuming the request for total distribution was honored by each of the EDOs contact persons, and all 322 executives and board members received the survey, the response rate would only be $8 \%$ (26 responses $/ 322$ recipients $=.08$ ). There is no evidence available to suggest all 322 candidates received the survey, making the $8 \%$ response rate an extremely conservative estimate.

Though the unimpressive response rates for this particular survey limit the conclusiveness of the results, it is still edifying to compare the relative scores of the three (3) regions. The integrity of the survey, in its design and simplicity, remains valid. As an academic survey depending upon voluntary participation, there was no authoritative leverage or incentives utilized to compel or induce participation. A qualified correlation of these social capital metrics and the relative rank ordering of the dependent variable in the MSAs will be presented in the final chapter. 


\subsubsection{The Discovery Phase}

In the Miami MSA, $22.6 \%$ of the respondents initially indicated there was little or no regular communications with colleagues in other counties. Even though more than $20 \%$ of the respondents had little or no regular communication with their colleagues from other counties, in response to Statement \#2, 86.7\% expressed favorable views regarding the reputation of their colleagues.

\begin{tabular}{|c|c|c|}
\hline \multicolumn{3}{|c|}{$\begin{array}{l}\text { Statement \#1: I have regular communications with my colleagues from } \\
\text { other counties in the region. }\end{array}$} \\
\hline Answer Options & $\begin{array}{c}\text { Response } \\
\text { Percent }\end{array}$ & $\begin{array}{l}\text { Response } \\
\text { Count }\end{array}$ \\
\hline strongly disagree & $3.2 \%$ & 1 \\
\hline disagree & $12.9 \%$ & 4 \\
\hline somewhat disagree & $6.5 \%$ & 2 \\
\hline somewhat agree & $25.8 \%$ & 8 \\
\hline agree & $35.5 \%$ & 11 \\
\hline strongly agree & $16.1 \%$ & 5 \\
\hline \multicolumn{2}{|c|}{ answered question } & 31 \\
\hline \multicolumn{2}{|c|}{ skipped question } & $\mathbf{0}$ \\
\hline
\end{tabular}

Table 47. Response \#1, Miami MSA

\begin{tabular}{|l|c|c|}
\hline \multicolumn{3}{|l|}{$\begin{array}{l}\text { Statement \#2: When it comes to sharing information, my colleagues } \\
\text { from other counties in the region have been very cooperative. }\end{array}$} \\
\hline Answer Options & $\begin{array}{c}\text { Response } \\
\text { Percent }\end{array}$ & $\begin{array}{c}\text { Response } \\
\text { Count }\end{array}$ \\
\hline strongly disagree & $0.0 \%$ & 0 \\
\hline disagree & $3.3 \%$ & 1 \\
\hline somewhat disagree & $0.0 \%$ & 0 \\
\hline no opinion / non-applicable & $10.0 \%$ & 3 \\
\hline somewhat agree & $16.7 \%$ & 5 \\
\hline agree & $56.7 \%$ & 17 \\
\hline strongly agree & $13.3 \%$ & 4 \\
\hline \multicolumn{2}{|r|}{ answered question } & $\mathbf{3 0}$ \\
\hline skipped question & $\mathbf{1}$ \\
\hline
\end{tabular}

Table 48. Response \#2, Miami MSA

The third statement measures the level of trust that exists relevant to the quality of the information exchanged. Though $12.9 \%$ of the respondents had no opinion on this 
statement, no negative views were expressed. The respondents provided an $87 \%$

favorable opinion in response to the statement designed to measure the social capital element of trust. The responses to Statement \#3 are listed on table 48 below.

\begin{tabular}{|l|c|c|}
\hline \multicolumn{3}{|l|}{$\begin{array}{l}\text { Statement \#3: Information I receive from my colleagues in other } \\
\text { counties of our region is reliable and dependable. }\end{array}$} \\
\hline Answer Options & $\begin{array}{c}\text { Response } \\
\text { Percent }\end{array}$ & $\begin{array}{c}\text { Response } \\
\text { Count }\end{array}$ \\
\hline strongly disagree & $0.0 \%$ & 0 \\
\hline disagree & $0.0 \%$ & 0 \\
\hline somewhat disagree & $0.0 \%$ & 0 \\
\hline no opinion / non-applicable & $12.9 \%$ & 4 \\
\hline somewhat agree & $3.2 \%$ & 1 \\
\hline agree & $67.7 \%$ & 21 \\
\hline strongly agree & $16.1 \%$ & 5 \\
\hline \multicolumn{2}{|r|}{ answered question } & $\mathbf{3 1}$ \\
\hline skipped question & $\mathbf{0}$ \\
\hline
\end{tabular}

Table 49. Response \#3, Miami MSA

\subsubsection{The Negotiation Phase}

In the Miami MSA, the responses to statements 4, 5, and 6 reveal a diminished degree of social capital (reciprocity, reputation and trust) among the respondents for the negotiation phase of a transaction. Statement \# 4 seeks to measure the degree of reciprocity for solving problems that exists among the respondents. While there is a prevailing favorable view, $24.1 \%$ did not agree with the statement. Five (5) of the survey respondents either skipped the statement or noted they did not have any regional experience to base an opinion.

The results pertaining to the reputation for cooperation to resolve problems in the region are underwhelming. Only 3.2\% strongly agreed they are confident in the way the communities come together to handle regional issues. A notable $35.5 \%$ indicated they 
lack confidence in the ability of the region's communities to cooperate and solve problems. [See table 52].

\begin{tabular}{|c|c|c|}
\hline \multicolumn{3}{|c|}{$\begin{array}{l}\text { Statement \#4: Working across county boundaries, regional problems } \\
\text { get resolved in a fair and reasonable way. }\end{array}$} \\
\hline Answer Options & $\begin{array}{c}\text { Response } \\
\text { Percent }\end{array}$ & $\begin{array}{c}\text { Response } \\
\text { Count }\end{array}$ \\
\hline strongly disagree & $0.0 \%$ & 0 \\
\hline disagree & $13.8 \%$ & 4 \\
\hline somewhat disagree & $10.3 \%$ & 3 \\
\hline somewhat agree & $34.5 \%$ & 10 \\
\hline agree & $31.0 \%$ & 9 \\
\hline strongly agree & $10.3 \%$ & 3 \\
\hline \multicolumn{2}{|l|}{ Other (please specify) } & 3 \\
\hline \multicolumn{2}{|c|}{ answered question } & 29 \\
\hline \multicolumn{2}{|c|}{ skipped question } & 2 \\
\hline
\end{tabular}

Table 50. Response \#4, Miami MSA

\begin{tabular}{|l|c|c|}
\hline $\begin{array}{l}\text { Statement \#5: I am confident in the way our communities come } \\
\text { together to handle regional issues. }\end{array}$ & $\begin{array}{c}\text { Response } \\
\text { Percent }\end{array}$ & $\begin{array}{c}\text { Response } \\
\text { Count }\end{array}$ \\
\hline Answer Options & $3.2 \%$ & 1 \\
\hline strongly disagree & $19.4 \%$ & 6 \\
\hline disagree & $12.9 \%$ & 4 \\
\hline somewhat disagree & $29.0 \%$ & 9 \\
\hline somewhat agree & $32.3 \%$ & 10 \\
\hline agree & $3.2 \%$ & 1 \\
\hline strongly agree & answered question & $\mathbf{3 1}$ \\
\hline \multicolumn{2}{|r|}{ skipped question } & $\mathbf{0}$ \\
\hline
\end{tabular}

Table 51. Response \#5, Miami MSA

For the element of trust within the context of the negotiation phase, there is a reassuring 93.6\% favorable view reported. In the Miami MSA, there is a lack of confidence in the capacity of the jurisdiction to achieve an equitable exchange, and the reputation of the negotiating solutions to regional problems leaves much to be desired, 
but there is no lack of trust in the ability of colleagues to negotiate in good faith. Trust in negotiations is a promising element of social capital available within the Miami MSA.

The results of Statement \#6 are presented in Table 53 presented below.

\begin{tabular}{|c|c|c|}
\hline \multicolumn{3}{|c|}{$\begin{array}{l}\text { Statement \#6: In discussions about regional issues, my colleagues from } \\
\text { other counties do their best to accurately represent the views of their } \\
\text { community. }\end{array}$} \\
\hline Answer Options & $\begin{array}{c}\text { Response } \\
\text { Percent }\end{array}$ & $\begin{array}{c}\text { Response } \\
\text { Count }\end{array}$ \\
\hline strongly disagree & $0.0 \%$ & 0 \\
\hline disagree & $0.0 \%$ & 0 \\
\hline somewhat disagree & $3.2 \%$ & 1 \\
\hline no opinion / non-applicable & $3.2 \%$ & 1 \\
\hline somewhat agree & $9.7 \%$ & 3 \\
\hline agree & $77.4 \%$ & 24 \\
\hline strongly agree & $6.5 \%$ & 2 \\
\hline \multicolumn{2}{|c|}{ answered question } & 31 \\
\hline \multicolumn{2}{|c|}{ skipped question } & $\mathbf{0}$ \\
\hline
\end{tabular}

Table 52. Response \#6, Miami MSA

\subsubsection{The Conclusion Phase}

The conclusion phase of any transaction for collective action is the most critical phase. To the extent social capital can be drawn upon to overcome the empirical threats to an agreement, an abundance of the social capital elements of reciprocity, reputation and trust are needed in the conclusion phase of any transaction. It is in this phase that the Miami MSA appears to come up short relative to the Houston and Atlanta MSAs. In this series of statements $(\# 7, \# 8$, and $\# 9)$ that are designed to capture the metrics for each of these elements, statement \#8 pertaining to the reputation of the local officials is perhaps of greatest concern.

The responses to statement \#7 provide an inkling of the difficulty associated with reciprocity in concluding agreements in the Miami MSA. A lack of confidence in the capacity of the counties to cooperate and effectively interact is clearly expressed by 
$23.3 \%$ of the respondents. Only $10 \%$ of the respondents strongly agree that the counties will cooperate if a regional approach is the best way to address a particular situation. The results of statement $\# 7$ are provided in table 54 listed below.

\begin{tabular}{|l|c|c|}
\hline \multicolumn{3}{|l|}{$\begin{array}{l}\text { Statement \#7: If a regional approach is the best way to address a } \\
\text { particular situation, our counties will cooperate to get the job done. }\end{array}$} \\
\hline Answer Options & $\begin{array}{c}\text { Response } \\
\text { Percent }\end{array}$ & $\begin{array}{c}\text { Response } \\
\text { Count }\end{array}$ \\
\hline strongly disagree & $3.3 \%$ & 1 \\
\hline disagree & $6.7 \%$ & 2 \\
\hline somewhat disagree & $13.3 \%$ & 4 \\
\hline no opinion / non-applicable & $0.0 \%$ & 0 \\
\hline somewhat agree & $43.3 \%$ & 13 \\
\hline agree & $23.3 \%$ & 7 \\
\hline strongly agree & $10.0 \%$ & 3 \\
\hline \multicolumn{2}{|c|}{ answered question } & $\mathbf{3 0}$ \\
\hline skipped question & $\mathbf{1}$ \\
\hline
\end{tabular}

Table 53. Response \#7, Miami MSA

\begin{tabular}{|c|c|c|}
\hline \multicolumn{3}{|c|}{$\begin{array}{l}\text { Statement \#8: Once a fair solution to a regional problem has been } \\
\text { found, getting all the officials from the different local jurisdictions to } \\
\text { bless it is relatively easy }\end{array}$} \\
\hline Answer Options & $\begin{array}{c}\text { Response } \\
\text { Percent }\end{array}$ & $\begin{array}{c}\text { Response } \\
\text { Count }\end{array}$ \\
\hline strongly disagree & $3.2 \%$ & 1 \\
\hline disagree & $16.1 \%$ & 5 \\
\hline somewhat disagree & $32.3 \%$ & 10 \\
\hline somewhat agree & $35.5 \%$ & 11 \\
\hline agree & $12.9 \%$ & 4 \\
\hline strongly agree & $0.0 \%$ & 0 \\
\hline \multicolumn{2}{|l|}{ Other (please specify) } & 0 \\
\hline \multicolumn{2}{|c|}{ answered question } & 31 \\
\hline \multicolumn{2}{|c|}{ skipped question } & $\mathbf{0}$ \\
\hline
\end{tabular}

Table 54. Response \#8, Miami MSA

The reputation for cooperation among the local officials in the Miami MSA is not favorable. Statement \#8, found in Table 55 , is the only statement that garnered a majority negative opinion (51.6\%) in any of the surveys administered in the three (3) MSAs. The respondents indicated that it would be difficult to get all the officials from the different 
local jurisdictions to approve an agreement, even after a fair solution to a regional problem has been found.

Even the results for the element of trust within the context of the negotiation phase give pause for concern. A solid $10 \%$ of the respondents either strongly disagree or disagree that the local jurisdictions of the region can be trusted to honor any commitments they make. Another $16.7 \%$ expressed similar views by indicating they somewhat disagreed with the statement. While it may be true that $73.4 \%$ of the respondents trust the local officials to honor commitments, this score is the lowest result for this question across the three (3) MSAs.

\begin{tabular}{|l|c|c|}
\hline $\begin{array}{l}\text { Statement \#9: The local jurisdictions of our region can be trusted to } \\
\text { honor any commitments they make }\end{array}$ & $\begin{array}{c}\text { Response } \\
\text { Percent }\end{array}$ & $\begin{array}{c}\text { Response } \\
\text { Count }\end{array}$ \\
\hline Answer Options & $3.3 \%$ & 1 \\
\hline strongly disagree & $6.7 \%$ & 2 \\
\hline disagree & $16.7 \%$ & 5 \\
\hline somewhat disagree & $36.7 \%$ & 11 \\
\hline somewhat agree & $36.7 \%$ & 11 \\
\hline agree & $0.0 \%$ & 0 \\
\hline strongly agree & & 0 \\
\hline Other (please specify) & answered question & $\mathbf{3 0}$ \\
\hline
\end{tabular}

Table 55. Response \#9, Miami MSA

\subsection{The Dependent Variable: Regional Economic Development Cooperation}

In this comparative case study, the Miami MSA is a region nearly devoid of cooperation in the economic development arena. The Miami MSA does not have a central, regional flagship EDO like Houston, and clearly ranks below Atlanta in terms of regional institutions supporting local economic development activities across the region. 
To this day, there is no public agenda to formulate a comprehensive economic development strategy for this MSA.

Each of the three (3) counties of the MSA has an established economic development agency working on behalf of their respective county. In interviews with officials from these agencies, there is a uniform recollection of the one instance when a promotional brochure for the three-county South Florida Region was produced and a joint marketing mission to Canada was undertaken. The resources for this collaborative venture were provided by a grant from Enterprise Florida. Once the state grant funds expired, the formal collaboration ended. Due to the local political concerns, it was only possible to collaborate regionally if non-local source revenues were being used.

There is only one specific instance of legislation adopted uniformly across the (3) three counties to memorialize economic development cooperation. The 1999 initiative was an agreement to only award incentive funds to companies relocating to South Florida. Any company that simply changes their address from one county to another within the MSA is not eligible for the incentives. Beyond this single policy of détente in the award of incentive dollars, not further cooperation has been adopted or codified.

The ongoing initiative spearheaded by the universities and the research institutions to promote a biomedical research corridor from Palm Beach County to Miami-Dade is supported by the EDOs of the three (3) counties. In the interviews, this single topic was alluded to by all of the EDO professionals in the MSA. There has not been any formal resolution among the county governments to contribute resources to collectively bolster this initiative. 
The Miami MSA is designated as a unified regional economy by the U.S. Census Bureau based upon the commuting patterns of the workforce across the region. The residents and employees of the region, by their behavior, have acknowledged the three (3) counties function as a regional economy. At this time, however, there is no regional economic development agreement that calls for the utilization of region-wide economic data in support of a unified marketing strategy in the Miami MSA.

\subsection{Conclusion}

Regional economic development cooperation does not currently occur in the Miami MSA, and is not likely to occur in the immediate future. Though the region is the least politically fragmented among the MSAs of this study, and the median household income is effectively homogenous across the three (3) counties of the MSA, there are other factors that diminish the likelihood of cooperation.

The stacked orientation of the three (3) counties, each with its own urban center, presents a formidable challenge: there is no central business district to facilitate coordination throughout the region. Without a cohesive downtown business community providing a unified voice to articulate a regional perspective, there is only intermittent agitation to pursue regional interests. This is not an environment that will produce a robust regional organization similar to the Greater Houston Partnership.

Compounding the problem, each of the three (3) county governments funds their respective funded economic development organization (EDO) with local tax dollars. As politically dependent organizations, the EDOs are not able to allocate their resources to advance regional interests, unless directed to do so by locally elected officials. The 
probability of the public sector launching, on its own volition, a movement for regional economic development cooperation is highly unlikely.

If a regional movement were afoot in the Miami MSA, the social capital necessary to achieve an agreement might prove inadequate. Relative to the social capital findings in the other MSAs, it appears a transaction in the Miami MSA might stumble at critical moments of the negotiations. The survey respondents indicate that they do not necessarily hold their colleagues from other counties in high esteem. The 'reputation' element of social capital is in limited supply. In the negotiation phase of a transaction, only $64.5 \%$ indicated were "confident in the way our region comes together to solve problems." In the conclusion phase of an agreement, only $48.4 \%$ believed "getting the local jurisdictions to ratify a plan is relatively easy." There is simply not a lot of confidence among the key stakeholders of the Miami MSA.

The MSA if further challenged by the configurations of the boundaries for the regional planning councils. The three (3) counties of the MSA largely ignore the economic development planning work of the two (2) regional councils. The comprehensive planning documents are used qualify local governments for federal economic assistance grants, but do not serve as economic development program guides for the MSA. After more than thirty years, the boundaries of the regional councils merit attention and modification.

Having evaluated the community profile characteristics, considered the challenges of the stepladder geographic configuration of the region, and assessed the relatively weak supply of social capital in the region, I have concluded there is little reason for optimism that a regional economic development initiative will emerge in Miami MSA. 


\section{CHAPTER 7 \\ CONCLUSION}

\subsection{Rejecting the Primary Hypothesis}

The evidence gathered in this comparative case study of three (3) MSA regions of the United States does not support the primary hypothesis of my research study. The hypothesis of this research declared: For regional economic development cooperation to occur, a reserve of social capital among the stakeholders is essential. It is not possible to conclude that social capital was essential to the emergence of regional economic development cooperation, as it is manifested in the Houston and Atlanta MSAs. As such, it is necessary to reject the hypothesis, and acknowledge a finding that the influence of legislative actions of the state government upon regional cooperation for economic development purposes is possibly of relative greater importance.

Social capital may be essential for those agreements that are legally defined and framed as social dilemmas, but the regional economic development cooperation that has been identified in this research has occurred without the sacrifice of local autonomy or the stamp of local government approval. State policies deserve significant credit for the emergence of regional economic development cooperation in the Houston MSA, as local governments were effectively sidelined from the process. The State of Georgia has encouraged the formation of Joint Development Authorities in the Atlanta MSA and supports the operations of the Georgia Resource Center, both factors that have facilitated the notable level of economic development cooperation in the Atlanta MSA region. 
Much of this research was conducted based on the flawed premise that public sector involvement in some form was a prerequisite to regional economic development cooperation. While local jurisdictions often serve as the authorizing agents for tax incentives, there is a wide range of economic development functions that do not necessarily require public sector participation. A private entity, such as the Metro Atlanta Chamber of Commerce, is quite capable of managing a database to improve the understanding of the cluster dynamics of a regional economy. Other functions, such as organizing trade missions to promote the advantages of a region are routinely carried out by the Greater Houston Partnership, and are probably best handled by the private sector. These regional economic development services are not matters that require a formal regional cooperative agreement.

Regional cooperative actions that do not require formal approval or authorization of local government parties are generally not matters that present a social dilemma. If there is no social dilemma associated with a particular form of regional cooperation, then there is no need to utilize a store of social capital to achieve consensus. Had my original hypothesis been framed to only apply to those forms of regional cooperation that involve the formal approval of a local government, it may have withstood scrutiny.

On the basis of the current research, it is also necessary to reject the secondary hypothesis of this research: Regional economic development programming is only possible if the local public officials and civic leaders reach an agreement to cooperate. While it may be ideal to have the full and complete support of the elected county officials of an MSA behind a regional economic development program, it is clearly not necessary. The downtown business community, if it sees an advantage in regionalizing certain 
aspects of economic development activities, is entirely capable of doing so without the express approval of public sector leaders.

There was another tangential finding of this research. There appears to be a principle at work that deserves further research and validation. The principle is this: In order to advance a regional economic development strategy, the autonomy of each local jurisdiction to attract and retain employers must be respected. The Greater Houston Partnership did not attempt to usurp economic development authority from the local EDOs of the Houston MSA; the GHP approached the sub-regional functionaries as allies. In Atlanta, the regional economic development programs of the Metro Atlanta Chamber of Commerce and the Georgia Resource Center occur in partnership with the local EDOs and Joint Development Authorities of the Atlanta MSA. The autonomy of every local EDO in the 28 counties of the Atlanta MSA is not threatened by regional cooperation.

In the process of conducting this qualitative research effort, I discovered that regional economic development cooperation among local jurisdictions is often rooted in the historic decisions of the State Legislature or the executive directives of a Governor. Local government officials and local EDO professionals are certainly key participants in any formal regional collective action, and the business community has demonstrated a capacity to effectuate regional economic development cooperation even without any formal cross-jurisdictional agreements. The findings of this study suggests the legislative and executive decisions of the state government often frame the parameters of any such endeavor, and therefore have an inordinate influence on the process of regional economic development cooperation. 


\subsection{The Survey Results and Community Profile Attributes}

Before expounding on the importance of state legislative intervention, a review of the findings of this regional economic development study is in order. At the conclusions of Chapters 4, 5, and 6 an assessment of the degree of regional economic development cooperation within each region was provided. The relative ranking of the assessments reveal that the Houston MSA has earned the highest ranking in light of the institutional manifestation of regional cooperation within the offices of the Greater Houston Partnership. Regional cooperation also occurs in the Atlanta MSA through the programming and operations of a number of actors, most notably the Georgia Resource Center and the Metro Atlanta Chamber of Commerce. The Atlanta MSA benefits from a cornucopia of state, regional and private institutions that facilitate regional cooperation among the numerous single-county and multiple-county agencies that provide economic development services in the 28-county region. The Miami MSA is ranked last among the three (3) regions, exhibiting a lack of regional coordination among both the business community and the public sector. There is general indifference to the concept of regional economic development cooperation by the public officials.

The social capital survey results bear witness to the ranking of the dependent variable in this qualitative case study. As noted in earlier chapters, the response rate to this study in the three (3) MSAs was underwhelming. The survey was designed to be compact and efficient to respect the busy schedules of the targeted recipients [several respondents confirmed it took less than two (2) minutes to complete]. Advance notification of the survey was sent, alerting recipients to expect the survey and ensuring 
them it would take but a few minutes to complete. The response rates were truly disappointing, in the range of $20 \%$ at best.

As the table below indicates, the positive responses from the Miami MSA were notable lower for almost every statement. The Houston MSA had the highest overall positive response rates, and the Atlanta MSA maintained a secondary rating in response to most of the statements. Table 55 presented below provides the aggregated positive response rates to the matrix statements of the survey. A graphic depiction of the positive responses, illustrating the greater accumulation of social capital reserve in the Houston MSA region and the Atlanta MSA in contrast to the results for the Miami MSA is provided in Table 57.

\begin{tabular}{|l|r|r|r|}
\hline \multicolumn{4}{|c|}{ MSA Positive Response Comparisons } \\
\hline & Atlanta & Houston & Miami \\
\hline \#1. Discovery - Reciprocity & 87.0 & 85.6 & 77.4 \\
\hline \#2. Discovery - Reputation & 89.0 & 90.5 & 86.7 \\
\hline \#3. Discovery - Trust & 90.8 & 90.5 & 87.0 \\
\hline \#4. Negotiation - Reciprocity & 84.7 & 90.0 & 75.8 \\
\hline \#5. Negotiation - Reputation & 84.7 & 90.4 & 64.5 \\
\hline \#6. Negotiation - Trust & 90.7 & 95.3 & 93.6 \\
\hline \#7. Conclusion - Reciprocity & 85.2 & 90.4 & 76.6 \\
\hline \#8. Conclusion - Reputation & 59.2 & 81.0 & 48.4 \\
\hline \#9.Concluson-Trust & 88.7 & 100.0 & 73.4 \\
\hline
\end{tabular}

Table 56. Aggregated Positive Survey Responses

Though the results of this survey effort do not withstand the scrutiny of quantitative research standards, the information is being provided for edification purposes. As the graph sweeps across the statements associated with the phases of discovery, negotiation and conclusion, the disparity in the response rates is heightened. These results comport with the heightened degree of difficulty associated with each 
progressive stage of a collective action transaction, and are consistent with the rankings of the dependent variable for the respective MSAs. In the graphic depiction, the Miami MSA responses show an extreme dip on questions 5 and 8 . The lack of confidence in the ability of county leaders to close a cooperative deal does not portend well for future transactions in the Miami MSA.

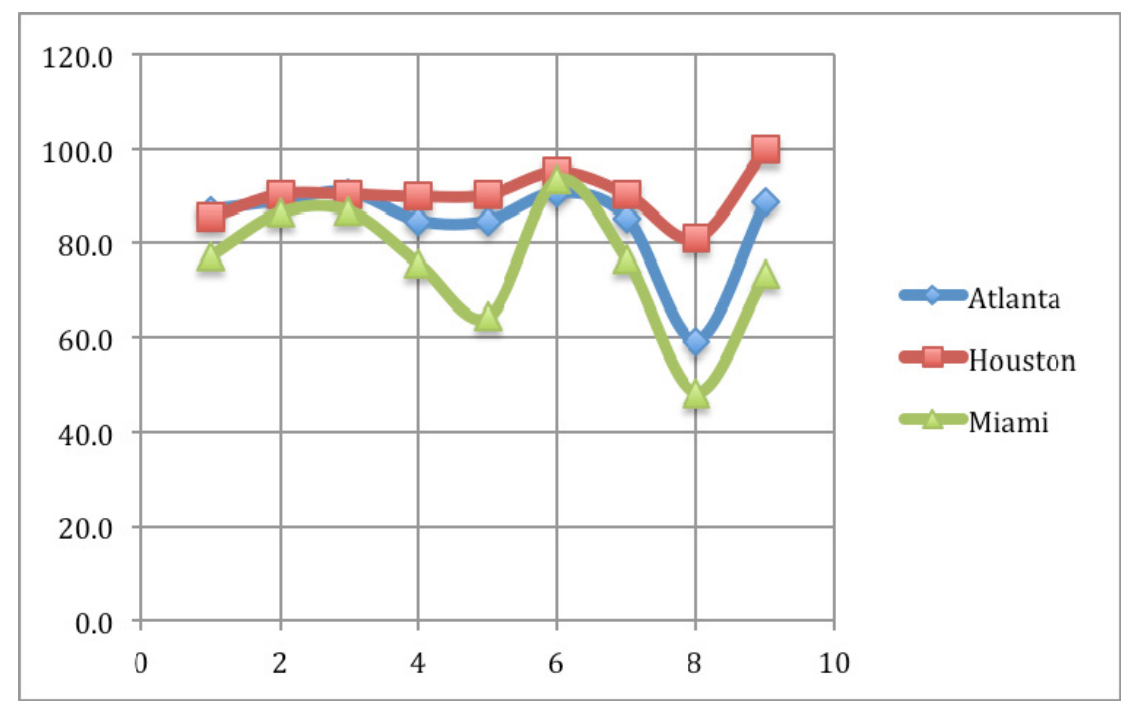

Table 57. Aggregated Positive Responses Graph

There is an admitted inability to calculate a reasonable estimation of margin of error in the sampling inflicted by the low response rate and the unconfirmed number of recipients due to the distribution methodology imposed by the subject EDOs. The concept of the survey, a matrix of collective action transaction phases intersecting the elements of social capital, is original in its design and is offered to the academic community for future utilization. With sufficient resources to conduct a defensible quantitative survey, this survey design could possibly yield beneficial findings for further research on this topic. For this project, it is only possible to note that the survey research mimics the findings associated with the dependent variable. 
The community profile data, the independent variables that serve as indicators of the likelihood of cooperation according to the large-N findings by Feiock (2009), did not align as expected with the dependent variables of this study. This departure in the expected alignment is likely due to the form of economic development cooperation that emerged $\mathrm{n}$ the subject regions. Initiated and driven by the private sector, the public sector social dilemmas were largely avoided, or of little consequence. Without the pubic sector involved, the collective action indicators were less reliable.

Whereas the dependent variable ranking order for regional economic development cooperation placed the Houston MSA at the top, the Atlanta MSA in the middle and the Miami MSA at the bottom, the findings for economic heterogeneity provided a different pattern. From the perspective of least disparity among the annual earnings reported by county, the Miami MSA is most homogenous, reporting a percentage variation among its counties of only $19.7 \%$. The Atlanta MSA reports the greatest disparity among its counties (153\% variation), and the Houston MSA is in the middle, reporting a considerable $91.8 \%$ variation. These results are presented in Table 59 listed below.

\begin{tabular}{|l|c|c|c|}
\hline \multicolumn{4}{|c|}{ Economic Heterogeneity } \\
\hline & Atlanta & Houston & Miami \\
\hline Median Household Income & $\$ 53,997$ & $\$ 55,532$ & $\$ 47,350$ \\
\hline High-Low Differential by & $\$ 88,040-$ & $\$ 80,638-$ & $\$ 55,538-$ \\
County & $\$ 35,835$ & $\$ 42,043$ & $\$ 42,969$ \\
\hline High-Low \% Variation by & $153 \%$ & $91.80 \%$ & $19.70 \%$ \\
County & &
\end{tabular}

Table 58. Comparative Economic Heterogeneity of the MSAs

In conducting this regional comparison across counties, it must be noted that the apparent homogeneity of the Miami MSA is due in part to the highly aggregated reporting that occurs with only three (3) counties constituting the MSA. Similarly, the 
extreme variation in the Atlanta MSA is due in part to the 28 counties reporting median income data. Overlooking these data assembly distortion factors, the Miami MSA would appear to be the most likely to cooperate bases upon economic heterogeneity.

Political fragmentation has been identified as a factor that challenges the ability of a region to cooperate. The premise of this assertion is based on the logic that it is inherently more difficult to conclude a collective action agreement when a greater number of parties are engaged in the process. As previous studies have found, the least fragmented a jurisdiction, the greater the likelihood of cooperation. Again, the findings of this research were not consistent with these findings. To gauge the relative political fragmentation of the regions, the population of the MSA was divided first by the number of counties, and then divided again by the number of municipalities, as illustrated in the formula below.

$$
\frac{\text { MSApopulation } / \# \text { counties }}{\# \text { cities }}=\text { FragmentationValue }
$$

By this formula, the Fragmentation Value for each MSA can be compared. A lower Fragmentation Value indicates greater political fragmentation. According to these results, the Atlanta MSA is the most politically fragmented $(18,127>4,071>1,290)$ and the Miami MSA is the least politically fragmented. Again, the findings of the research are inconsistent with this indicator, as regional economic development cooperation is not occurring in the Miami MSA.

\begin{tabular}{|c|l|l|l|}
\hline \multicolumn{4}{|c|}{ Relative Political Fragmentation of MSAs } \\
\hline & Atlanta & Houston & Miami \\
\hline PF Value & 1,290 & 4,071 & 18,127 \\
\hline
\end{tabular}

Table 59. Lower value indicates greater fragmentation 
The diversity of the counties and the MSAs was a topic explored in depth during this case study. The Herfindahl Index for determining market share was utilized to measure the relative diversity of the regions. The lower the percentage score, the more diverse the jurisdiction. As a social capital variable, Feiock has discounted the relevance of ethnic composition as a factor influencing the likelihood of regional cooperation. To the extent that there is no direct correlation with the dependent variable in this research, there is no evidence gleaned to dispute the assertion of Feiock. As table 61 listed below illustrates, the MSAs of Houston and Miami have the exact same diversity scores, but are at opposite ends of the spectrum in terms of regional economic development cooperation.

\begin{tabular}{|c|c|c|c|}
\hline \multicolumn{4}{|c|}{ Diversity Ratings for MSAs } \\
\hline & Atlanta & Houston & Miami \\
\hline HI Score & $40 \%$ & $33 \%$ & $33 \%$ \\
\hline
\end{tabular}

Table 60. Herfindahl Index, Diversity Results for MSAs

The diversity ratings of the member counties within each MSA were calculated to provide a basis for deeper understanding of the community compositions within the regions. The HI Scores for counties grouped into regional commissions by the State of Georgia seemed to present a pattern of similar diversity ratings. However, the review of the voluntary alignment of Georgia counties as Joint Development Authorities made clear there was no persistent pattern of association based on the diversity ratings of the member counties. Race and ethnicity were not found to be influential factors relative to regional economic development cooperation. 


\subsection{The Impact of the State on Regional Cooperation}

This research effort has found direct links between the state laws and administrative decisions of the state government and the current state of regional economic development cooperation in the MSAs of this study. The influence of state policies may be of greater import than the measure of social capital or the community profile attributes of a region. A regulatory framework that creates an economic development power vacuum, or provides incentives for local EDOs to cooperate, or reinforces local control by virtue of funding mechanisms, might be the greatest factor to influence economic development cooperation in a region.

Indeed, the origins of regional cooperation in the Houston MSA seem to be nestled in the fine print of Texas State Law. Until late in the 20th century, a power vacuum existed in the economic development arena due to the Constitutional prohibition on public expenditures for economic development activities. Economic development was largely a private matter. In the wake of the recession of the $1980 \mathrm{~s}$, corporate and civic leaders filled that void and created the Greater Houston Partnership.

In the wake of the recession of the 1980s, and the prolonged struggle of the U.S. energy sector, the civic leadership of Houston responded by merging the interests of the Houston Chamber of Commerce, the Economic Development Council of Houston and the Houston World Trade Center into the Greater Houston Partnership (GHP). The responsibility to act fell to the private sector primarily due to the Constitutional ban on any public dollars being expended to advance private sector development. The public sector was largely on the sidelines throughout this period of time. 
The GHP simply declared its jurisdiction to be the entire Houston MSA. It worked to have the Constitution amended to allow for public expenditures, and then dedicated itself to creating professional capacity within the fledgling city-based EDOs that subsequently emerged. The GHP is largely supported by the energy sector of the Houston MSA and is very well financed. The GHP itself pays membership dues to the other sub-regional EDOs that serve the port businesses and the communities surrounding the Space Center.

The Constitutional ban that kept the public sector on the sidelines may have been the key to the success of this flagship regional EDO. Unimpeded by local political considerations, the GHP has effectively defined the MSA region as its territory. The GHP sponsors all the major public functions featuring elected and appointed government officials. Working with its EDO Allies, the GHP drives the economic development programming for the region.

In the Atlanta MSA, the provision in Georgia law that allows a county authority to offer an additional $\$ 500$ Job Tax Credit if it enters into a Joint Development Authority (JDA) agreement with a neighboring county authority has spurred regional cooperation. This seemingly innocuous provision in the state law has led every local development authority to enter into a JDA with at least one neighboring county. As a result of this incentive to collaborate, broader cooperation among the county authorities has resulted. Some JDAs jointly invest in industrial parks and others engage in cluster specific promotional efforts. Several local authorities belong to more than one JDA, which is further evidence that the cooperation among local EDOs is not simply grounded in 
qualifying for the additional incentive dollars. This incentive for cooperation has proven to be a key policy tool for advancing regional collaboration in the Atlanta MSA.

There are also other Georgia policy decisions that may partially hinder regional economic development cooperation in the Atlanta MSA. The decision by the State Department of Community Affairs to divide the 28 counties of the MSA into five (5) different regional commissions has not buttressed the cohesion of the economic region. Each regional commission is also designated as an Economic Development District (EDD) for purposes of federal economic assistance. The responsibility of the regional commissions to produce the Comprehensive Economic Development Strategy (CEDS) for the EDD yields divergent results than is found in the cluster analysis of the entire Atlanta MSA.

In the Miami MSA, it appears the additional Local Business Tax proceeds and the General Fund dollars that fund the EDOs of the region have indirectly impacted the capacity of the public - private partnership organizations to act regionally. The last place finish for the Miami MSA in terms of regional economic development cooperation may be rooted in this decision by the State Legislature to allow for the imposition of the additional Local Business Tax.

The additional Local Business Tax enabled the counties of Miami-Dade and Broward to stand up countywide EDOs to assist in the recovery from the economic challenges of the 1980s. During this same time period, Palm Beach County recognized the Business Development Board of Palm Beach as its official agency. The continuous, substantial public funding for several decades has created a dependent relationship between the EDOs and their respective political bodies. 
As noted in Chapter 6, the county commissions of the region have only engaged in sporadic policy agreements relative to economic development in the region. A formal détente in 1999 governing inter-MSA incentives was the last known effort. There have not been any proactive policies adopted by the governing bodies of the region to further economic development cooperation since then. In the absence of any political cover to expend resources on regional initiatives, the local EDOs are somewhat constrained in their capacity to act regionally. The unintended consequence of the decision by the Florida State Legislature to authorize this additional Local Business Tax has been a region bereft of economic development cooperation.

In the Miami MSA, the division of the region into two (2) separate State of Florida planning commission jurisdictions may also be considered an impediment to regional economic development cooperation. The boundaries for the South Florida Regional Planning Council and the Treasure Coast Regional Planning Council were set over 30 years ago. The failure of the State of Florida to update these regional boundaries has consequences. The opportunity to mend the interests of the economic region through a collaborative planning process is lost. The impact of this policy should not be overstated. It truly is more of a lost opportunity than an actual impediment. It is not recognized as a barrier among the key stakeholders in the region, as many are not aware of the CEDS documents or the existence of the Economic Development District boundaries.

In summary, this research effort has resulted in the rejection of the hypothesis and its corollary. As this research found, regional cooperation for economic development purposes is manifested in various forms, and formal agreements involving the 
expenditure of social capital accumulated among the public and private key stakeholders of the region are not always evident. The GHP of the Houston MSA is entirely a private sector venture fueled by the energy sector and appreciated by the public sector. The regional cooperation that occurs in the Atlanta MSA, spurred by job tax incentives, is a concerted effort of the Metro Atlanta Chamber of Commerce, the Georgia Resource Center, the Georgia Economic Development Association, Joint Development Authorities, and local development authorities. The lack of regional economic development cooperation in the Miami MSA is likely a consequence of county-centric EDOs relying too heavily on public funding from county government sources. The Miami MSA is further challenged by the lack of a centralized, downtown urban business district; each county of the region has its own downtown business community.

\subsection{Recommendations}

In order to effectuate cohesive economic development policies for the metropolitan regions of the nation, there must be an effort to align the planning and development efforts undertaken by various local, state and federal agencies. Every tier of government should agree to common criteria to define an economic metropolitan region. The static boundaries of planning councils, or changes to the boundaries that do not prioritize the regional economic factors, only hamper the effort to promote regional economic development cooperation.

The evaluation by the U.S. Census Bureau of commuting patterns within metropolitan areas provides a definition of a region that reflects the regional behavior of the people. This factor should trump most other considerations. Just as the Georgia 
Legislature defined the boundaries of a county according to the daily commuting distance of a rider on horseback, the boundaries of an economic region could be similarly drawn every ten years with the census results to reflect the commuting patterns of the day. To the extent other factors should be considered, every tier of government should agree to the common criterion.

By aligning the regional planning council boundaries with the commonly defined metropolitan economic regions, the planning efforts undertaken by the regional councils would be much more relevant. If every MSA had a Comprehensive Economic Development Strategy (CEDS) document, and the economic development organizations of the region utilized the CEDS as a common source of information, regional economic development efforts could be more effectively aligned.

To facilitate coordination among the regional EDOs, state policymakers should review the Joint Development Authority policies of Georgia. By providing an incentive for cooperation, it is possible to spur local authorities to embrace regional cooperation. If the condition precedent for a local jurisdiction to grant state approved economic incentives is voluntary participation with other EDOs in the region, it is reasonable to expect the local EDOs will partner with another local EDO.

To improve the level of cooperation among the local EDOs in the regional economies of the United States, state legislatures should consider various incentives to reward local jurisdictions for participating in regional economic development programming. In areas with minimal reserves of social capital, the ability to transcend local concerns may require more than incentives. State coordination of research and state management of a regional database might help. With common information about the 
industry clusters and economic advantages of the region, local business leaders may succeed in engaging local officials in a cooperative regional agreement to facilitate and promote economic development. 


\section{REFERENCES}

1960 census. (1960). Retrieved November 13, 2012, from

http://www.census.gov/prod/www/abs/decennial/1960.html\#pop

Abbot, G. (2008). Economic development handbook. Austin, TX: Attorney General of Texas.

Additional Tax on Local Business Tax, Ordinance U.S.C. 8A-171.2 (2012).

Agreement with BDB of Palm Beach County, 4A4, December 6 Board of County

Commissioners. (2011).

American community survey. (2009). Retrieved June 12, 2012, from

http://www.census.gov/acs/www/

American fact finder. (2010). Retrieved April 24, 2012, from

http://factfinder2.census.gov/faces/nav/jsf/pages/index.xhtml

Anderson, C. (2010). Beacon council quarterly reports (Audit No. No)(Beacon Council)

Annual report to bondholders (2010). (CAFR 2010). Miami, FL: Miami-Dade County Finance Department. (Bondholders)

Atlanta regional commission (2012). Retrieved 05/14, 2012, from

http://www.atlantaregional.com/about-us/board--committees/arc-board

Bartik, T. J. (1994). Jobs, productivity, and local economic development: What implications does economic research have for the role of government? (symposium on state and local development policy)

Bay area Houston economic partnership. (2012). Retrieved 12/4, 2012, from http://www.bayareahouston.com/default/index.cfm/target-industries/

Baytown, Texas. (2012). Retrieved 12/4, 2012, from http://www.baytown.org/

Blakely, E. J. (2002). Planning local economic development: Theory and practice (2nd ed.). Thousand Oaks, Calif.: Sage Publications.

Boothroyd, P., \& Davis, H. C. (1993, April). Community economic development: Three approaches journal of planning education and research April 1993 vol. 12, no. 3 230-240 Journal of Planning Education and Research, 12(3), 230-240. 
Broward Economic Development Partnership Agreement, Agenda Item U.S.C. A1-8704 (2011).

Broward EDO official (2012) [Anonymity requested].

Broward.org. (2012). Retrieved 12/13, 2012, from http://www.broward.org/Intergovernmental/Pages/BrowardAlliance.aspx

Buss, T. F. (2001). The effect of state tax incentives on economic growth and firm location decisions: An overview of the literature. Economic Development Quarterly, 15(1), 90 .

CenterPoint energy. (2012). Retrieved 12/2, 2012, from http://www.centerpointenergy.com/about/values/community/

Coase, R. (1988). The nature of the firm: Meaning. Journal of Law, Economics, \& Organization, 4(1), 19.

Combs, S. (2010). Biennial reports (Reinvestment Zone for Tax Abatement Registry. Austin, TX: Texas Comptroller.

Dabson, B. (2005). The meaning of entrepreneurship. Texas Entrepreneurship Summit: Expanding Economic Opportunity, Austin, Texas. pp. 1-10.

Davis, S. (2009). South Florida regional planning council audit (Independent Audit. Hollywood, FL: South Florida Regional Planning Council.

Drabenstott, M. (2006). Rethinking federal policy for regional economic development. Economic Review - Federal Reserve Bank of Kansas City, 91(1), 115.

The economic alliance. (2012). Retrieved 12/4, 2012, from http://www.allianceportregion.com/EconomicClusters/EconomicClusters.aspx

Economic development administration. (2012). Retrieved 05/06, 2012, from http://www.eda.gov/investmentPriorities.htm

Enterprise Florida. (2012). Retrieved 12/12, 2012, from http://www.eflorida.com/

Eyman, S. (2010, January 25). Business development board CEO is a networking dynamo. Palm Beach Post,

Federal register, vol. 75(2010). (Federal Notice No. 123). Washington, DC: Office of Management and Budget. (Delineating Metropolitan and Micropolitan Statistical Areas) 
Fehr, S. C. (Monday, June 21, 2010). The united regions of America. Stateline.Org, Monday, June 21, 2010. doi: April 22, 2010

Feiock, R., Steinacker, A., \& Park, H. (2009). Institutional collective action and economic development joint ventures. Public Administration Review, 69(2), 256.

Feldstein Soto, L. (1986, June 8). Dade gets its legislative wish list. Miami Herald, pp. 1B. doi: $12 / 14$

Finefrock, D. (1997, November 14). Now it's Miami-Dade County Miami Herald, pp. $1 \mathrm{~A}$.

Florida DOT. (2012). Retrieved 12/17, 2012, from http://www.dot.state.fl.us/publicinformationoffice/moreDOT/districts/district.shtm

Florida Regional Planning Council Act, Statute U.S.C. 186.502 (2012).

Florida regional planning councils. (2012). Retrieved 12/12, 2012, from http://ncfrpc.org/state.html

Foreign consular offices in the United States (2012). (pdf. Washington, DC: U.S. Department of State.

Fox, G. (2007). The real coase theorems. Cato Journal, 27(3), 373.

Fox, W. F., \& Murray, M. N. (2004). Do economic effects justify the use of fiscal incentives? (tax incentives)

Fredriksson, P. G., List, J. A., \& Millimet, D. L. (2004). Chasing the smokestack: Strategic policymaking with multiple instruments. Regional Science and Urban Economics, 34(4), 387-410.

Friedman, T. L. (2005). The world is flat: A brief history of the twenty-first century (1st ed.). New York: Farrar, Straus and Giroux.

Fukuyama, F. (1995). Trust: Social virtues and the creation of prosperity. New York: Free Press.

FY 2012 budget Houston (2011). (Municipal Budget. Houston, TX: City of Houston. (Demographic / Economic Summary)

Gainsborough, J. (2003). Business organizations as regional actors: The politics of regional cooperation in metropolitan America. Polity, 35(4), 555-572. doi: February, 7,2013 
Georgia association of regional commissions. (2012). Retrieved 05,02, 2012, from http://garc.ga.gov/main.php?Home-7

Georgia Department of Community Affairs. (2010). Counties participating in multicounty joint development authorities

Georgia department of community affairs. (2012a). Retrieved 05/02, 2012, from http://www.dca.ga.gov/development/PlanningQualityGrowth/PAGES/Legal.asp\#ST ATEWIDE

Georgia department of community affairs. (2012b). Retrieved 05/16, 2012, from http://www.dca.state.ga.us/economic/taxcredits/programs/historical_ct_jda.asp

Georgia economic development association. (2012). Retrieved 11/18, 2012, from http://www.geda.org/

Georgia Humanities Council. (2012). The new Georgia encyclopedia. Retrieved 04/24, 2012, from www.georgiaencyclopedia.org

Georgia mountains regional commission. (2012). Retrieved 05/15/, 2012, from http://www.gmrc.ga.gov/EconDevel.htm

Georgia Planning Act, Georgia Law U.S.C. 50-8 (1981).

Georgia resource center. (2012). Retrieved 11/18http://selectgeorgia.com/ourservices/georgia-resource-center.cshtml

Georgia USA. (2012). In Georgia Department of Community Affairs (Ed.), Georgia 2012 job tax credit tiers

GHP partners list (2012). [Updated May 16, 2012]. Houston, TX: Greater Houston Partnership.

Gordon, V. (2007). Partners or competitors? perceptions of regional economic development cooperation in Illinois. Economic Development Quarterly, 21(1), 6078 .

County budget presentation: County budget presentation: County budget presentation: Florida International University town hall (2011).

Miami-Dade 2012-2013 Proposed Budget, Volume I, 2012Cong. (2012).

Grady hospital. (2012). Retrieved 11/11, 2012, from http://www.gradyhealth.org/history.html 
Greater Fort Lauderdale alliance. (2012). Retrieved 12/9, 2012, from http://www.gflalliance.org/index.php?submenu=AboutUs\&src=gendocs\&ref=Board OfDirectors $2012 \&$ category $=$ AboutUs

Greater Houston partnership. (2012). Retrieved 06/11/2012, 2012, from http://www.houston.org/economic-development/factsfigures/demographics/index.aspx

Greater Houston partnership 2005-2012 strategic plan (2005). (Brochure. Houston, TX: Greater Houston Partnership.

Gulf Coast Economic Development District. (2009). 2009-2011 comprehensive economic development strategy. Houston, TX:

Blackside (Producer), \& Hampton, H. (Director). (1987). Eyes on the prize. [Video/DVD] PBS.

Hansen, T., \& Kalambokidis, L. (2010). How are businesses responding to Minnesota's tax-free zone program? Economic Development Quarterly, 24(2), 180.

Hanson, K. J. (2009). The path to regional competitiveness. The International Journal of Public Sector Management, 22(3), 210.

Hart, A. (2012, August 1, 2012). Voters reject transportation tax. The Atlanta JournalConstitution,

Horton, J. O., \& Horton, L. E. (2001). Hard road to freedom. New Brunswick, New Jersey and London: Rutgers University Press.

Houston ED official( 2012). [Interview \#2]

Houston interviews( 2012). . Miami, FL: Murphy.

Houston-Galveston Area Council. (2008). Foresight panel on environmental effects (Risk Assessment. Houston, Texas: (Environmental Effects)

Houston-Galveston area council. (2012). Retrieved 06/11, 2012, from http://www.hgac.com/home/

Joint Development Authorities, Georgia Statute U.S.C. Title 36, Chapter 62, 5(1) d (2012).

Judd, R., \& McNeil, R. (2008). Large firms \& small firms: Job quality, innovation and economic development. Journal of American Academy of Business, Cambridge, 14(1), 164. 
Kelly, J. (1981, November 23). South Florida: Trouble in paradise. TIME,

Kendrick, M. (2012). Executive director, barnseville-lamar county industrial development authority

Kimmel, K. (2012). Heard county, GA financial report (Financial. Richland, GA:

Atlanta: State of the region breakfast: Atlanta: State of the region breakfast: Atlanta Regional Commission, State of the Region (2012).

Life sciences corridor. (2012). Retrieved 12/12, 2012, from http://lifesciencessf.org/mission/index.shtml

Local Business Taxes, Florida Statute U.S.C. 205.033 (2012).

Lotz, J. (1977). Understanding Canada regional and community development in a new nation. Toronto, Ontario: NC Press Limited.

Lukic, E. A. (2011). Review of the broward alliance (Audit No. 11-05). Broward County, FL: Office of the County Auditor. (Audit)

Mahoney, J. (2000). Path dependence in historical sociology. [Path Dependence in Historical Sociology] Theory and Society, 29(4), 507-548.

Martin, M. (2012). President, Cherokee office of economic development

Mazzei, P. (2012, 10/16). Miami-dade commissioner takes on beacon council. Miami Herald,

McAlpin, Cavalcanti, \& and Lewis. (2009). Treasure coast independent audit (Audit. November 16: Treasure Coast Regional Planning Council.

Metro Atlanta arts. (2012). Retrieved 11/18, 2012, from http://www.metroatlantaarts.org/about-origins.shtml

Metro Atlanta chamber of commerce. (2012). Retrieved 11/09, 2012, from http://www.metroatlantachamber.com/economic-development/globalcommerce/why-atlanta-for-your-investment/why-atlanta-presentations

Metropolitan Atlanta regional transit authority. (2012). Retrieved 11/11, 2012, from http://www.itsmarta.com/about-marta.aspx

Miami EDO official (2012). [Anonymity requested]. Miami, FL 
Miami-dade charter. (2012). Retrieved 12/12, 2012, from http://www.miamidade.gov/charterreview/

Miles, K. A. (2009, February 23). Cobb commission chairman olens wins national honor. The Atlanta Journal-Constitution,

Resolution 1323-99, R-1393-99, 1999 County Commission Cong. (1999).

Moran, C. (May 30, 2012). Hobby expansion approved. Houston Chronicle,

Morfessis, I. T., Motoyama, Y., \& Malachuk, D. (2011). Advanced discussion: Global businesses, local strategies: Lessons for economic development. Charlotte, NC: International Economic Development Council.

Morgan, D. (1999). Central-City/Suburban inequity and metropolitan political fragmentation (statistical data included). Urban Affairs Review (Thousand Oaks, Calif.), 34(4), 578.

Moukheiber, Z. (2011, January 9). Another multi-million dollar gift to U.S. hospital from billionaire Arab ruler. Forbes,

Code of Ordinances, Heard County, Municipal Code U.S.C. Part 1 (2012).

Murphy, T. (2011, July 10). South Florida's economy needs regional approach. Miami Herald, pp. A15.

Norris, D. F. (2001). Prospects for regional governance under the new regionalism: Economic imperatives versus political impediments. Journal of Urban Affairs, 23(5), 557-571.

Northeast Georgia regional commission. (2012). Retrieved 05/15, 2012, from http://www.negrc.org/front-desk-resources.php

Northwest Georgia regional commission. (2012). Retrieved 05/15, 2012, from http://www.nwgrc.org/age-plan.html

Official code of Georgia. (2012).

Olberding, J. (2002a). Diving into the "third waves" of regional governance and economic development strategies: A study of regional partnerships for economic development in U.S. metropolitan areas. Economic Development Quarterly, 16(3), 251. 
Olberding, J. (2002b). Does regionalism beget regionalism? The relationship between norms and regional partnerships for economic development. Public Administration Review, 62(4), 480.

One community, one goal. (2012). Retrieved 12/15, 2012, from http://beaconcouncilfoundation.org/onecommunityonegoal/

One Georgia authority. (2012). Retrieved 11 / 11, 2012, from http://www.onegeorgia.org/programs

Ostrom, E. (1998). A behavioral approach to the rational choice theory of collective action presidential address, American political science association, 1997. The American Political Science Review, 92(1), 1.

Palm beach BDB. (2012). Retrieved 12/9, 2012, from http://www.bdb.org/index.php?submenu=board_of_directors\&src=gendocs\&ref=Bo ardofDirectors\&category $=$ Who We Are

Palm beach county budget 2010. (2012). Retrieved 12/14, 2012, from http://www.pbcgov.com/ofmb/budget/annual_budget/2010/

Palm Beach EDO official (2012). [Anonymity requested]

Panek, S. D., Baumgardner, F. T., \& McCormick, M. J. (2007). Introducing new measures of the metropolitan economy: Prototype GDP-by-metropolitan-area estimates for 2001-2005

Peirce, N. R., Johnson, C., \& and Hall, J. S. (1993). Citistates: How urban America can prosper in a completive world . Washington, DC: Seven Locks Press.

Planning Investments and CEDS, Federal RegulationsU.S.C. Title 13, Part 303 (2012).

Porter, M. E. (2001). Clusters of innovation initiative No. ISBN 1-889866-23-7). United States of America: Council on Competitiveness.

Putnam, R. D. (2000). Bowling alone: The collapse and revival of American community. (First Touchstone Edition ed., pp. 19). New York: Simon \& Schuster.

Putnam, R. D. (2005). The civic enigma. American Prospect, 16(6), 33-33.

Regional Commissions, Georgia Law U.S.C. Title 50, Chapter 8, Article 2 (2011).

Regional Transportation and Transit Authorities, Florida LawU.S.C. Chapter 343 (2012). 
Rendeiro, C. (2012). Interview \#5 Houston. File saved in dissertation data folder.

Report to the community (2009). (Annual Report. Miami, FL: The Beacon Council.

Revenue and Taxation, Statute U.S.C. Chapter 7 (2012).

Rhoades, S. A. (1993). "The herfindahl-hirschman index "Fed. res. bull.79 (1993): 188. No. Bulletin 79. Federal Reserve. (Herfindahl Index)

Richard, C. J. (2012). Interview \#3 Houston. Filed in dissertation data folder.

Ross, K. (2012). Professor, Emory university school of law

Seven50: SE Florida prosperity. (2012). Retrieved 12/11, 2012, from http://seven50.org/

Seven50.org. (2012). Retrieved 12/17, 2012, from http://seven50.org/overview/faqs/

SFRTA 2011 CAFR (2011). (Financial. Pompano Beach, FL: South Florida Regional Planning Council. (CAFR)

South Florida CEDS 2012-2017(2012). (Economic Development. Hollywood, FL: South Florida Regional Planning Council. (CEDS)

South Florida regional planning council 2007-2012 CEDS (2007). (Comprehensive Economic Development Strategy. Hollywood, FL: South Florida Regional Planning Council. (CEDS)

Southeast Florida climate change compact. (2012). Retrieved 12/19, 2012, from http://www.broward.org/NaturalResources/ClimateChange/Pages/SummitResources. $\underline{\operatorname{aspx}}$

Southeast Florida compact website. (2012). Retrieved 12/19, 2012, from http://southeastfloridaclimatecompact.org/

Georgia resource center presentation: Georgia resource center presentation: Georgia resource center presentation: Resource Center Orientation (2012).

StatsAmerica. (2012). Retrieved 05/21, 2011, from http://www.statsamerica.org/innovation/anydata/index.asp?T1

Story, L. (2012, 12/2). As companies seek tax deals, governments pay high price. New York Times, pp. 1.

Sydney, K. (2012). Interview 
Targeted Job Tax Incentives, Ordinance 00-98 U.S.C. 2-1251 (2012).

Texas Code Chapter 391, General Law U.S.C. Section 001 (2012).

Texas Constitution, 15 (2012).

Texas conversations (2012). In Murphy T. (Ed.), [Telephone conversation with Vince Yokum, Executive Director of Waller County EDC.]. Miami, FL:

Texas Statute 312, tax abatementU.S.C. 204 (2012).

Three rivers regional economic development district annual progress report. (2010).

Tollett, J. (2012). Interview \#1 Houston. Saved in dissertation data folder.

Treasure coast CEDS 2007-2012(2007). (Economic Development. Stuart, FL: Treasure Coast Regional Planning Council. (CEDS)

TSHA. (2012). Texas state historical association. Retrieved 10/27, 2012, from www.tshaonline.org/handbook/online/articles/mzgfq

United states census bureau. (2012). Retrieved April 24, 2012, from http://www.census.gov/population/metro/

Vock, D. C. (2006, May 16). Court allows smokestack chasing -- for now. Message posted to http://www.stateline.org/live/details/story? contentId=112763

Wallman, B. (2010, May 20). Broward strong mayor proposal returns! Sun Sentinel,

Weinstein, B. L. (1994). The giveaway game: You lose. (The use of tax credits and other fiscal incentives)

Wemple, C. (2012). Interview \#4 Houston, filed in dissertation data folder

Whatley, C. (2012). Director, DeKalb county economic development. Atlanta, Georgia:

Wilkins, M. (2012). GHP interview: Saved as "interview 2 in Houston" dissertation data folder. Houston, Texas:

Willis, D. (2009, October). Georgia's regional commissions: Serving local governments. Georgia County Government, 78-79-80.

Woolcock, M. (2004). Social capital: A theory of social structure and action. Cambridge university press, 2001. 278 pp. Journal of Social Forces, 82(3), 1209-1211. 
Young, N. (2010, October). It's about Georgia jobs. Georgia Trend. 
VITA

\section{TERENCE MURPHY}

Place of Birth: $\quad$ Greenville, South Carolina

Education: $\quad$ Master of Public Administration

Florida International University

Miami, Florida

B.A., American Studies

University of Iowa

Iowa City, Iowa

Employment: $\quad$ Miami-Dade County Commission

Senior Policy Advisor

1988-2011

Public Affairs Concepts, Inc.

President

2012-Present

Publication: $\quad$ GIS: Changing the Economic Development World. Handbook of Research on Strategies for Local E-

Government Adoption and Implementation: Comparative Studies, 631-646 (2009) 